Florida International University FIU Digital Commons

FIU Electronic Theses and Dissertations

University Graduate School

$3-29-2018$

\title{
Reconfigurable Antennas Using Liquid Crystalline Elastomers
}

John Gibson

Florida International University, jgibs023@fiu.edu

DOI: 10.25148 /etd.FIDC006536

Follow this and additional works at: https:// digitalcommons.fiu.edu/etd

Part of the Electrical and Electronics Commons, Electromagnetics and Photonics Commons, Polymer and Organic Materials Commons, and the Systems and Communications Commons

\section{Recommended Citation}

Gibson, John, "Reconfigurable Antennas Using Liquid Crystalline Elastomers" (2018). FIU Electronic Theses and Dissertations. 3706. https://digitalcommons.fiu.edu/etd/3706

This work is brought to you for free and open access by the University Graduate School at FIU Digital Commons. It has been accepted for inclusion in FIU Electronic Theses and Dissertations by an authorized administrator of FIU Digital Commons. For more information, please contact dcc@fiu.edu. 


\title{
FLORIDA INTERNATIONAL UNIVERSITY
}

\author{
Miami, Florida
}

\section{RECONFIGURABLE ANTENNAS USING LIQUID CRYSTALLINE ELASTOMERS}

A dissertation submitted in partial fulfillment of

the requirements for the degree of

DOCTOR OF PHILOSOPHY

in

ELECTRICAL ENGINEERING

by

John Gibson 
To: Dean John L. Volakis

College of Engineering and Computing

This dissertation, written by John Gibson, and entitled Reconfigurable Antennas Using Liquid Crystalline Elastomers, having been approved in respect to style and intellectual content, is referred to you for judgment.

We have read this dissertation and recommend that it be approved.

\begin{tabular}{rr}
\hline Nezih Pala \\
\hline Taylor Ware \\
\hline Jean Andrian \\
\hline Félix Miranda \\
\hline Kinzy Jones \\
\hline Stavros V. Georgakopoulos, Major Professor
\end{tabular}

Date of Defense: March 29, 2018.

The dissertation of John Gibson is approved.

Dean John L. Volakis College of Engineering and Computing

Andres G. Gil

Vice President for Research and Economic Development and Dean of the University Graduate School

Florida International University, 2018 


\section{DEDICATION}

I dedicate this dissertation to my lovely family, my parents, my grandmother, and my two beautiful kids, Johan and Jaime. 


\section{ACKNOWLEDGMENTS}

I would like to thank to my major professor, Dr. Stavros V. Georgakopoulos, for his outstanding mentoring and support through my Ph.D. program at FIU. He has provided for me all the necessary tools and knowledge base to excel in the next stage of my career. I also appreciate Dr. Nezih Pala, Dr. Jean Andrian, Dr. Félix Miranda, Dr. Kinzy Jones, and Dr. Taylor Ware for serving on my dissertation defense committee.

I also thank all the members of FIU Electrical and Computing Engineering Department and to my lab members Dr. Hao Hu, Dr. Shun Yao, Kun Bao, Daerhan Liu, Xueli Liu, Karina Quintana, Yousuf Shafiq, and Oscar Silveira for their help and

friendship. Special thanks to Dr. Sonya Montas-Hunter, Dr. Shekhar Bhansali, Dr. Alla Mirzoyan, and Krystine Pimentel for the incredible amount of support.

I would wish to recognize the financial backing of the Florida Education Fund McKnight Doctoral Fellowship, Air Force Office of Scientific Research, Florida International University (FIU) Graduate School Enhancement, and the National Science Foundation Florida Georgia LSAMP FIU Bridge to the Doctorate HRD \#1301998. 


\section{ABSTRACT OF THE DISSERTATION \\ RECONFIGURABLE ANTENNAS USING LIQUID CRYSTALLINE ELASTOMERS \\ by}

John Gibson

Florida International University, 2018

Miami, Florida

Professor Stavros. V. Georgakopoulos, Major Professor

This dissertation demonstrates the design of reversibly self-morphing novel liquid crystalline elastomer (LCE) antennas that can dynamically change electromagnetic performance in response to temperature. This change in performance can be achieved by programming the shape change of stimuli-responsive (i.e., temperature-responsive) LCEs, and using these materials as substrates for reconfigurable antennas. Existing reconfigurable antennas rely on external circuitry such as Micro-Electro-Mechanical-Systems (MEMS) switches, pin diodes, and shape memory alloys (SMAs) to reconfigure their performance. Antennas using MEMS or diodes exhibit low efficiency due to the losses from these components. Also, antennas based on SMAs can change their performance only once as SMAs response to the stimuli and is not reversible. Flexible electronics are capable of morphing from one shape to another using various techniques, such as liquid metals, hydrogels, and shape memory polymers.

LCE antennas can reconfigure their electromagnetic performance, (e.g., frequency of operation, polarization, and radiation pattern) and enable passive (i.e., battery-less) temperature sensing and monitoring applications, such as passive radio frequency 
identification device (RFID) sensing tags. Limited previous work has been performed on shape-changing antenna structures based on LCEs. To date, self-morphing flexible electronics, including antennas, which rely on stimuli-responsive LCEs that reversibly change shape in response to temperature changes, have not been previously explored. Here, LCE antennas will be studied and developed. Also, the metallization of LCEs with different metal conductors and their fabrication process, by either electron beam (E-Beam) evaporation or optical gluing of the metal film will be observed. The LCE material can have a significant impact on sensing applications due to its reversible actuation that can enable a sensor to work repeatedly. This interdisciplinary research (material polymer science and electrical engineering) is expected to contribute to the development of morphing electronics, including sensors, passive antennas, arrays, and frequency selective surfaces (FSS). 


\section{TABLE OF CONTENTS}

CHAPTER

PAGE

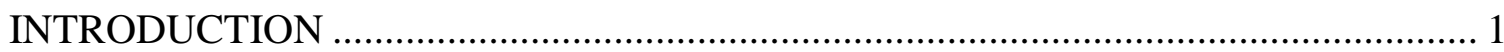

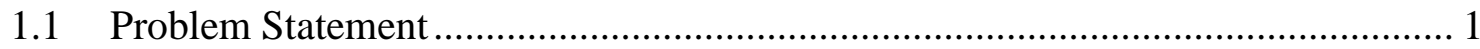

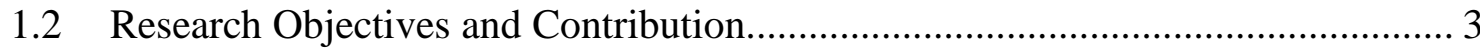

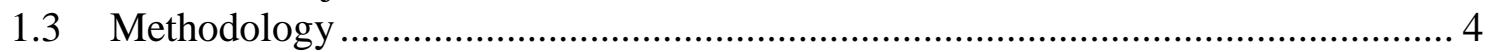

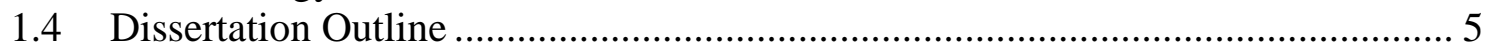

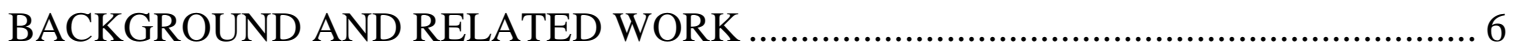

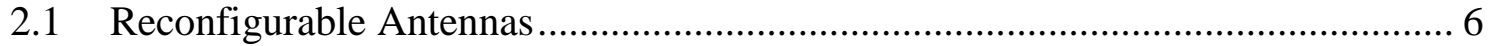

2.2 Reconfigurable Antennas Using Smart Materials............................................. 9

2.3 Liquid Crystalline Elastomers.................................................................. 12

2.4 Radio Frequency Identification Devices (RFID) Applications for Cold Chains .. 14

RECONFIGURABLE ANTENNAS BASED ON SELF-MORPHING LCES AT STATIC (FIXED) STATES WITH HEAT ……………….................................. 17

3.1 LCE Twisted Nematics (TN) Structures Used in Antennas ................................ 17

3.2 Reconfigurable Antennas Based on LCEs ........................................................... 22

3.2.1 Pattern Reconfigurable LCE Antenna \#1 ..................................................... 28

3.2.2 Pattern Reconfigurable LCE Antenna \#2 ……............................................ 30

3.2.3 Frequency Reconfigurable LCE Antenna ..................................................... 34

SETUP DESIGN AND METALLIZATION OF DYNAMIC LCE ANTENNAS .......... 40

$4.1 \quad$ External Stimulus Designs .......................................................................... 41

4.1.1 External Stimulus with Soldering Tool and Beaker ....................................... 41

4.1.2 External Stimulus with Acrylic/Plastic Box........................................................ 50

4.1.3 Cylinder Brace for Larger LCE Antennas .......................................................... 56

4.2 Different Metallization Techniques used for LCE Antennas ............................... 62

DUAL-BAND SELF-MORPHING LIQUID CRYSTALLINE ELASTOMER (LCE)

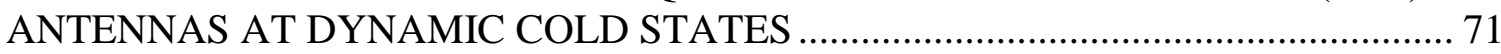

5.1 Synthesis and preparation of TN LCEs .............................................................. 71

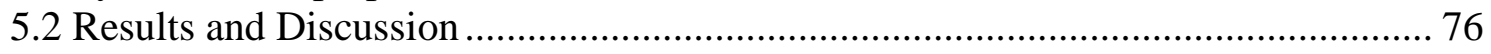

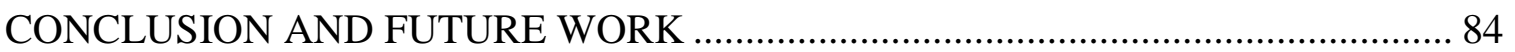

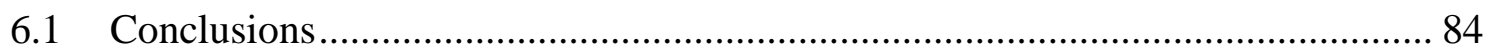

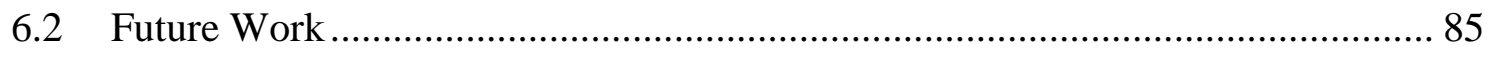

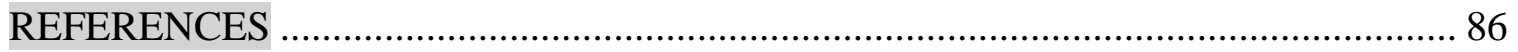

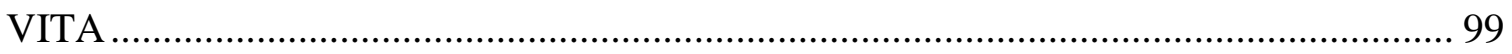




\section{LIST OF TABLES}

TABLES

PAGE

Table 3.1. Temperatures of Reconfigurable States of LCE Antennas ........................... 28

Table 3.2. Performance of the Pattern-Reconfigurable LCE Antenna ............................ 34

Table 3.3. Performance of Each State of the Frequency Reconfigurable LCE

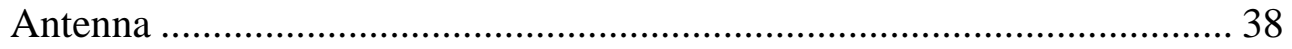

Table 3.4. Comparison Between the Two States of the Frequency Reconfigurable LCE Antenna .............................................................................. 38

Table 4.1 Performance of Each State of the Dynamically Reconfigurable LCE Antenna

Table 5.1. Measured Resonant Frequency and Bandwidth of Dual-band Au LCE Antenna 1 at Each Number of Turns in Response to Temperature. 80

Table 5.2. Measured Resonant Frequency and Bandwidth of Dual-band Au LCE Antenna 2 at Each Number of Turns in Response to Temperature. 82 


\section{TABLE OF FIGURES}

FIGURES

PAGE

Figure 2.1. Diagram of various techniques of smart materials [53]. 10

Figure 2.2. Examples of self-morphing electronics using smart materials: shape memory alloy (SMA) [1], shape memory polymer (SMP) [10], and shape memory ceramic (SMC) [48]. 11

Figure 2.3. Example of a twisted nematic LCE actuating in response to heat. 12

Figure 2.4. (a) Side-view images of 3D-printed $4 \times 2$ array of $1 \mathrm{~mm}$ diameter disk, printed in an Archimedean chord pattern at room temperature and (b) a cone shaped array when heated.

Figure 3.1. Illustration of the 90 degree twist in the orientation of the nematic director in the so-called twisted nematic configuration. 19

Figure 3.2. LCE prepared in the TN orientation transform from flat to helical shape upon heating. Images shown when the LCEs are heated at 130 ${ }^{\circ} \mathrm{C}$ : (top) $+60^{\circ}$ (FS) to $-30^{\circ}$ (BS) yields a right-handed helix; and (bottom) $-60^{\circ}$ (FS) to $30^{\circ}$ (BS) yields left-handed helix.

Figure 3.3. Temperature dependence of the number of turns of an LCE strip. 20

Figure 3.4. Temperature dependence of the inverse of the helical pitch angle (PH).

Figure 3.5. LCE with aluminum showing the different stages of the polymer changing its structure due to the increased temperature.

Figure 3.6. Simulated models of LCE pattern-reconfigurable antenna \#1 from: (a) straight to (b) 1.1-turn spiral. 25

Figure 3.7. Simulated models of LCE pattern-reconfigurable antenna \#2 from: (a) straight to (b) 1.1-turn helix. 26

Figure 3.8. Simulated model of LCE frequency-reconfigurable antenna from: (a) 0.5-turn loop to (b) 1.5-turn helix.

Figure 3.9. Prototype LCE pattern-reconfigurable antenna at different temperatures: (a) straight at $30^{\circ} \mathrm{C}$, (b) 1.1 -turn helix at $92^{\circ} \mathrm{C}$

Figure 3.10. Prototype of LCE frequency-reconfigurable antenna at different temperatures: (a) 0.5 -turn loop at $80^{\circ} \mathrm{C}$, (b) 1.5 -turn helix at $104^{\circ} \mathrm{C}$. 27 
Figure 3.11. Static prototype of pattern-reconfigurable LCE antenna \#1 at different states: (a) straight and (b) 1.1-turn spiral

Figure 3.12. Simulated and measured S11 of pattern-reconfigurable LCE antenna \#1 at: (a) straight state operating in omnidirectional mode; and (b) 1.1-turn spiral state operating in directional mode.

Figure 3.13. Static prototype of pattern-reconfigurable LCE antenna \#2 at different states: (a) straight and (b) 1.1-turn helix 32

Figure 3.14. Simulated and measured $S_{11}$ of pattern-reconfigurable LCE antenna \#2 at: (a) straight state operating in omnidirectional mode; and (b) 1.1-turn helical state operating in directional mode. 33

Figure 3.15. Simulated and measured elevation patterns of the patternreconfigurable antenna \#2 at (a) straight state, and (b) 1.1-turn helix. 33

Figure 3.16. Comparison of measured elevation-plane patterns of the patternreconfigurable antenna at two different states. 34

Figure 3.17. Static prototype frequency-reconfigurable LCE antenna at two states: (a) 0.5-turn loop, and (b) 1.5-turn helix. 36

Figure 3.18. Simulated and measured $S_{11}$ of frequency-reconfigurable antenna: (a) 0.5-turn loop; (b) 1.5-turn helix. 37

Figure 3.19. Simulated and measured elevation patterns of the frequencyreconfigurable antenna: (a) 0.5-turn loop, and (b) 1.5-turn helix. 37

Figure 3.20. Comparison of measured elevation-plane patterns of the frequency reconfigurable antenna at different states. 38

Figure 4.1. The first design of a helical antenna using LCE in response to temperature of this dissertation research.

Figure 4.2. Dynamic LCE Antenna self-twisting in response to heat. The number of turns increases as the temperature increases and will return to original state once the heat is removed.

Figure 4.3. A metallic insulated heat-tape wrapped around a PYREX beaker that encloses a dynamic LCE Antenna (b), used for an external heat source. 
Figure 4.4. Proposed design of an external stimuli enclosure in anechoic chamber. (a) LCE antenna without heat $\left(24^{\circ} \mathrm{C}\right)$; (b) Hot plate heating beaker; (c) Hot beaker enclosure dynamically actuating LCE antenna $\left(50^{\circ} \mathrm{C}\right)$; (d) Digital thermometer monitoring temperature inside the enclosure during measurement.

Figure 4.5. LCE antenna inside beaker enclosure at different temperature states;

(a) room temperature $\left(24^{\circ} \mathrm{C}\right)$; (b) heated $\left(50^{\circ} \mathrm{C}\right)$; and (c) dynamically actuated inside the anechoic chamber.

Figure 4.6. Comparison of measured $\mathrm{S}_{11}$ of multiband LCE antenna at two different temperature states.

Figure 4.7. The measured radiation patterns of the reconfigurable antenna at $\theta=$ $90^{\circ}$. (a) $6.7 \mathrm{GHz}$ with no heat. (b) $2.9 \mathrm{GHz}$ and (c) $6.8 \mathrm{GHz}$ are with heat.

Figure 4.8. Examples of acrylic or polystyrene (plastic) boxes with drilled holes and solder reworking station external stimuli setup.

Figure 4.9. External stimuli enclosure setup in the chamber with reworking station hose.

Figure 4.10. Simulated model of LCE frequency-reconfigurable antenna that reshapes itself from (a) 1-turn helix to (b) 2-turn helix to (c) 3 turn helix.

Figure 4.11. Dynamic prototype LCE frequency-reconfigurable antenna at different temperatures: (a) 1-turn helix at $45^{\circ} \mathrm{C}$, (b) 2-turn helix at $60^{\circ} \mathrm{C}$, and (c) 3-turn helix at $80^{\circ} \mathrm{C}$ 53

Figure 4.12. Simulated $S_{11}$ of frequency-reconfigurable antenna for three states with a simulated $3 \mathrm{D}$ radiation gain. 54

Figure 4.13. Measured $S_{11}$ of frequency-reconfigurable antenna four three states 54

Figure 4.14. Simulated and measured elevation patterns of the frequencyreconfigurable antenna at different states: (a) 1-turn helix, (b) 2-turn helix, and (c) 3-turn helix.

Figure 4.15. Prototype of LCE antenna for dynamic measurements at different orientations: upside down, right side up, and $90^{\circ}$ degrees inside the anechoic chamber.

Figure 4.16. Dynamic prototype LCE Antenna with and without the Polylactic Acid (PLA) cylinder brace. 
Figure 4.17. Simulated model of LCE frequency-reconfigurable antenna that reshapes itself from (a) 1-turn helix to (b) 2-turn helix to (c) 3 turn helix. 58

Figure 4.18. Dynamic prototype LCE Antenna inside the cylinder brace at different states: no turns at $25^{\circ} \mathrm{C}, 1$-turn at $40^{\circ} \mathrm{C}, 2$-turn helix at $63^{\circ} \mathrm{C}$, and 3-turn helix at $80^{\circ} \mathrm{C}$.

Figure 4.19. (a) Simulated and (b) measured $\mathrm{S}_{11}$ of dynamic frequencyreconfigurable LCE antenna at each different state

Figure 4.20. Simulated and measured elevation patterns of the dynamic frequency-reconfigurable LCE antenna at different states: (a) 1-turn helix at $10 \mathrm{GHz}$, (b) 2-turn helix at 10Ghz, (c) 2-turn helix at 14 $\mathrm{GHz}$, and (d) 3-turn helix at $15 \mathrm{GHz}$

Figure 4.21. Metallized LCEs on glass slides with: (a) glued Al and (b) E-beam evaporated Al.

Figure 4.22. SEM images of metallized LCE films before heat cycles with: (a) glued $\mathrm{Al}$ and (b) E-beam evaporated Al.

Figure 4.23. SEM images of metallized LCE films: (a) glued Al before heat, (b) E-beam evaporated $\mathrm{Al}$ before heat, (c) glued $\mathrm{Al}$ after heat, and (d) Ebeam evaporated $\mathrm{Al}$ after heat.

Figure 4.24. Two LCE antennas were prepared using two different metallization methods: (a) Antenna 1 used Al attached to the LCE with optical glue, and (b) Antenna 2 used electron beam evaporation.

Figure 4.25. Two LCE antennas after 50 heat cycles.

Figure 4.26. AFM images of glued Al before and after 50 heat cycles. 68

Figure 4.27. Metallized LCE samples that will be actuated through a different number of heat cycles: (a) 25 cycles, (b) 50 cycles, and (c) 100 cycles.

Figure 4.28. SEM images showing Al glued (left side) and evaporated (right side) with (a) no heat, (b) 25 , (c) 50 , and (d) 100 heat $\left(25^{\circ} \mathrm{C}-90^{\circ} \mathrm{C}\right)$ cycles from top to bottom respectively.

Figure 5.1. (a) RM82 and n-butylamine used to synthesize the reactive LCEs and (b) The fabrication process of LCE sample metallized with gold. POM images to confirm twisted alignment: (c) front (d) back. (e) An evaporated $\mathrm{Au} \mathrm{LCE}$ antenna at room temperature. 
Figure 5.2. The cooling bath's temperature regions

Figure 5.3. SEM micrographs of: (a) evaporated Au LCE film after lift-off; (b) evaporated Au LCE film after 50 cycles; (c) evaporated Au LCE helical at one turn; and (d) top view of evaporated Au LCE film.

Figure 5.4. Au LCE antenna 1's number of turns increase as the temperature decrease.

Figure 5.5. Measured reflection coefficient $\left(S_{11}\right)$ of the Au LCE antenna 1 as the number of turns increased as temperature decreases.....

Figure 5.6. Au LCE antenna 2's number of turns increase as the temperature decrease.

Figure 5.7. Measured reflection coefficient $\left(S_{11}\right)$ of the Au LCE antenna 2 as the number of turns increased as temperature decreases

Figure 5.8. Measured frequency response of the reflection coefficient $\left(\mathrm{S}_{11}\right)$ after the Au LCE antenna has been reversibly actuated through cold temperatures from 0 to 100 cycles. 


\section{CHAPTER 1}

\section{INTRODUCTION}

\subsection{Problem Statement}

Traditional electronic devices, including antennas, are generally planar, rigid, and static. A static communication system relies on one or more single-function antennas and is designed to meet specific parameters. Reconfigurable antennas can change their performance to support different services, e.g., operating frequency, polarization, and radiation pattern. Reconfigurable antennas have previously relied on external circuitry employing shape memory alloys (SMAs) and solid-state switches (i.e., pin diodes, RF switches, etc.) [1-3]. Antennas using MEMS or diodes exhibit low efficiency due to the losses from these components. Flexible electronics have been developed for diverse applications, such as biosensors [4] and antennas [5]. However, fewer examples of electronic devices capable of morphing from one shape to another are available. Even though various techniques, such as, liquid metals [6], hydrogels [7], and shape memory polymers [8] have been recently applied to produce self-morphing electronics, these strategies each have significant disadvantages. Liquid metals are either highly toxic or rapidly oxidize in the presence of air [9]; hydrogels only work in aqueous environments [7], and shape memory polymers exhibit irreversible changes in shape [10]. The proposed novel LCE antennas can provide multi-functionality and enable passive (i.e., battery-less) temperature sensing and monitoring. LCEs exhibit reversible actuation, larger shape deformation, simpler processing, and lower cost in comparison to shape memory alloys $[11,12]$. 
Metallization is required for LCE substrates to be used as functional antennas. Metallized polymer films are widely used in industries ranging from food packaging to biosensors $[13,14]$. One of the problems to consider is the adhesion of the metal layer to the LCE substrate as well as the film thickness [15-17]. It has been observed that when metal films are stretched or bent, the compliant substrate deforms, but the stiff films may end up cracking or delaminating. Adhesion of the metal layer to the polymer can be increased by various methods, including chemical changes, plasma charge, laser and ion beam irradiation [18]. Mechanical failure is one of the main challenges for the development of flexible and stretchable electronics. It is expected that the metal thickness achievable using metal evaporation will not be able to exceed the skin-depth in the RF range. The effects of the material thickness to self-morphing abilities of the LCE antennas will be also considered and performance trade-offs (i.e., thinner materials are easier to fold versus thicker materials that exhibit less resistive loss) will be studied.

Temperature is also an important environment parameter in a diverse variety of fields such as infrastructure monitoring, chemistry, environmental engineering, and cold supply chain management. Current methods to monitor temperature are typically powered by batteries or only detect threshold violations. Also, in the cold supply-chain, temperature is poorly monitored, which leads to nearly $20 \%$ loss of fresh food in transit, which in turn results in significant financial loss and environmental burden [19]. Due to these problems, the need for temperature sensors has increased. Most of the wireless temperature sensors [20] consist of transceivers, memory, and batteries to maintain a temperature log history, but these sensors are expensive and can only be used in limited deployments. 


\subsection{Research Objectives and Contribution}

According to our knowledge, no previous work has been performed on selfmorphing flexible electronics, including antennas, which rely on stimuli-responsive LCEs that reversibly change shape in response to temperature. Consequently, the lack of fundamental knowledge on how to design and fabricate shape-changing LCE antennas is an important problem. This dissertation addresses these four main components: 1) To design novel reversibly self-morphing LCE antennas that dynamically reconfigure their electromagnetic performance (e.g., frequency, radiation pattern, or polarization) in response to temperature for passive sensing, 2) To develop simulation electromagnetic models that can validate the performance of reconfigurable structures and fabricate LCE antennas that can be reconfigured in a repeatable and robust way, 3) To study the electrical and mechanical performance of metalized LCEs, via evaporation deposition or glued metal films, and 4) To develop multifunctional LCE antennas.

The objective of this interdisciplinary research is to design reversibly self-morphing novel LCE antennas that can dynamically change electromagnetic performance in response to different temperatures. Also, the metallization of the LCEs with different conductors (aluminum and gold) and their fabrication process, by either electron beam (E-Beam) evaporation or optical gluing of the metal film will be observed. The LCE material can have a significant impact on various communication and sensing applications due to its

reversible actuation. LCE antennas can provide a reconfigurable performance in terms of radiation pattern, gain, and frequency of operation. 


\subsection{Methodology}

This research involves three main parts: 1) Program stimuli-responsive LCE material capable of reversible actuation in response to temperature, 2) Fabricate LCE antennas using a metallization technique and characterize antenna shape change, and 3) Analyze and measure electromagnetic performance. This research integrates material science with electromagnetics. Key parameters for enabling mechanical responses and generating spatial variation in the directionality and hierarchical orientation of LCE materials are surface-alignment techniques, which can include traditional rubbing, magnetic fields and light (photoalignment) [21]. For example, the formations of a helical or spiral shape are dictated by the aspect ratio (width-to-thickness) of the film. Appropriate twisted nematics (TN) can be programmed in metallized LCEs to generate reversibly selftwisting antennas in response to temperature changes.

Our antenna analysis was performed using ANSYS HFSS, which is a full-wave electromagnetic simulation software [22]. An external stimuli enclosure will be constructed for the light-weight responsive material to smoothly change its structure without ambient temperature interference. To form the antennas using LCE films, a thin metallized layer is attached on the film using different techniques. An analysis of the effects of skin depth will be performed. The LCE antenna prototypes will be tested and validated using a vector network analyzer and an anechoic chamber. The measurements will be analyzed with mathematical tools, such as Matlab and Origin 8. 


\subsection{Dissertation Outline}

The dissertation is organized as follows: Chapter 2 reviews background and related work for different types of reconfigurable antennas and different types of smart materials.

In Chapter 3, the pattern and frequency reconfigurable antennas based on shape-morphing LCEs are presented in a fixed (static) state. In Chapter 4, the measurement setup and metallization of reconfigurable LCE antennas are optimized for dynamic reconfiguration. Chapter 5 discusses novel reversibly self-morphing LCE antennas that can dynamically change frequency performance in response to cold temperatures. Finally, Chapter 6 provides the conclusions of this dissertation along with future work. 


\section{CHAPTER 2}

\section{BACKGROUND AND RELATED WORK}

In this chapter, previous work on reconfigurable antennas is reviewed in Section 2.1. Also, self-morphing antennas using smart material are reviewed in Section 2.2. Liquid crystalline elastomer (LCE) materials are presented in Section 2.3. Finally, RFID coldchain applications are introduced in Section 2.4.

\subsection{Reconfigurable Antennas}

Traditional wireless systems are designed to provide a single pre-determined performance. Therefore, the antennas of these systems also possess some fixed parameters such as frequency band, radiation pattern, polarization, and gain. A single reconfigurable antenna can replace a number of single-function antennas. Thereby reconfigurable antennas can reduce the overall size, cost and complexity of a system. Reconfigurable antennas are able to vary their performance characteristics, i.e., steer their pattern, place a null in their pattern, switch from right-hand to left-hand circular polarization, and/or change their operating frequency [23].

The reconfiguration of antennas is achieved by altering the radiated fields of the antennas' effective aperture, redistributing the antenna currents or reconfiguring the radiating edges [24]. The first reconfigurable antennas were based on mechanical movement of part of the antenna, such as the feed. Smart antenna arrays took reconfigurability to a new level with the electronic control of the antenna's pattern. Recently, reconfigurable antennas have gained research interest in numerous applications. 
In mobile and satellite communications, reconfigurable antennas are used to support a large number of standards (e.g., UMTS, Bluetooth, WiFi, and WiMA) to mitigate strong interference and cope with changing environmental conditions [25].

There are several methods that have been proposed for reconfigurable antennas. These methods are divided into four major categories: electrical, optical, geometrical change, and material change [26], which are shown in Table 2.1. Electrically reconfigurable antennas are based on switches such as, radio-frequency microelectromechanical systems (RFMEMS) [27-29], PIN diodes [30-32], or varactors [33, 34] that redirect their surface currents. Microelectromechanical systems (MEMS) switches possess good RF characteristics and can be used for low- and high-frequency applications [27]. A pin-diode is a versatile device and can be biased to behave like an open circuit, a short circuit, or exhibit any desired reflection coefficient in between [35]. Despite all their advantages, the use of these switching elements reduces the efficiency of antennas and increases the complexity of antenna systems as biasing networks are needed to control the switches. Antennas that rely on photoconductive switching elements are called optically reconfigurable. These switches are incorporated into an antenna structure that becomes conductive once it is subjected to light source (e.g., a laser beam) [36]. Physically reconfigurable antennas can be achieved by altering their geometry. Such antennas have been developed based on origami principles [37-40]. Currently dipole antenna arrays in various configurations constitute one of the most common antennas deployed on CubeSats [41]. The merging of reconfigurable and deployable antennas appears to be a solution with increased demand for communication agility in space [42]. Many types of actuators can be 
used to achieve mechanical reconfiguration. The choice of such actuators depends on the nature of the antenna and its material composition. For example, a helical antenna [43] deploys in stages by resorting to actuators. The sequential deployment tunes the antenna's operating frequency. The concept is based on the fact that only the part of the antenna that is above the deployed ground plane radiates [43]. Finally, reconfigurable antennas can be implemented through smart adaptive materials. RFID antennas have been used in the past as temperature sensors [44-46] and most existing RFID solutions rely on active or semipassive tags that require batteries to power a dedicated temperature sensor.

Table 2.1. Reconfiguration Techniques

\begin{tabular}{|c|c|c|c|}
\hline $\begin{array}{c}\text { Reconfigurable } \\
\text { Techniques }\end{array}$ & Types & Function & References \\
\hline Electrical & $\begin{array}{c}\text { RF-MEMS } \\
\text { switches, PIN } \\
\text { diodes, Varactors }\end{array}$ & $\begin{array}{c}\text { Redistribute the surface } \\
\text { currents and alter the } \\
\text { antenna radiating } \\
\text { structure topology }\end{array}$ & {$[27-34]$} \\
\hline Optical & $\begin{array}{c}\text { Photoconductive } \\
\text { switches }\end{array}$ & $\begin{array}{c}\text { Activate conductivity on } \\
\text { silicon switches by } \\
\text { shining light (e.g., laser) }\end{array}$ & {$[36]$} \\
\hline $\begin{array}{c}\text { Geometrical } \\
\text { change }\end{array}$ & $\begin{array}{c}\text { Altering antenna } \\
\text { structure, Origami }\end{array}$ & $\begin{array}{c}\text { Reconfiguration by } \\
\text { changing the antenna } \\
\text { radiating structure }\end{array}$ & {$[37-40]$} \\
\hline $\begin{array}{c}\text { Material } \\
\text { properties } \\
\text { change }\end{array}$ & $\begin{array}{c}\text { Liquid crystal, } \\
\text { Ferrites, Liquid } \\
\text { metals, } \\
\text { Ferroelectronics }\end{array}$ & $\begin{array}{c}\text { The material change in } \\
\text { relative electrical } \\
\text { permittivity or magnetic } \\
\text { permeability }\end{array}$ & {$[7-10,47,48]$} \\
\hline
\end{tabular}

Antennas can have various designs with enhanced performance and unique capabilities, such as patch antennas [49] or array antennas [33]. Recent MEMS technology enables the realization of MEMS with switching speed and compact size. A switching time of $225 \mathrm{~ns}$ 
has been reported [28], and MEMS with dimensions as small as a few microns have been developed [29]. However, integrating large numbers of lumped components might increase the RF loss, noise, and complexity of the bias circuitry. For this reason, an alternative approach for developing reconfigurable antennas relies on tunable materials, such as ferrite, ferroelectric materials, shape memory alloys, and shape memory polymers.

\subsection{Reconfigurable Antennas Using Smart Materials}

A smart material is defined as material that can sense and adapt to external stimuli [50]. Recently, adaptive/additive material research introduced new approaches to reconfigurable antennas via self-morphing materials that change their shape in response to external stimuli, as shown in Figure 2.1. To date, adaptable electromagnetic (EM) structures that use control of macroscopic shape to control antenna performance have not been explored in a widely-applicable or reliable manner. Even though various techniques, such as, liquid metals [6], hydrogels [7], ferroelectronics [47, 48], and shape memory polymers [8] have been recently used to develop self-morphing electronics, shown in Figure 2.2, these strategies each have disadvantages. Liquid metals are either highly toxic or rapidly oxidize in the presence of air [51]; hydrogels only work in aqueous environments; and shape memory polymers exhibit irreversible changes in shape [10]. Some other approaches use conventional electronic materials coupled to active polymer substrates. Shir used stretchable gold micro-heaters on a thermally-responsive hydrogel to actively modulate shape [52], but these materials only work in aqueous environments [7]. 


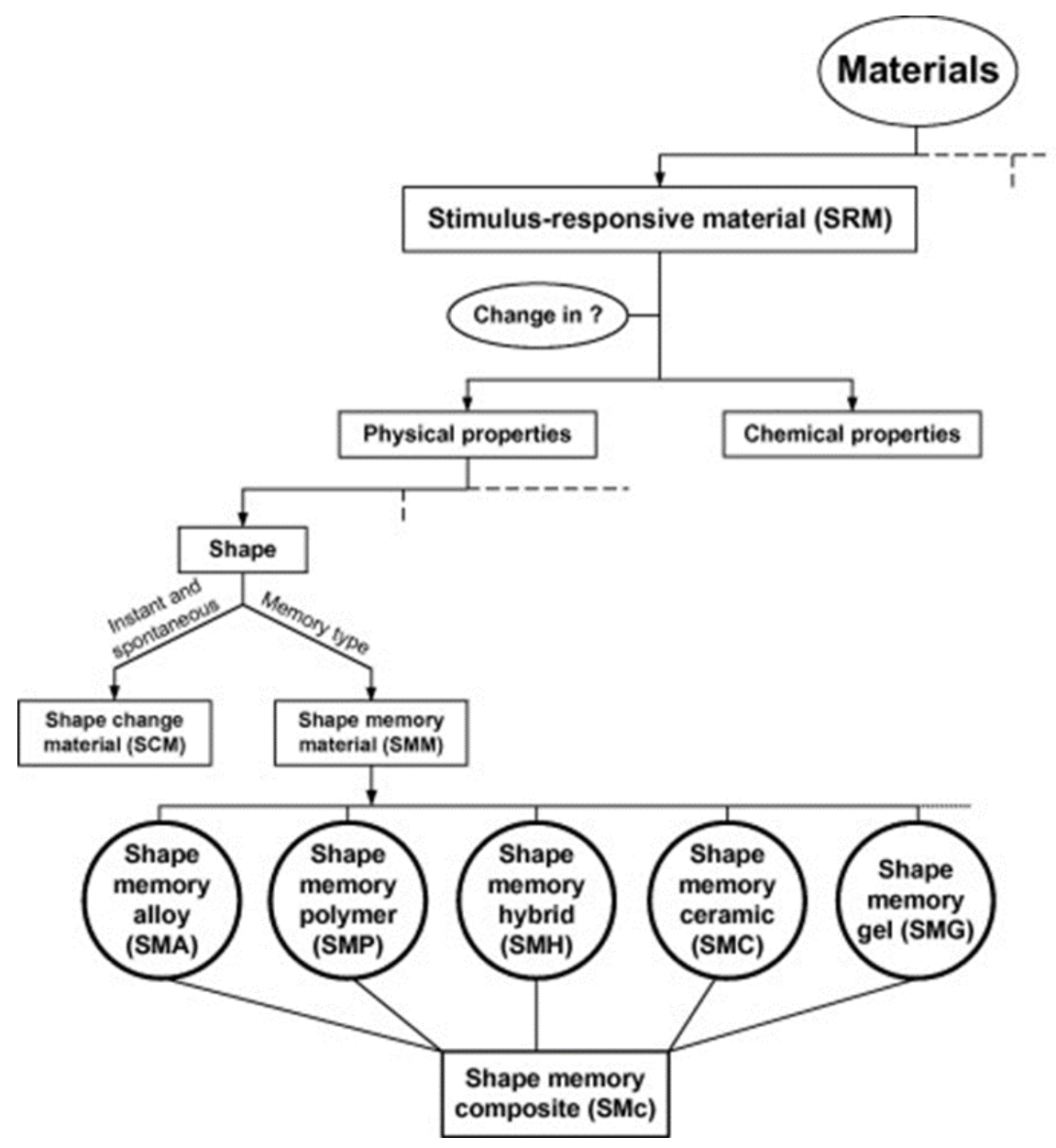

Figure 2.1. Diagram of various techniques of smart materials [53].

A reconfigurable helical antenna was implemented using shape memory alloy spring actuators to adjust its height [1]. A microstrip patch antenna operating at $5 \mathrm{GHz}$ was tuned by liquid crystals (LC) [49]. However, due to the high losses in the LC material, the antennas suffered from poor efficiency (20-40\%). Both antennas used tunable material [1, 49], with drawbacks of low efficiency and a required DC bias affecting the antenna's performance.

Very promising passive RFID tags in terms of cost and size are tags that use the antenna itself as the temperature sensor. Such RFID tags have been developed before [20, 45] with 
single-use tags that use an irreversible shape memory polymer to cause a frequency shift that can be used to detect only one temperature threshold violation. Therefore, such tags cannot provide continuous monitoring of temperature. LCEs support reversible changes in shape in response to changes in temperature. Therefore, they can be used to develop a new generation of passive (i.e., battery-less) RFID sensors, which are capable of real-time monitoring of temperature and detecting multiple temperature threshold.

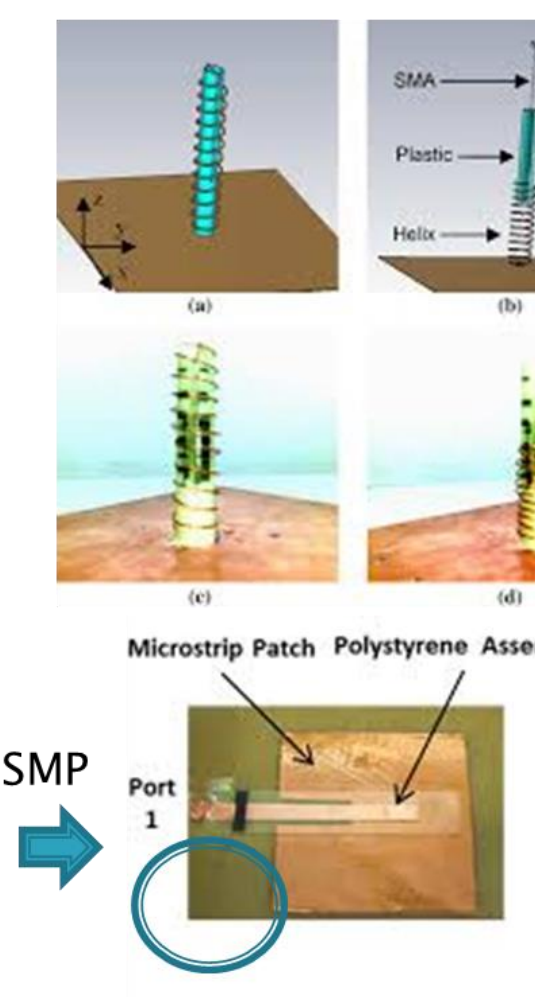

(a) Prior to activation

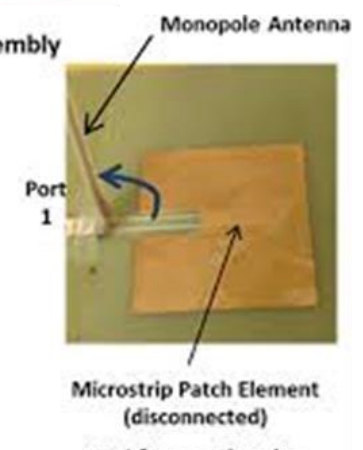

(b) After activation

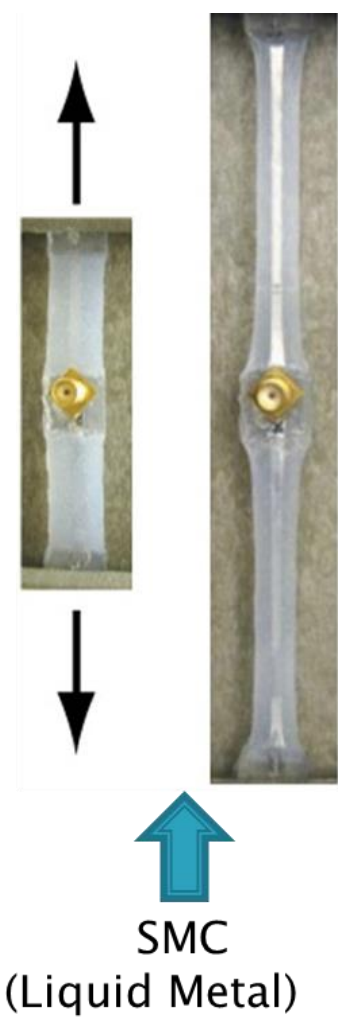

\section{(Liquid Metal)}

Figure 2.2. Examples of self-morphing electronics using smart materials: shape memory alloy (SMA) [1], shape memory polymer (SMP) [10], and shape memory ceramic (SMC) [48]. 


\subsection{Liquid Crystalline Elastomers}

Liquid Crystal Elastomers (LCEs), shown in Figure 2.3, are a class of responsive polymers [54] in which molecular order can be programmed spatially and hierarchically to give rise to anisotropic shape change in response to stimuli, such as temperature [55, 56], light [57], or solvents [58]. By patterning the molecular orientation nematic director, these actuators can morph from flat into a 3D shape [59-61]. Stimuli-responsive LCEs are shapechanging materials that provide an unprecedented amount of reversible strain and programmability, and are well-suited for morphing electronics [11]. Such LCE materials can enable the development of new passive antenna systems with novel capabilities, such as 2-D and 3-D antenna elements that can reversibly morph their geometrical shape to control the performance parameters when the temperature changes and achieves multifunctionality.

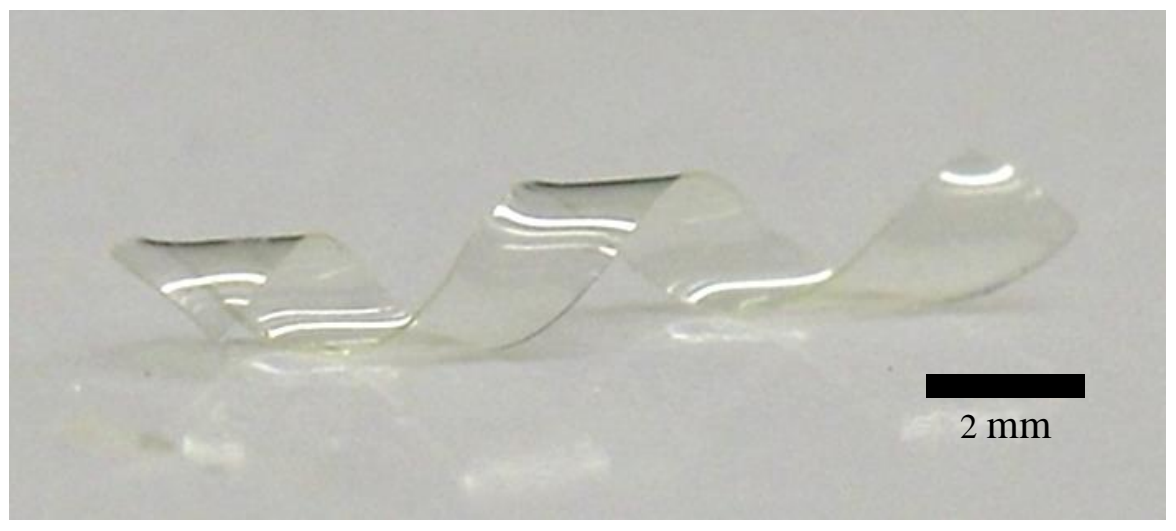

Figure 2.3. Example of a twisted nematic LCE actuating in response to heat.

Actuation of LCEs has some potential advantages compared to shape memory alloys (SMAs), including a considerable increase in the magnitude of shape deformation as well as simpler processing $[11,12]$. The stimuli-induced response is reversible wherein the 3-D 
shape restores to a 2-D flat shape after removal of the stimuli. Temperature is the most common stimulus for directing shape change in LCEs. Even when compared to shapememory polymers, which recover deformation only once [10], LCEs show repeated shape shifting over many cycles. This repeated shape shifting opens the possibility for selfreconfiguring electronics and new sensors.

Four-dimensional (4D) printing is a term that has made significant advances in 3D printing technology with respect to materials, printers, and processes because $4 \mathrm{D}$ printed structures have the capability to change form or function over time (t) in response to stimuli. 4D printing describes additive manufacturing of stimuli-responsive materials and enables a wide variety of material strategies morphing structures from soft robots [62-64] to morphing medical devices [65-67]. Direct-write printing enables fabrication of 3D thermally responsive liquid crystal elastomers (LCEs) structures with molecular order encoded during fabrication, and the resulting structures undergo programmed shape change. Each aligned LCE filament undergoes $40 \%$ reversible contraction along the print direction on heating. Shear forces intrinsic to direct-write printing processes orient LC reactive inks along the print path, and these inks can be subsequently polymerized into responsive elastomers. The interplay of molecular orientation and geometry enables an array of thermally driven structural adaptations [55]. Printing LCEs with nonuniaxial print paths within the plane or through the thickness leads to materials that undergo complex deformations on heating. Directing the printer to extrude the LC ink in an Archimedean chord pattern results in LCE films programmed with the director pattern associated with a +1 topological defect, where orientation varies azimuthally around a single point. The 
printed +1 topological defect LCE morphs from flat at room temperature, as shown in Figure 2.4(a), into a cone at a higher temperature, as shown in Figure 2.4(b). Such LCEs can reach heights up to 10 times larger than the original film thickness [55].

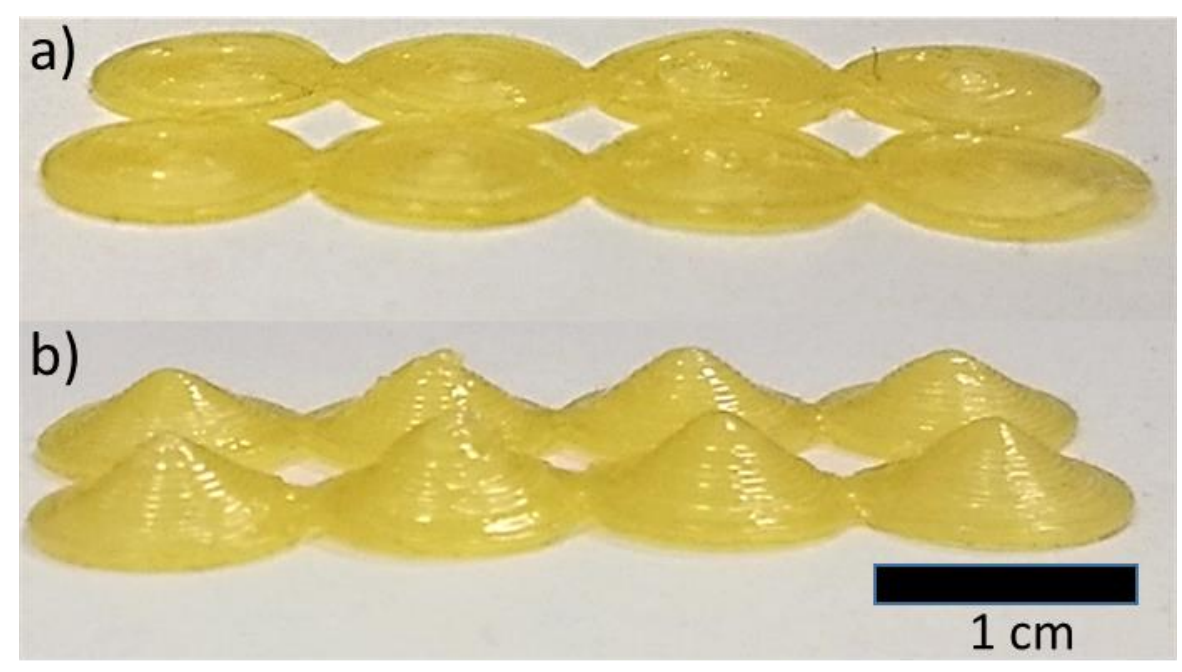

Figure 2.4. (a) Side-view images of 3D-printed $4 \times 2$ array of $1 \mathrm{~mm}$ diameter disk, printed in an Archimedean chord pattern at room temperature and (b) a cone shaped array when heated.

\subsection{Radio Frequency Identification Devices (RFID) Applications for Cold Chains}

Perishables (produce, meat, and dairy) products require temperature controlled supply chains, since exposure to certain ambient temperature conditions can result in deterioration of the product and financial loss. Cold chain is a term that describes a supply chain that provides the best temperature conditions required to maintain the initial quality of the product, and prolong its shelf life. The unbroken cold chain should be uninterrupted after the initial cooling of the product, and maintain a desired low-temperature range. Current methods to monitor temperature of perishables use either expensive data loggers or disposable time-temperature color indicators. Typically, these devices are color-changing indicators, which, while simple, require a direct line of sight to the sensor and are inefficient 
to read in bulk. Furthermore, once "triggered" these sensors no longer provide useful data and must be discarded [68]. A sensing system is needed that provides real-time, batteryless and non-visual sensing of temperature to improve product safety.

RFID technology's usage is growing in supply chain management systems. RFID tagging overcomes the limitations of optical barcodes, which are line-of-sight and weather dependent and require manual inspection. RFID systems are beneficial for many food manufacturing operations and supply chains. Retail chains such as WalMart and Home Depot already use RFID, because RFID systems provide safety and security benefits by tracking the origin of food supplies, retailers are considering ways to integrate this technology into the management of their supply chains.

An RFID system consists of a transponder (tag), with electronically programmed information, and of a detector (reader) that is capable to retrieve the identity of the tags through a wireless wave. The passive RFID tag usually is composed of a tag antenna and an IC chip. Various temperature-sensing RFID tags have been developed. However, most existing solutions rely on active or semi-active RFID tags that utilize a battery and a dedicated temperature sensor, such as, FreshtimeTM semi-active RFID tags from Infratab Inc, RFID-based temperature datalogger (i-Q32T) by Identec Solutions, and IDS-SL13A from IDS Microchip AG [69]. Passive RFID tags are preferred over active and semi-active tags as they are low cost, do not require batteries, and can uniquely identify each product. Such advantages are expected to help the supply chain to operate very fast and efficiently.

Some challenges for RFID systems in food supply chains is that environmental factors, such as water and the presence of metal, can affect the quality of RF signals thereby 
affecting their operation. The first challenge is the use of multiple frequencies around the globe. The fast development of the global economy, the exchanges of products made from different countries have become more and more frequent. The different regulations with respect to frequency ranges allocated for RFID commercial purposes, vary according to the country and complicate global RFID ventures. For example, UHF tags sent in a shipment from the U.S. (with a UHF frequency allocation between $902-928 \mathrm{MHz}$ ) will be able to be read in Europe (frequency allocation of $865-868 \mathrm{MHz}$ ) if used EPC Global Gen-2 standards (which call for readers to be able to read along the entire UHF spectrum) but will not be able to be reprogrammed and sent back with a shipment. In order to make the tag attached to the products effective, the RFID system should operate in dual-band or multiband region [70-73]. Therefore, a design of dual-frequency or multi-frequency tag antenna is of great importance for RFID application in different countries.

The other challenge of RFID systems related to the presence of metal near tags, which introduces a parasitic capacitance that changes the performance of tags including their radiation pattern, impedance, gain and bandwidth. As a result, tags can become unreadable from readers within normal reading range. There has been prior research into the development of RFID tag based sensors. For example, the development of displacement sensor was developed using the fact that RIFD tags performance changes in close proximity to metals [20]. Also, changes in the background dielectric material will certainly influence RFID tag performance both in terms of the power backscattered by the tag as well as the threshold transmitted power required to power up the tag [74]. 


\section{CHAPTER 3}

\section{RECONFIGURABLE ANTENNAS BASED ON SELF-MORPHING LCES AT STATIC (FIXED) STATES WITH HEAT}

In this chapter, pattern- and frequency-reconfigurable antennas using metallized LCEs that can change their geometries from flat to spiral and helical shapes are studied. The design of the LCE with twisted nematic (TN) orientation used for antennas is described in Section 3.1. The pitch angle and number of turns in this transformation are controlled by temperature. The reconfigurable antennas built on an LCE substrate are presented in Section 3.2. The results which show the pattern- and frequency-reconfigurability at a fixed state is presented in Section 3.2.1, Section 3.2.2, Section 3.2.3, respectively [75, 76]. An external heat source is applied to reshape the geometry of these antennas, thereby reconfiguring their performance in terms of radiation and frequency of operation.

\subsection{LCE Twisted Nematics (TN) Structures Used in Antennas}

The magnitude and direction of the thermomechanical response are controlled by the orientation of the nematic director to the film geometry. By programming twist directly into the molecular orientation $\left(90^{\circ}\right)$ through the thickness of the LCE twisted nematic (TN) alignment, torsional actuation can be induced, as illustrated in Figure 3.1. The orientation generates large deflection when subjected to thermal or optical stimuli due to the cooperation of the front and back surfaces. Twisted alignment is achieved by aligning the front surface (FS) of the film along the long axis, and offsetting the bottom surface (BS) alignment $45^{\circ}$ the top director to the principal axes of the sample, resulting in shear that yields a three-dimensional torsional deformation [77-79]. The handedness of the twisting 
is controlled by the material's chirality across the LCE thickness. When the nematic director rotates from a negative angle to a positive angle through the film thickness, an originally flat LCE spontaneously forms a left-handed (LH) helix upon heating. When the nematic director rotates from a positive angle to a negative angle through the film thickness, the originally flat LCE spontaneously forms a right-handed (RH) helix upon heating. The nature and degree of the twist are dependent upon the aspect ratio of the printed material. Appropriate TN will be programmed in the metallized LCEs to generate reversibly self-twisting antennas in response to temperature changes both above and below room temperature.

To prepare LCEs in the TN orientation, a monomer mixture is initially melted to isotropic state for homogenous mixing on a glass substrate coated with an Elvamide film, then cooled into the nematic phase and photopolymerized after a chain-extension reaction, as described previously [80]. The thickness of the LCE used in our studies is $50 \mu \mathrm{m}$. LCE samples were prepared to genearte both $\mathrm{RH}$ and $\mathrm{LH}$ spirals. The sample strips are $18 \mathrm{~mm}$ long by $2 \mathrm{~mm}$ wide. Figure 3.2 shows the variation of the nematic director within the two strips and their corresponding helices. Specifically, in Figure 3.2(a), the nematic director rotates from $+60^{\circ}$ (FS) to $-30^{\circ}$ (BS) when it is heated at $130{ }^{\circ} \mathrm{C}$ above the glass transition temperature $\left(T_{g}\right)$ and it forms a RH helix. This orientation will be represented as $+60^{\circ} \%-30^{\circ}$. In Figure 3.2(b), the nematic direction rotates from $-60^{\circ}$ (FS) to $+30^{\circ}$ (BS) when it is heated at $130{ }^{\circ} \mathrm{C}$ and it forms a LH helix. This nematic director will be represented as $-60^{\circ} \%+30^{\circ}$. 


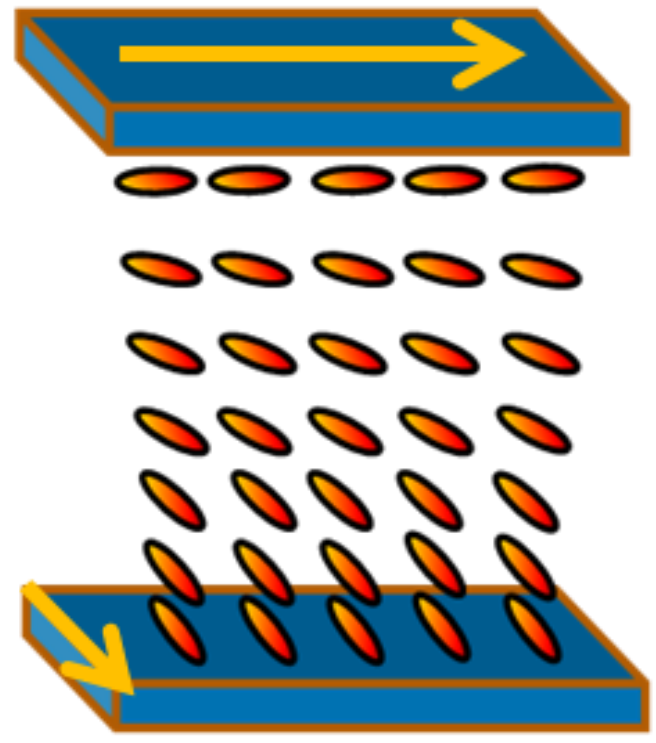

Figure 3.1. Illustration of the 90 degree twist in the orientation of the nematic director in the so-called twisted nematic configuration.
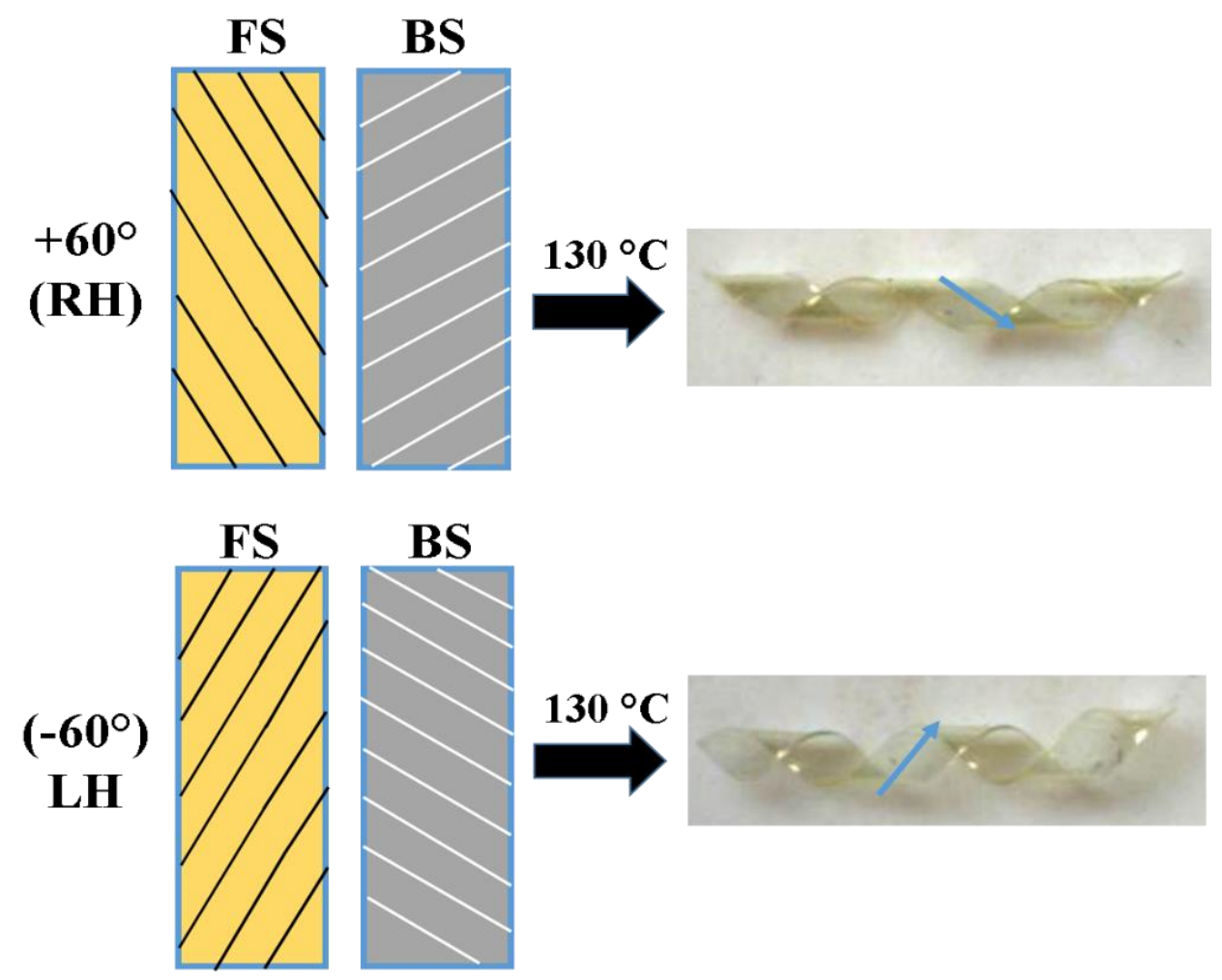

Figure 3.2. LCE prepared in the TN orientation transform from flat to helical shape upon heating. Images shown when the LCEs are heated at $130^{\circ} \mathrm{C}$ : (top) $+60^{\circ}$ (FS) to $-30^{\circ}$ (BS) yields a right-handed helix; and (bottom) $-60^{\circ}$ (FS) to $30^{\circ}$ (BS) yields left-handed helix. 
Due to the substantial mismatch of the coefficient of thermal expansion (CTE) between FS and BS above the glass transition temperature of the polymer $\left(T_{g}\right)[81]$ the tightness of the spiraling can be controlled by temperature [78]. Figure 3.3 illustrates the number of turns versus temperature for two LCE strips: one that produces a left-handed (LH) helix and one that produces a right-handed $(\mathrm{RH})$ helix. Figure 3.4 shows that, as the temperature increases, the number of turns increases. The external heat source varies the temperature of the LCE film from $30^{\circ} \mathrm{C}$ to $150^{\circ} \mathrm{C}$. Notably, the LH twisting LCE strips achieve a larger number of turns, than the RH ones for the same temperature. The asymmetric response is also observed from other literature [82]. In Figure 3.5, the inverse of the pitch angle for the $\mathrm{RH}$ and LH strips is plotted versus temperature. As the temperature increases, the $\mathrm{LH}$ pitch angle increases more rapidly than the $\mathrm{RH}$.

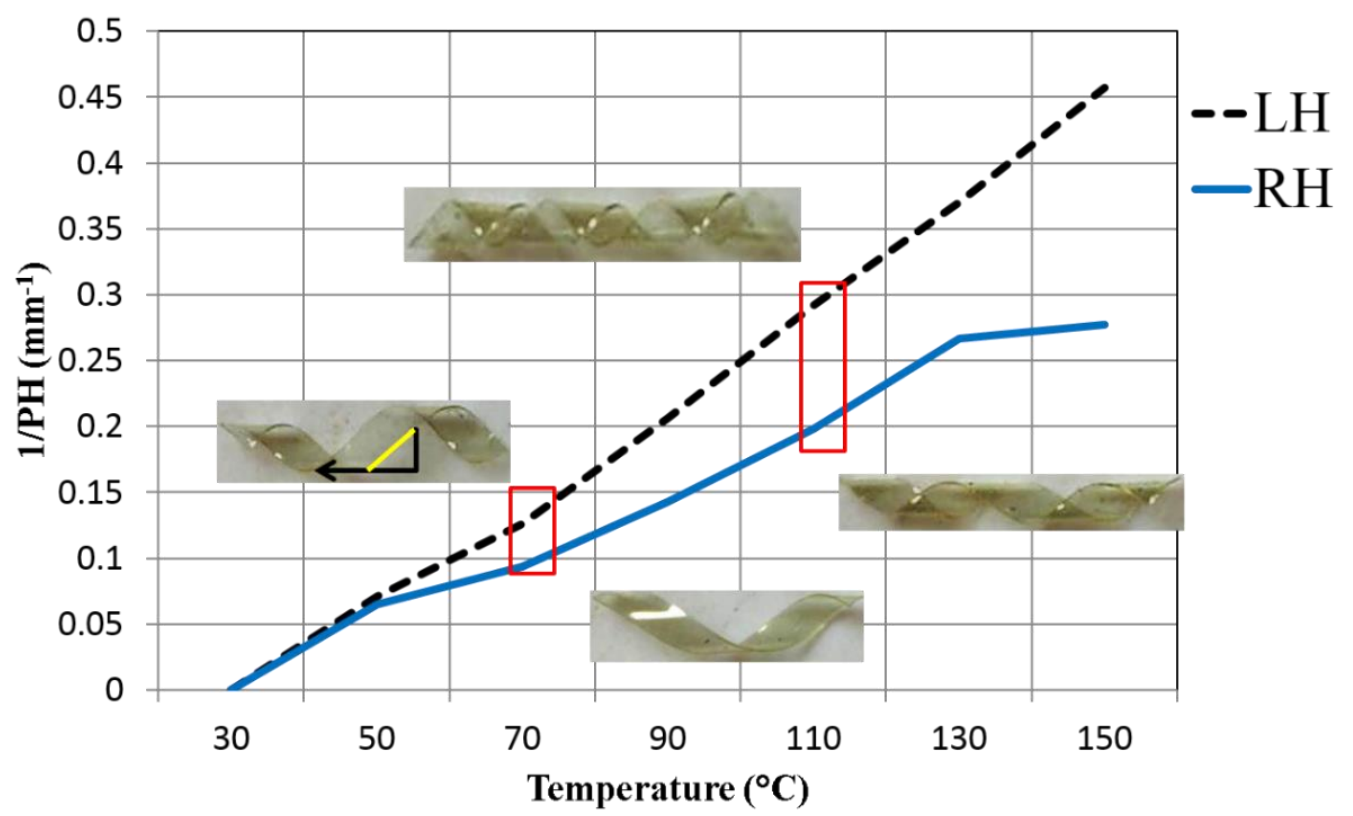

Figure 3.3. Temperature dependence of the number of turns of an LCE strip. 


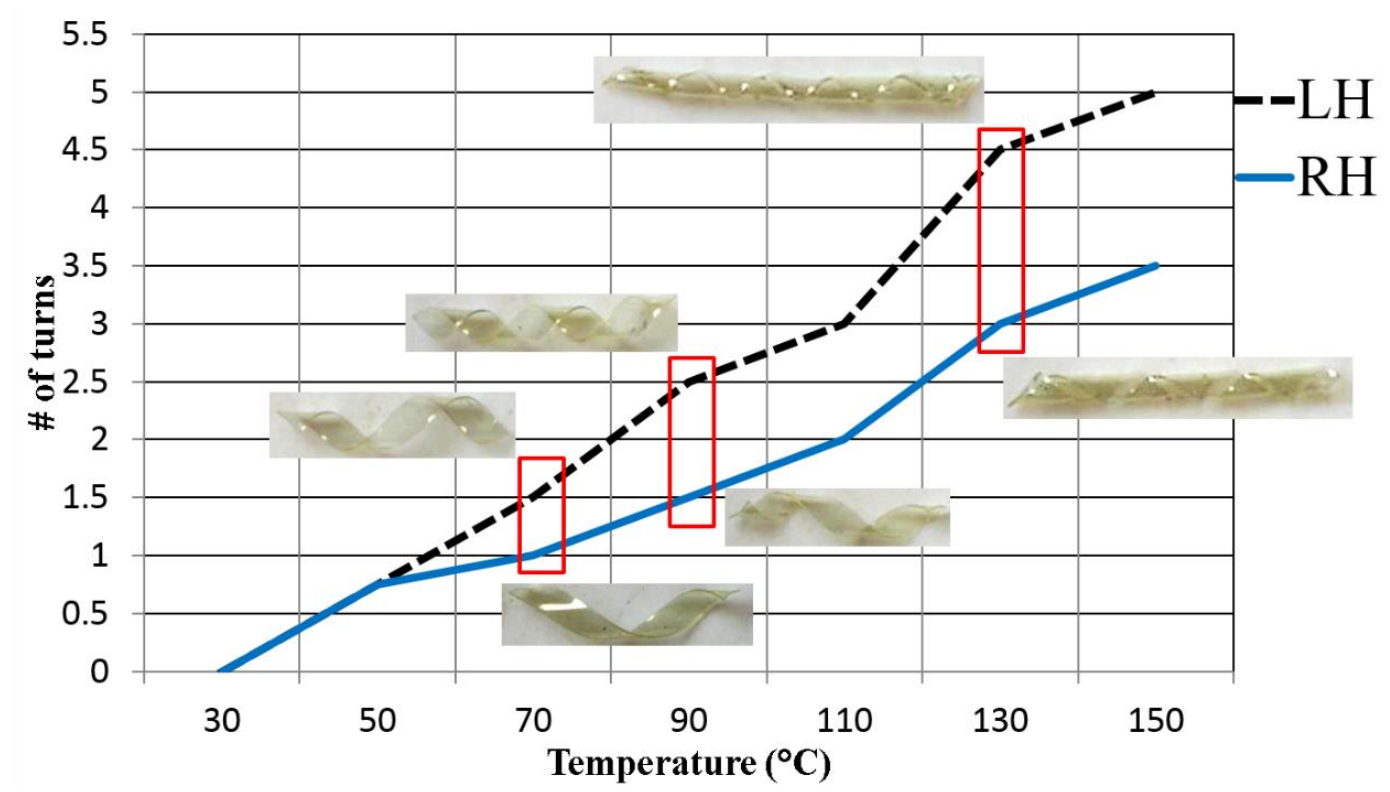

Figure 3.4. Temperature dependence of the inverse of the helical pitch angle (PH).

In order to form antennas using these LCE strips, a thin aluminum layer is attached using optical glue to the LCE. In this bi-strip, the thickness of the polymer is $50 \mu \mathrm{m}$, which is considerably larger than the thickness of the aluminum layer $(1.8 \mu \mathrm{m})$. To prepare the antennas, the LCE films were spin-coated with a thin layer of Norland optical adhesive \#75 and immediately attached to $1.8 \mu \mathrm{m}$ thick Aluminum (Geisnote). After UV curing the optical glue ( $5 \mathrm{~min})$, the film was cut into strips $20-30 \mathrm{~mm}$ in length and $2-3 \mathrm{~mm}$ in width. Once the aluminum was attached to the polymer, experiments were conducted to confirm that the nascent thermomechanical response of the LCEs illustrated in Figures 3.2-3.4 is not affected by the thin aluminum layer. Figure 3.5 shows an LCE strip, which has aluminum attached to it, reshaping itself at different temperatures. The aspect ratio (i.e., length/width) of the LCE strips had to be large enough to achieve the shape transformations that are of interest, such as, helices or spirals. The aspect ratio used in all the films in this chapter ranges from 8.5 to 11. 


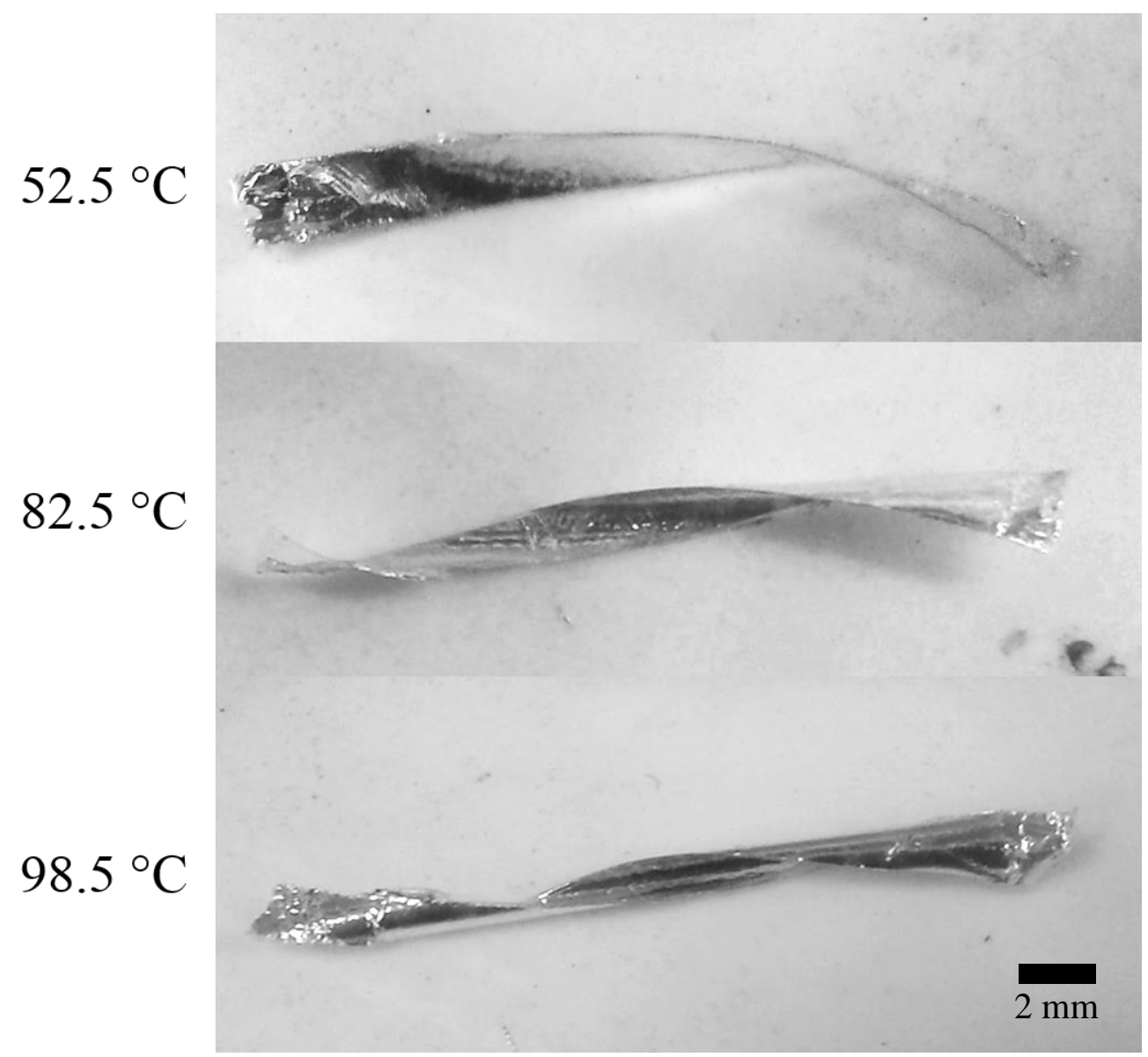

Figure 3.5. LCE with aluminum showing the different stages of the polymer changing its structure due to the increased temperature.

\subsection{Reconfigurable Antennas Based on LCEs}

Two pattern-reconfigurable antennas and a frequency-reconfigurable antenna are proposed here based on LCEs laminated with an aluminum layer. The patternreconfigurable antennas can reshape itself at different temperatures to radiate: (1) omnidirectionally when it is straight, and (2) directionally when it is coiled into a helical or spiral due to heating. On the other hand, the frequency-reconfigurable antenna can change its number of turns at varying temperatures to radiate directionally at different frequencies. These reconfigurable antennas were simulated using ANSYS HFSS and the simulation models are shown in Figures 3.6- 3.8. 
The helix consists usually of $N$ turns, diameter $D$ and spacing $S$ between each turn. The total length of the antenna is $L=N S$ while the total length of the wire is $L n=N L 0=N \sqrt{ } S 2+$ $C 2$ where $L 0=\sqrt{ } S 2+C 2$ is the length of the wire between each turn and $C=\pi D$ is the circumference of the helix. Helical antennas have different modes of operation (Normal and Axial) [23]. In Normal mode, the circumference is very small with respect to the wavelength $(N L o<<\lambda \mathrm{o})$. The radiation is perpendicular to the axis of the helix and acts like a linear dipole. In the Axial mode, the circumference is in the order of the wavelength or large fractions of it $\left(3 / 4<C \lambda_{0}<4 / 3\right)[23]$.

The first antenna proposed here is a pattern-reconfigurable antenna that was built using an LCE with aluminum strip, which was cut at an orientation with nematic director $60^{\circ}$ $30^{\circ}$. This LCE strip is $33 \mathrm{~mm}$ long and $3 \mathrm{~mm}$ wide and it is attached to the SMA bulkhead connector, using epoxy. It was discovered during experiments that attaching the aluminum foil to a different side of the polymer would affect the spiraling direction of the antenna upon heating. Also, the side length of the square ground is $20 \mathrm{~mm}$. This design is larger from the other two shown in this chapter.

The second antenna proposed here is another design for a pattern-reconfigurable antenna (i.e., reconfigures its radiation pattern) that was built using an LCE with aluminum strip, which was cut at an orientation with nematic director $70^{\circ} / 20^{\circ}$. This LCE with aluminum strip is $17 \mathrm{~mm}$ long and $2 \mathrm{~mm}$ wide. The ground plane is a square with side lengths of $15 \mathrm{~mm}$ cut from a double-sided copper FR-4 substrate $\left(\varepsilon_{\mathrm{r}}=4\right)$. Both of the ground plane sides are connected to the outer conductor of the SMA bulkhead connector and function as ground. The copper thickness of each side of the substrate is $0.035 \mathrm{~mm}$. The 
substrate is $1.5 \mathrm{~mm}$ thick and an LPKF ProtoMat S103 was used to fabricate the ground plane. Conductive silver epoxy was used to electrically connect the LCE strip to the feed line of the $50 \Omega$ SMA bulkhead connector that is connected to the ground plane as shown in Figure 3.9. The epoxy needed to be cured under room temperature for approximately 4 hours.

The third antenna proposed here is a frequency-reconfigurable antenna that uses an LCE with the aluminum strip cut at an orientation with nematic director $60^{\circ} \%-30^{\circ}$. This antenna is smaller with the LCE strip being $18 \mathrm{~mm}$ long and $2 \mathrm{~mm}$ wide and it is attached to the SMA bulkhead connector, using epoxy (Figure 3.10). The side length of the square ground is $18 \mathrm{~mm}$. The side lengths of the square ground planes for these two antennas are selected so that: (a) the omnidirectional radiation of the straight LCE strip is not negatively affected, and (b) the directional gain of the LCE antennas is enhanced at the coiled states. Specifically, the pattern-reconfigurable antenna is designed to radiate: (a) omnidirectionally at the straight state, and (b) directionally at the 1.1-turn helical state. However, the frequency-reconfigurable antenna is designed to radiate directionally at different frequencies as the LCE antenna morphs from 0.5-turn loop to 1.5-turn helix for different temperatures.

The temperatures at which the different states of these last two antennas reconfigure themselves are listed in Table 3.1. The heat was uniformly applied by wrapping an insulated heat-tape around a PYREX beaker that enclosed the antenna. The temperature was measured using a temperature probe alongside the antenna. The metallic heat-tape that was used to heat the LCE antennas affects the antenna performance. Also the heating 
equipment was difficult to fit in our anechoic chamber, therefore 3-D supports printed by the MakerBot Replicator Z18 were used to fix the antennas at different states. These supports were used to fix the antennas in different states after they had reshaped themselves in response to different temperatures. The 3-D supports were polylactic acid (PLA) with a relative permittivity $\left(\varepsilon_{\mathrm{r}}\right)$ of 3.2 [83]. Return-loss measurements $\left(\mathrm{S}_{11}\right)$ were taken using a vector network analyzer (E5071C, Agilent Technologies). The radiation patterns of the first LCE antenna design were measured an AMS-8050 (ETS-Lindgren) anechoic chamber. The other two designs' radiation patterns and gain measurements were conducted using a StarLab antenna measurement system.
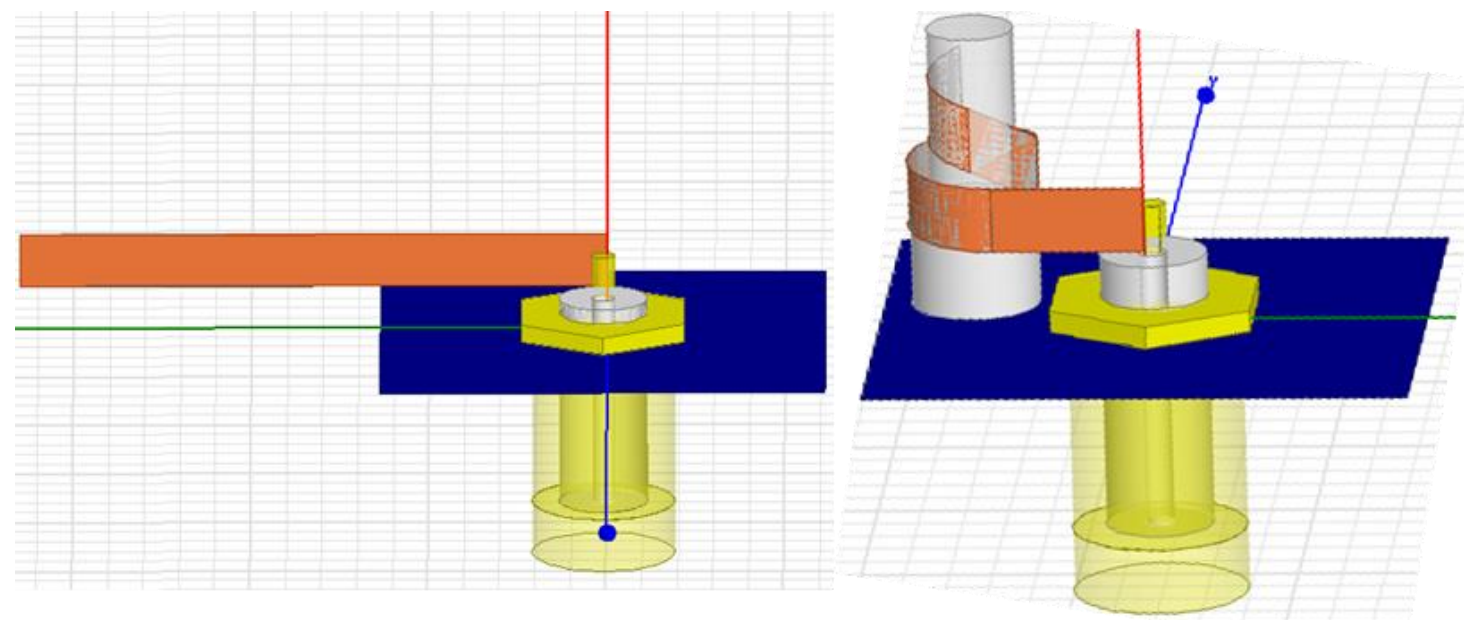

Figure 3.6. Simulated models of LCE pattern-reconfigurable antenna \#1 from: (a) straight to (b) 1.1-turn spiral. 


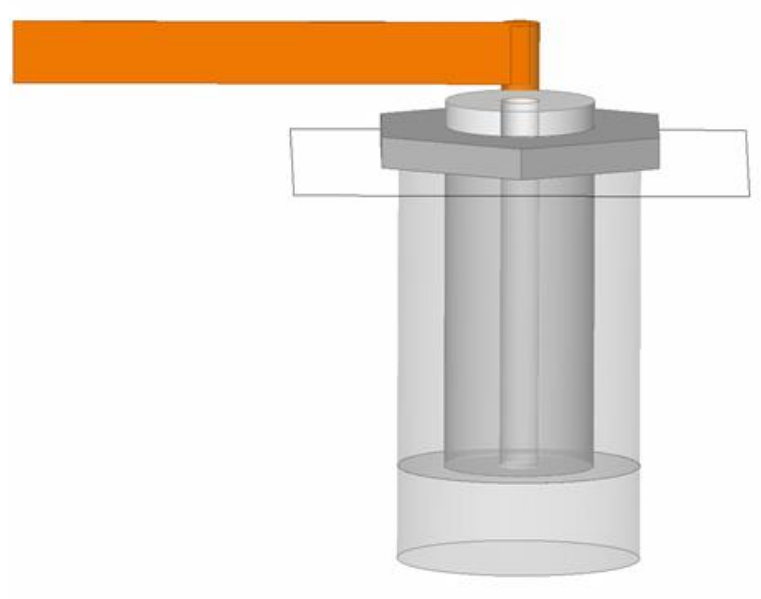

(a)

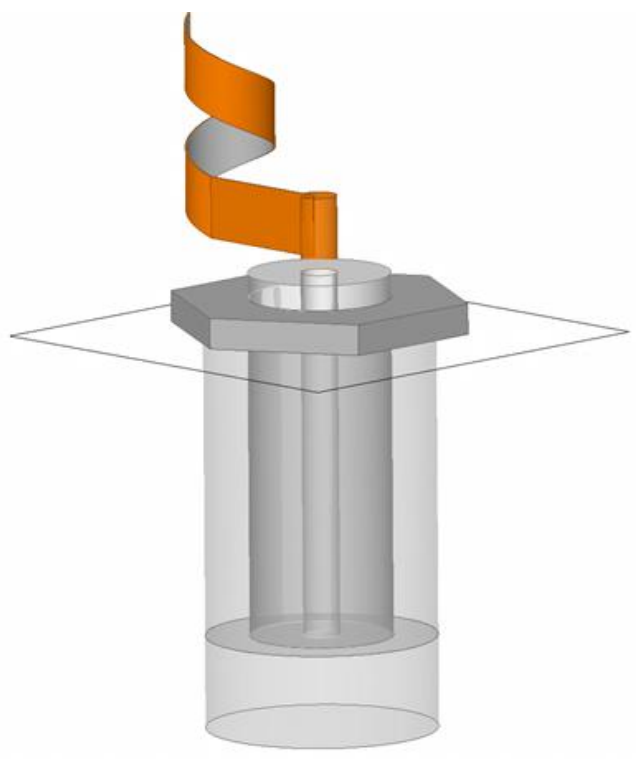

(b)

Figure 3.7. Simulated models of LCE pattern-reconfigurable antenna \#2 from: (a) straight to (b) 1.1-turn helix.

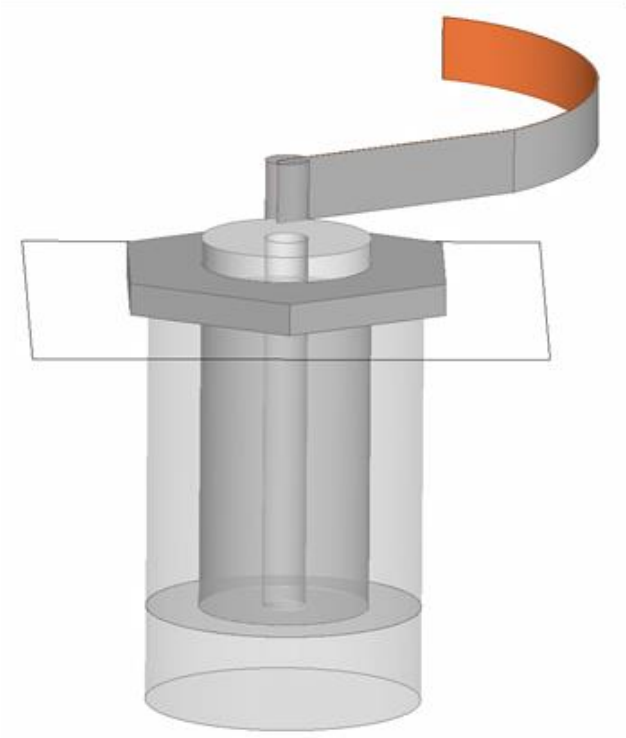

(a)

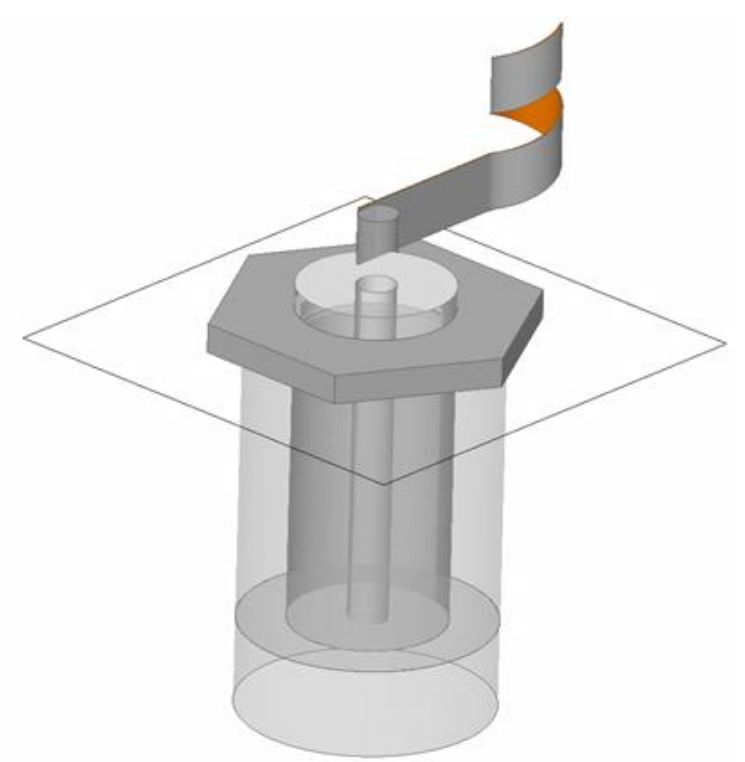

(b)

Figure 3.8. Simulated model of LCE frequency-reconfigurable antenna from: (a) 0.5-turn loop to (b) 1.5-turn helix. 


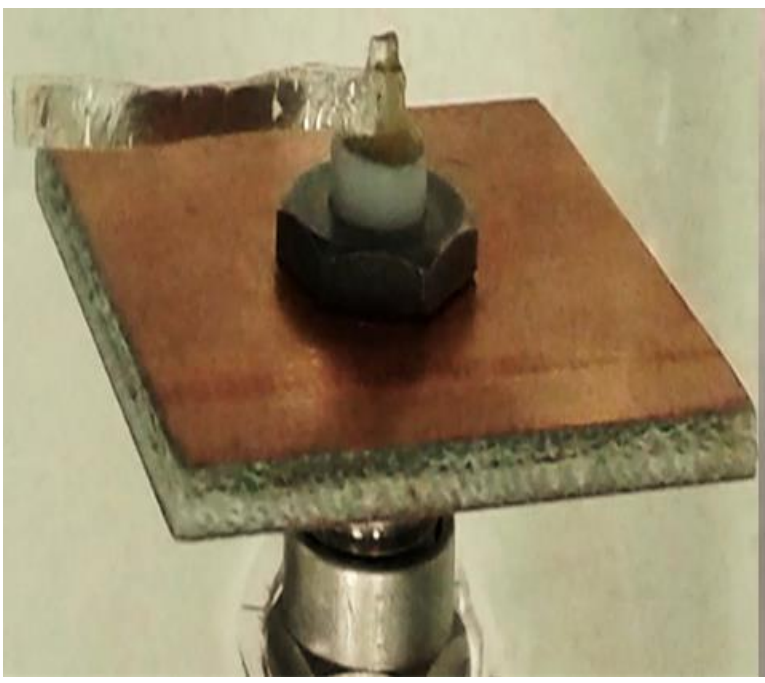

(a)

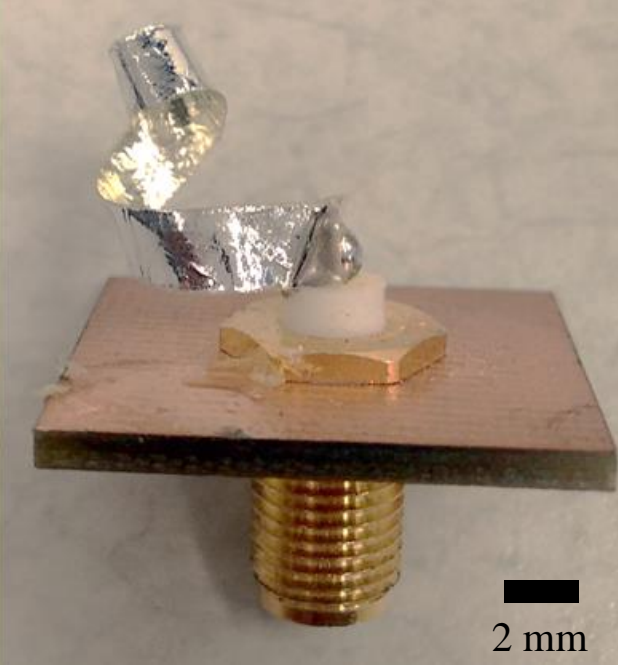

(b)

Figure 3.9. Prototype LCE pattern-reconfigurable antenna at different temperatures: (a) straight at $30^{\circ} \mathrm{C}$, (b) 1.1 -turn helix at $92^{\circ} \mathrm{C}$.

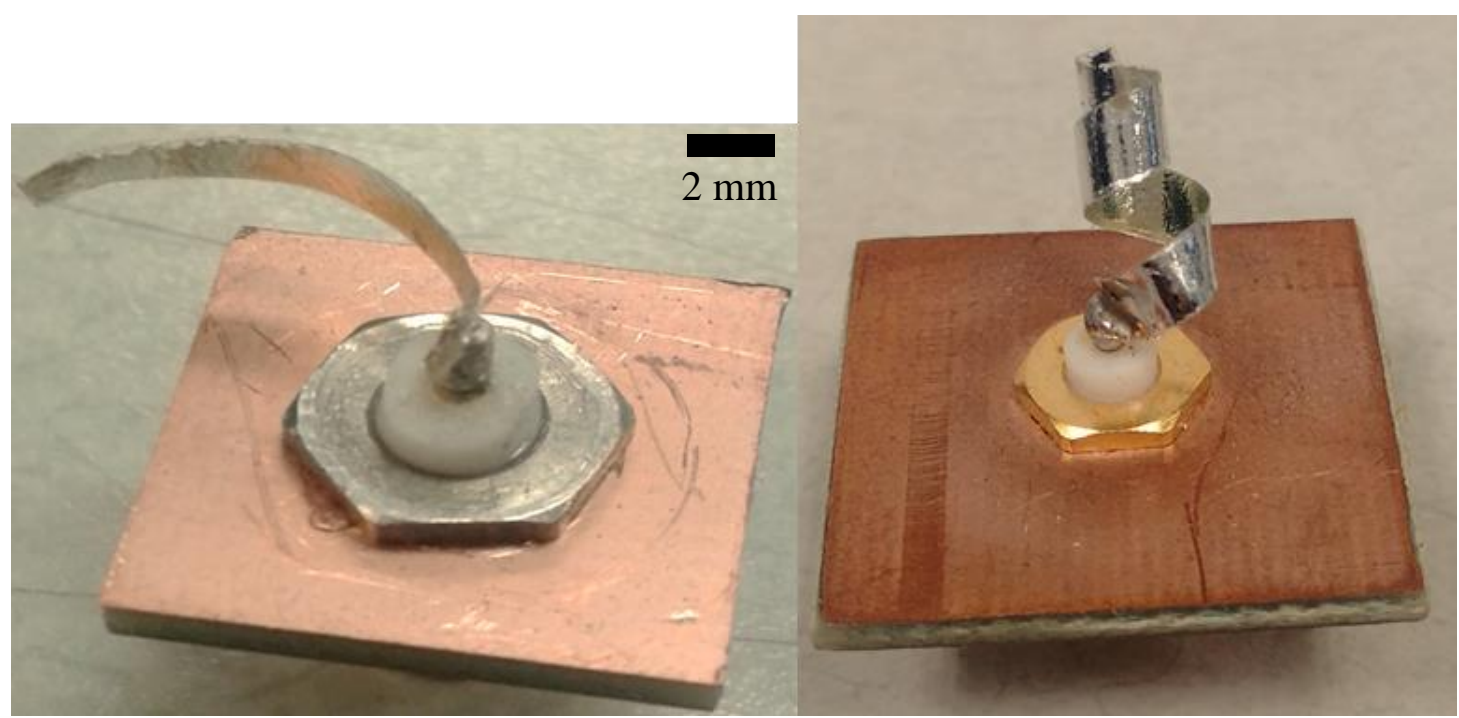

(a)

(b)

Figure 3.10. Prototype of LCE frequency-reconfigurable antenna at different temperatures: (a) 0.5 -turn loop at $80^{\circ} \mathrm{C}$, (b) 1.5 -turn helix at $104^{\circ} \mathrm{C}$. 
Table 3.1. Temperatures of Reconfigurable States of LCE Antennas

\begin{tabular}{c|c|c|c|c|}
\hline & \multicolumn{2}{|c|}{$\begin{array}{c}\text { Pattern-reconfigurable LCE } \\
\text { Antenna \#2 }\end{array}$} & \multicolumn{2}{|c|}{$\begin{array}{c}\text { Frequency-reconfigurable } \\
\text { LCE Antenna }\end{array}$} \\
\hline States & Straight & 1.1-turn Helix & 0.5-turn Loop & 1.5-turn Helix \\
\hline Temp $\left({ }^{\circ} \mathrm{C}\right)$ & 30 & 92 & 80 & 104 \\
\hline
\end{tabular}

\subsubsection{Pattern Reconfigurable LCE Antenna \#1}

When the pattern-reconfigurable LCE antenna is at a fixed straight state and parallel to the ground as shown in Figure 3.11(a), it works in the normal mode. Its resonant frequency can be approximated using $f r=c /(4 L)$, where $L$ is the length of the antenna. When this LCE antenna is heated to a 1.1-turn spiral state, it was fixed with a PLA support and works in the axial mode as shown in Figure 3.11(b). The resonant frequency of the axial mode can be approximated using $f r=c / \lambda=c N / L$, where $L$ is the total length of the antenna, and $N$ is the number of loops of the antenna. The simulated and measured $\mathrm{S}_{11}$ for the straight and 1.1-turn spiral states are shown in Figure 3.12 accordingly. The measured operating frequencies and 3D patterns of the two states are respectively $2.48 \mathrm{GHz}$ and 13.2 $\mathrm{GHz}$, as denoted by triangles in Figure 3.12. The measured frequency is in close agreement with the simulated frequency and 3D patterns of the two states, $2.6 \mathrm{GHz}$ and $13.3 \mathrm{GHz}$, respectively. 


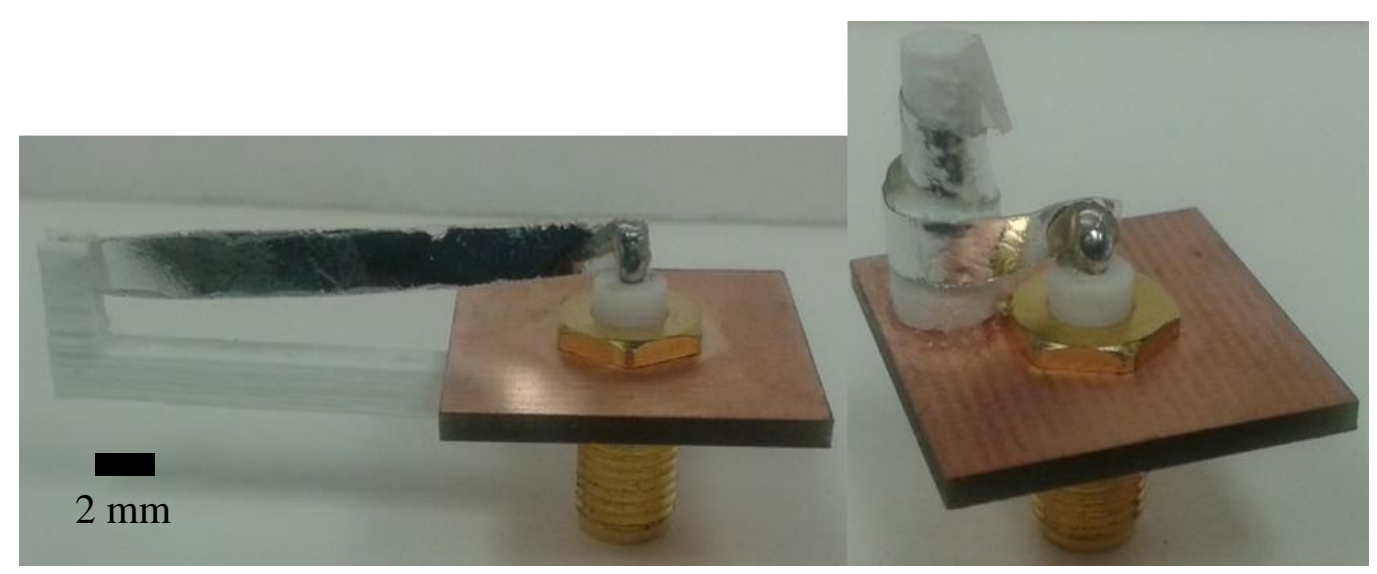

(a)

(b)

Figure 3.11. Static prototype of pattern-reconfigurable LCE antenna \#1 at different states: (a) straight and (b) 1.1-turn spiral.

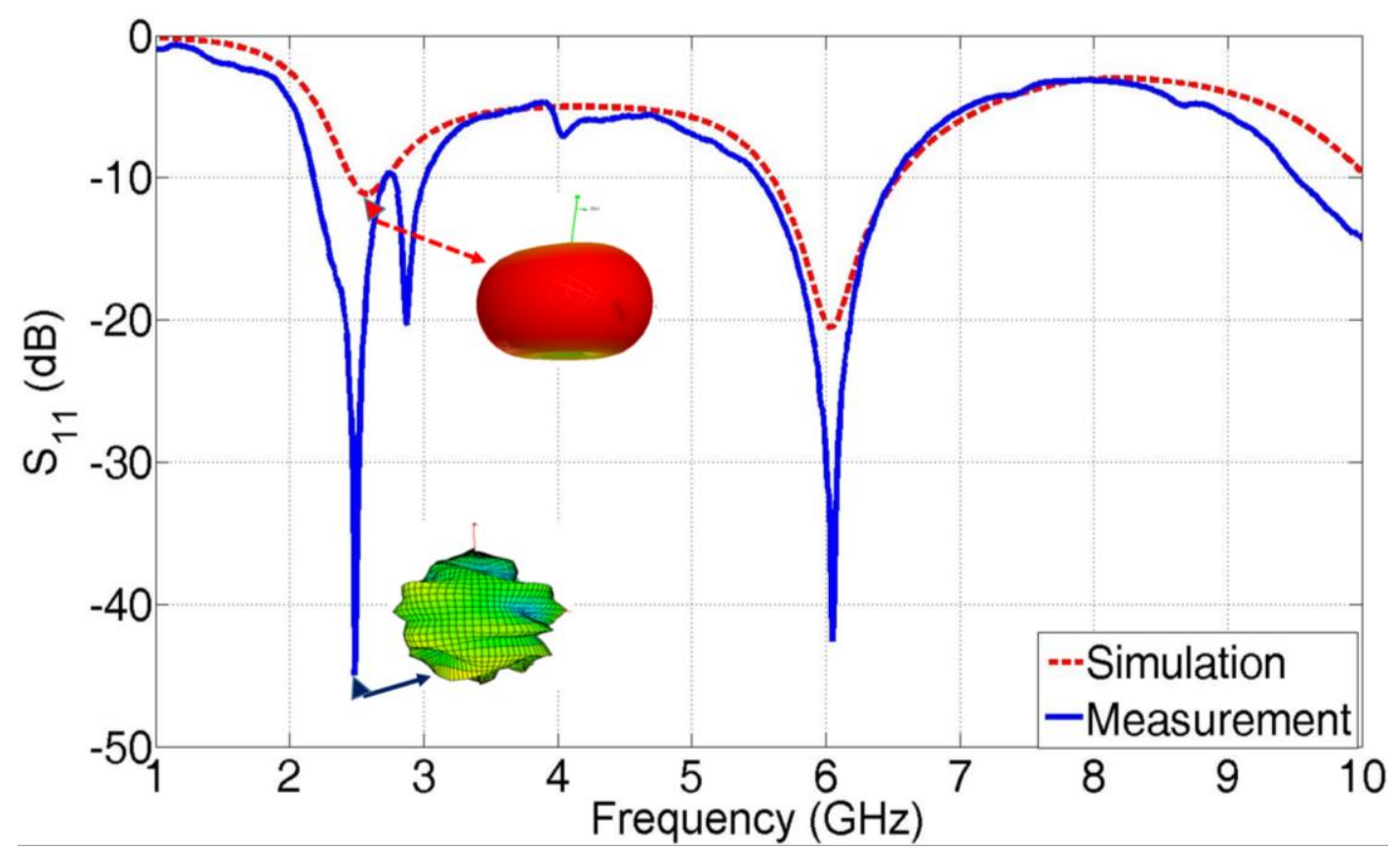

(a) 


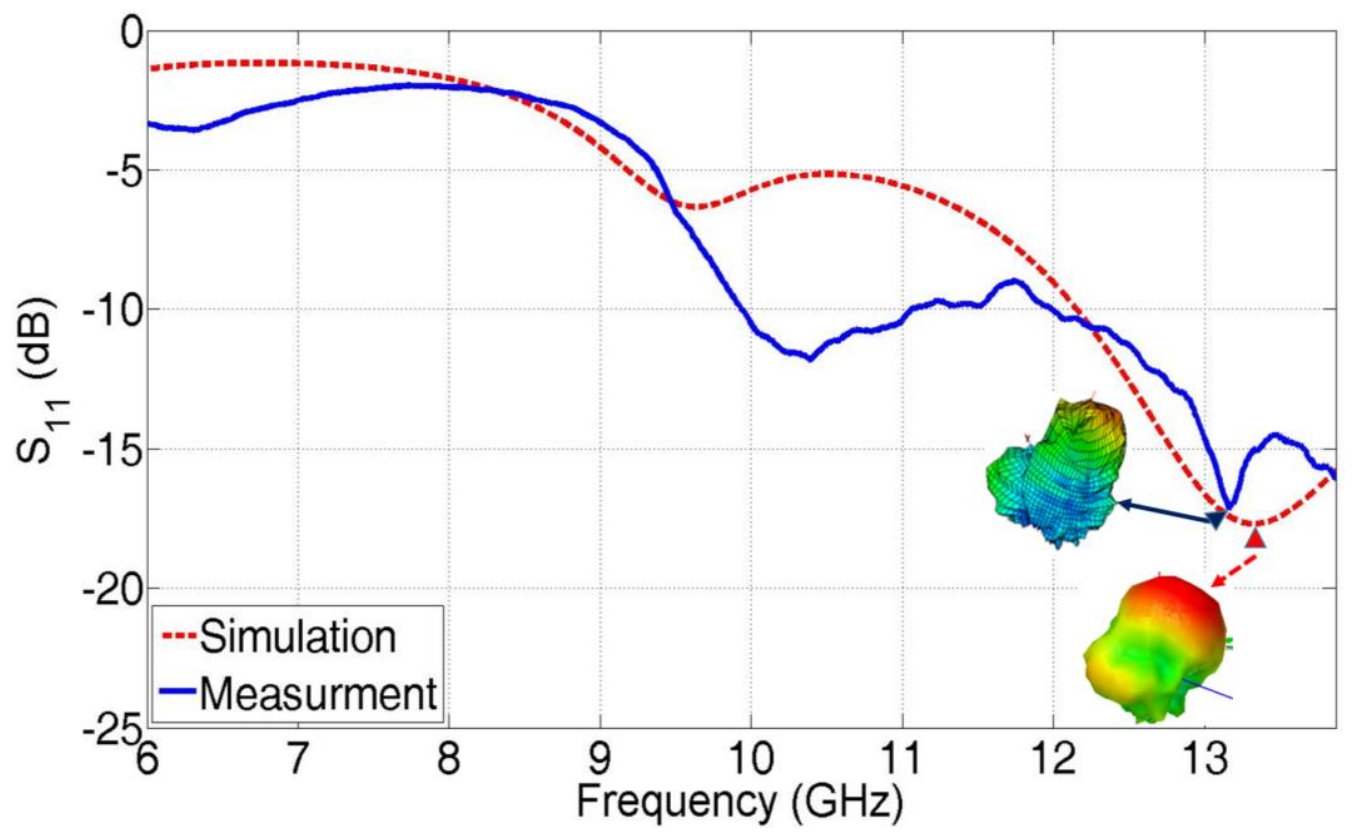

(b)

Figure 3.12. Simulated and measured S11 of pattern-reconfigurable LCE antenna \#1 at: (a) straight state operating in omnidirectional mode; and (b) 1.1-turn spiral state operating in directional mode.

\subsubsection{Pattern Reconfigurable LCE Antenna \#2}

The fixed straight state of the pattern-reconfigurable LCE antenna is shown in Figure 3.13(a). When this LCE antenna is heated to $92^{\circ} \mathrm{C}$, it self-coils to a 1.1-turn helical state, and it was fixed with a PLA support as shown in Figure 3.13(b). The simulated and measured $S_{11}$ for the straight and 1.1-turn helical states are shown in Figure 3.14 accordingly.

The purpose of this section is to illustrate that this LCE antenna can reconfigure its radiation pattern from omnidirectional to directional as it changes states (i.e., from straight state to 1.1-turn helical state). Therefore, the operating frequencies of the two states are picked based on the radiation pattern performance and not based on the $S_{11}$ nulls shown in 
Figure 3.14. The operating frequencies and 3D patterns of the two states are respectively 4.9 GHz and $14.04 \mathrm{GHz}$, as denoted by triangles in Figure 3.14. Specifically, the operating frequency of the straight state is picked to be $4.9 \mathrm{GHz}$ as it was found through our measurements that the best omnidirectional pattern is achieved at this frequency with a return loss of $8.5 \mathrm{~dB}$ and maximum measured realized gain of $1.7 \mathrm{~dB}$, as shown in Figures 3.14(a) and 3.15(a). Also, the operating frequency of the 1.1-turn helical state is picked to be $14.04 \mathrm{GHz}$ as it was found through our measurements that the best directional pattern is achieved at this frequency with the lowest side lobes, as shown in Figure 3.14(b). The 1.1-helical turn state exhibits a return loss of $6.6 \mathrm{~dB}$ at $14.04 \mathrm{GHz}$, which does not correspond to the null of $S_{11}$, as shown in Figure 3.14(b); however, at $14.04 \mathrm{GHz}$, this antenna exhibits directional pattern with a maximum measured realized gain of $6.6 \mathrm{~dB}$, as shown in Figures 3.14(b) and 3.15(b). The return loss of both antenna states can be increased by adding matching networks. However, this was not implemented in this section, because the goal of this work is to illustrate that this LCE antenna can reconfigure its radiation pattern. The radiation patterns of Figure 3.15 clearly illustrate that the LCE antenna of Figure 3.9 is able to change its shape (i.e., reshape itself) in response to heat, which in turn changes its radiation pattern from omnidirectional to directional. Figure 3.16 compares the measured radiation patterns of the two states at $4.9 \mathrm{GHz}$ and $14.04 \mathrm{GHz}$. The following can be concluded from Figure 3.16: (a) the straight state (achieved at $30^{\circ} \mathrm{C}$ ) exhibits a significantly better omnidirectional pattern than the 1.1-turn helical state (achieved at $92^{\circ} \mathrm{C}$ ), and (b) the 1.1-turn helical state (achieved at $92^{\circ} \mathrm{C}$ ) exhibits a significantly better directional pattern toward zenith at $14.04 \mathrm{GHz}$ than the straight state (achieved at $30^{\circ} \mathrm{C}$ ). This data is summarized in Table 3.2. 


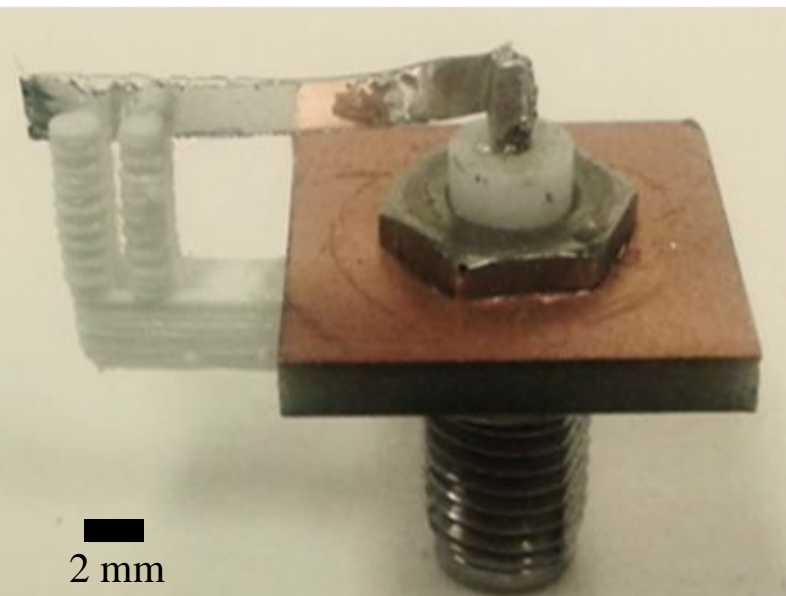

(a)

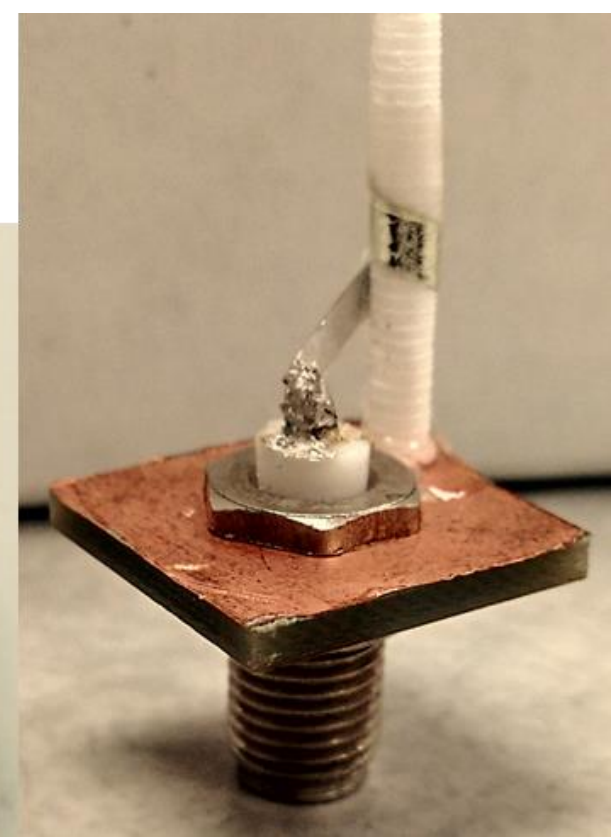

(b)

Figure 3.13. Static prototype of pattern-reconfigurable LCE antenna \#2 at different states: (a) straight and (b) 1.1-turn helix.

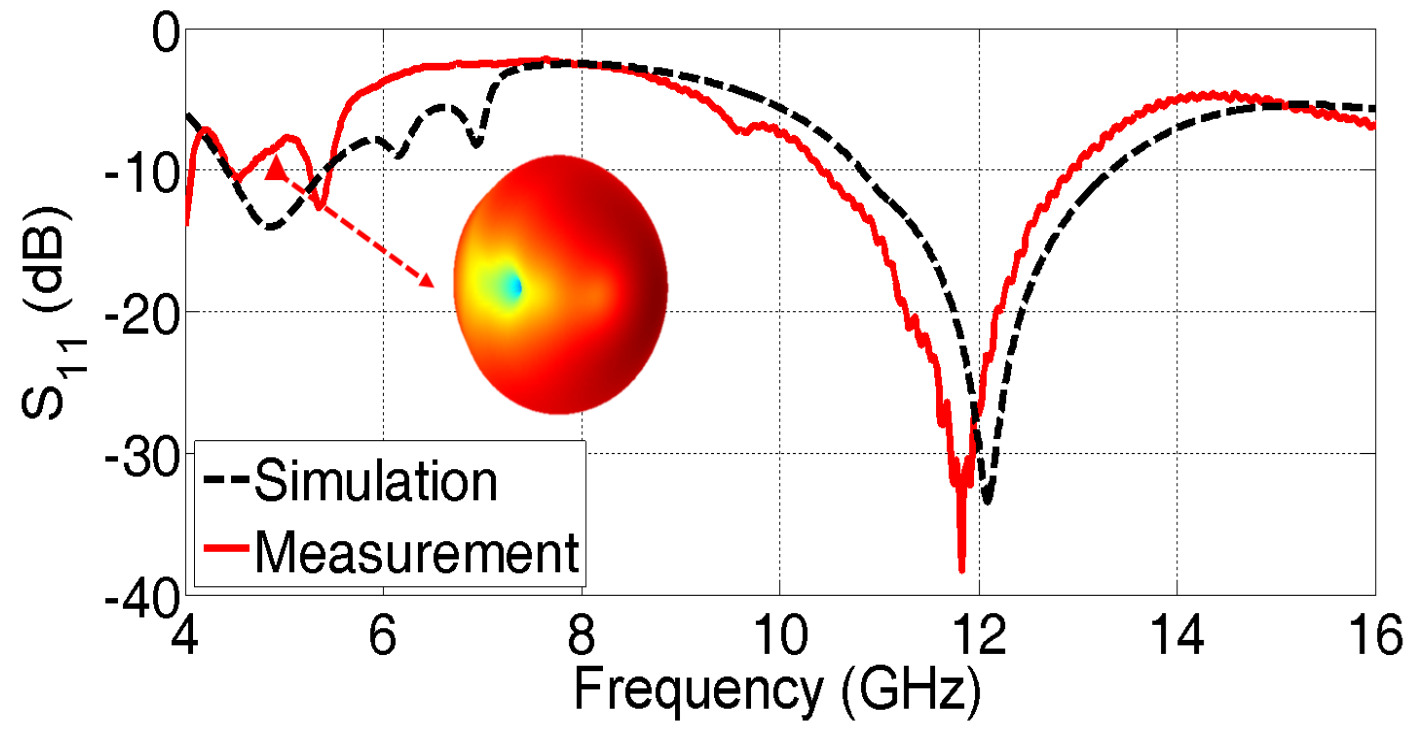

(a) 


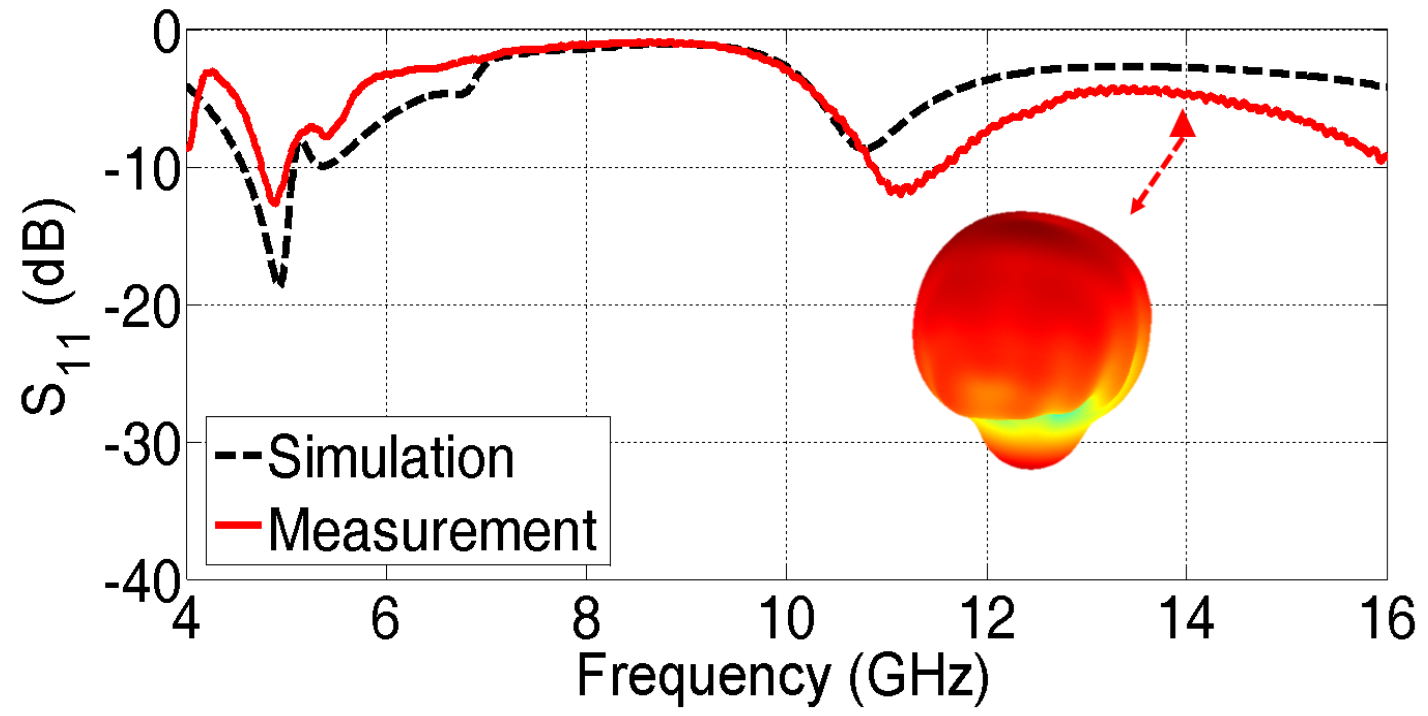

(b)

Figure 3.14. Simulated and measured $S_{11}$ of pattern-reconfigurable LCE antenna \#2 at: (a) straight state operating in omnidirectional mode; and (b) 1.1-turn helical state operating in directional mode.
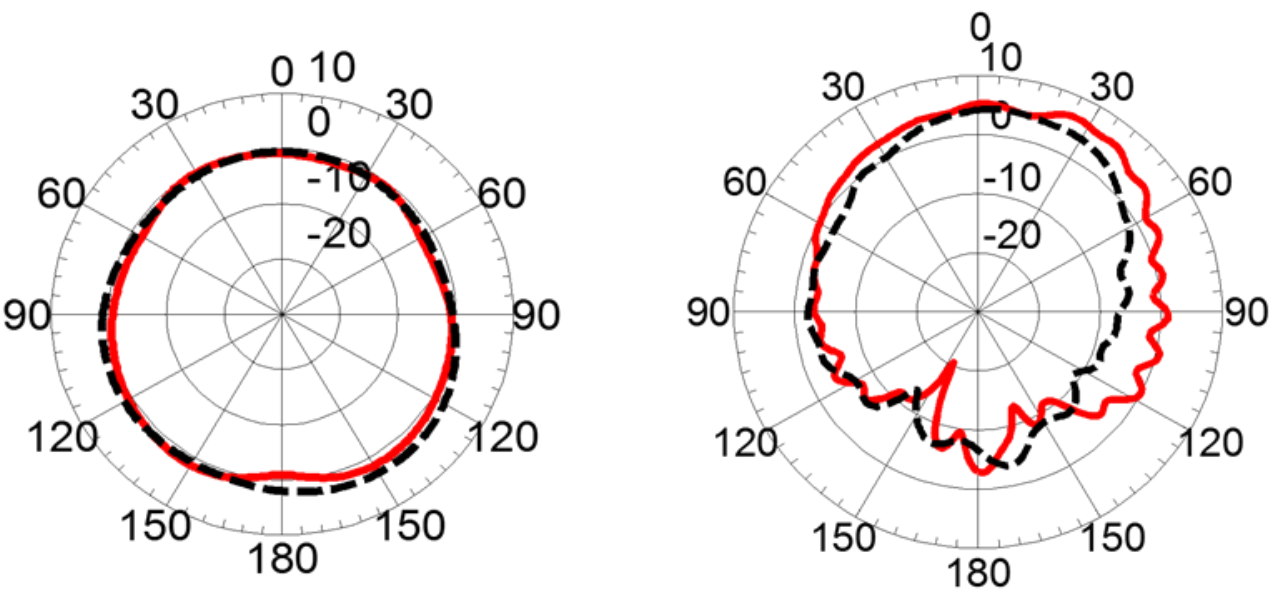

\section{- - - Simulation at $4.9 \mathrm{GHz}$ Measurement at $4.9 \mathrm{GHz}$}

(a)

(b)

Figure 3.15. Simulated and measured elevation patterns of the pattern-reconfigurable antenna \#2 at (a) straight state, and (b) 1.1-turn helix. 
Table 3.2. Performance of the Pattern-Reconfigurable LCE Antenna

\begin{tabular}{|c|c|c|}
\hline $\begin{array}{ll}\text { Performance } & \text { States } \\
\end{array}$ & Straight & $\begin{array}{l}\text { 1.1-turn } \\
\text { helix }\end{array}$ \\
\hline Operating Mode & Omnidirectional & Directional \\
\hline Operating Frequency (GHz) & 4.9 & 14.04 \\
\hline Simulated Realized Gain at Zenith (dB) & -0.53 & 4.15 \\
\hline Measured Realized Gain at Zenith (dB) & -0.88 & 5.13 \\
\hline
\end{tabular}

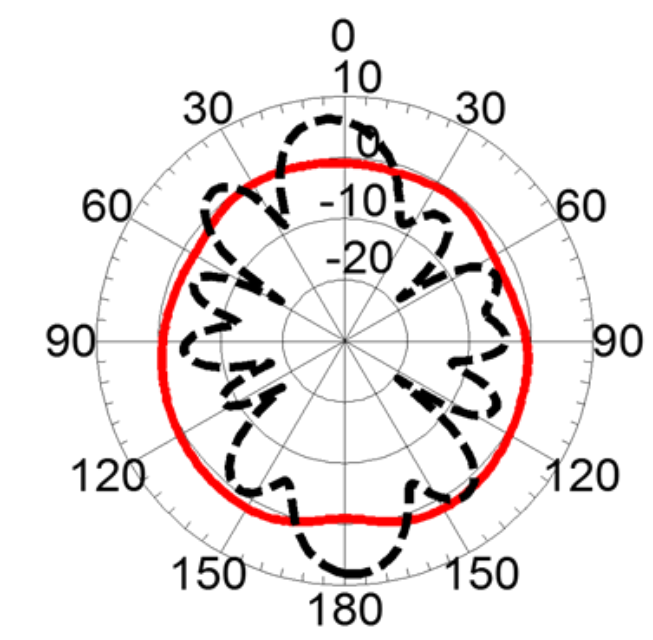

- - - 1.1-turn helix at 4.9 GHz

- Straight at $4.9 \mathrm{GHz}$

(a)

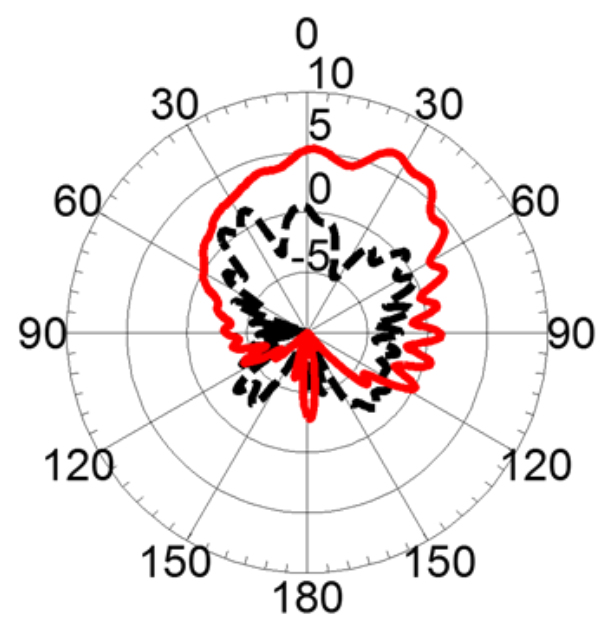

-1.1-turn helix at $14.04 \mathrm{GHz}$ - - - Straight at $14.04 \mathrm{GHz}$

(b)

Figure 3.16. Comparison of measured elevation-plane patterns of the patternreconfigurable antenna at two different states.

\subsubsection{Frequency Reconfigurable LCE Antenna}

In order to measure the two states of the frequency-reconfigurable antenna shown in Figure 3.10 (namely 0.5-turn loop and 1.5-turn helix) the states were fixed, as shown in Figure 3.17, after the LCE antenna morphed itself at $80^{\circ} \mathrm{C}$ and $104^{\circ} \mathrm{C}$. The simulated and measured $S_{11}$ for the two states are shown in Figure 3.18. All patterns of the two states 
were measured by a StarLab antenna measurement system. The operating frequencies of the two states were picked by measuring their radiation patterns and finding the frequencies where their patterns were directional toward the zenith and exhibited the lowest side-lobe level. Specifically, the operating frequencies and 3D patterns of the 0.5-turn loop and 1.5turn helix were picked to be $12 \mathrm{GHz}$ and $10.7 \mathrm{GHz}$, respectively, as denoted by the triangles in Figure 3.18.

The $\mathrm{S}_{11}$ and realized gain of this LCE antenna at the operating frequencies of the two states are shown in Table 3.3. The elevation radiation patterns of the two states are shown in Figure 3.19 at their corresponding frequencies. Figure 3.19 and Table 3.3 illustrates that this LCE antenna exhibits directional patterns at both states and can operate at either: (a) $12 \mathrm{GHz}$ with a measured gain of $5.37 \mathrm{~dB}$ towards the zenith of the 0.5 -turn state, or (b) $10.7 \mathrm{GHz}$ with a measured gain of $3.53 \mathrm{~dB}$ towards the zenith of the 1.5-turn helical state. The higher realized gain can be possibly achieved at $10.7 \mathrm{GHz}$ with a matching network. However, this was not implemented in this section because the goal of this work is to illustrate that this LCE antenna can reconfigure its frequency of operation by reshaping itself when it is heated. Also, based on the measured axial ratio shown in Table 3.3, this LCE antenna is linearly polarized for both states.

Figure 3.20 compares the elevation-plane radiation patterns of the two states in their corresponding two operating frequencies. Figure 3.20 clearly shows the following: (a) the 0.5-turn loop exhibits at its own operating frequency of $12 \mathrm{GHz}$ a higher gain than the 1.5turn helix, and (b) the 1.5-turn helix exhibits at its own operating frequency of $10.7 \mathrm{GHz}$ a higher gain and lower side-lobe level than the 0.5-turn loop. Therefore, at its operating 
frequency each state of the LCE antenna outperforms the other state in terms of gain and side-lobe level. These data are also summarized in Table 3.4. The radiation patterns shown in Figure 3.20 and the data in Table 3.4 clearly illustrate that the LCE antenna of Figure 3.10 is able to change its shape (i.e., reshape itself) in response to heat and shift its operating frequency from $12 \mathrm{GHz}$ to $10.7 \mathrm{GHz}$.

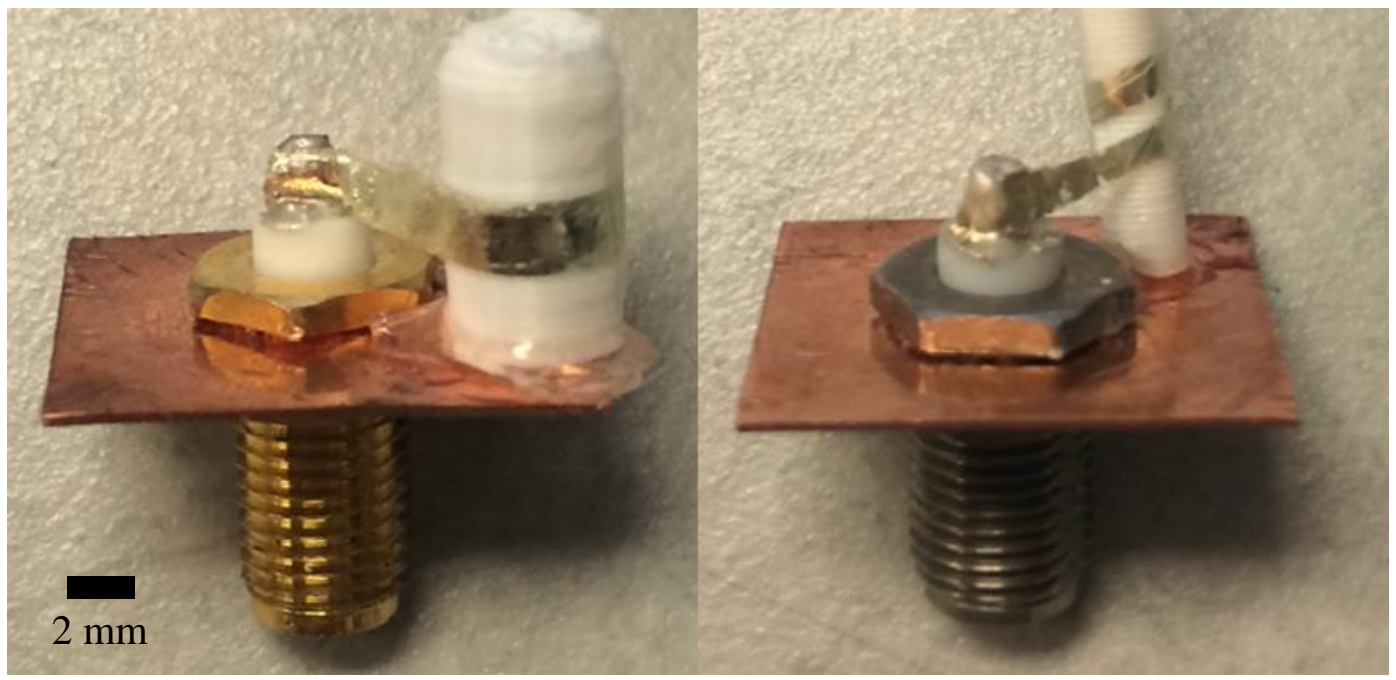

(a)

(b)

Figure 3.17. Static prototype frequency-reconfigurable LCE antenna at two states: (a) 0.5-turn loop, and (b) 1.5-turn helix.

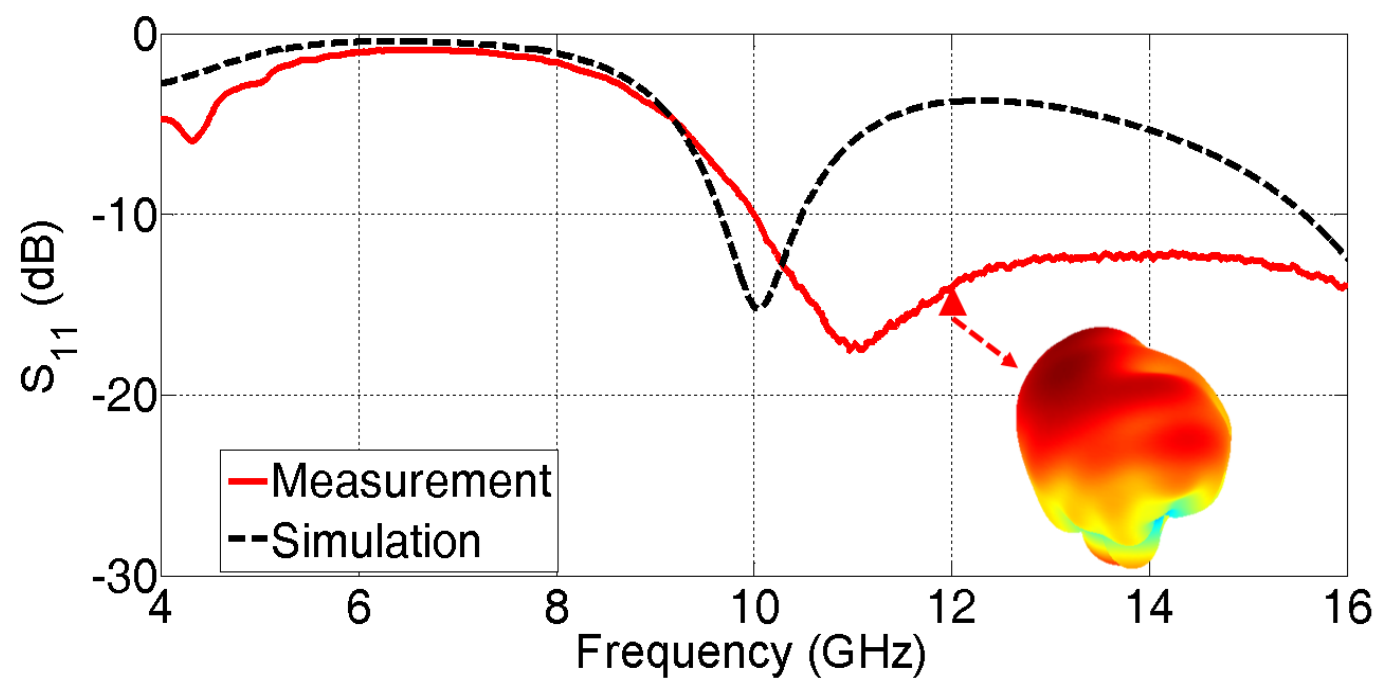

(a) 


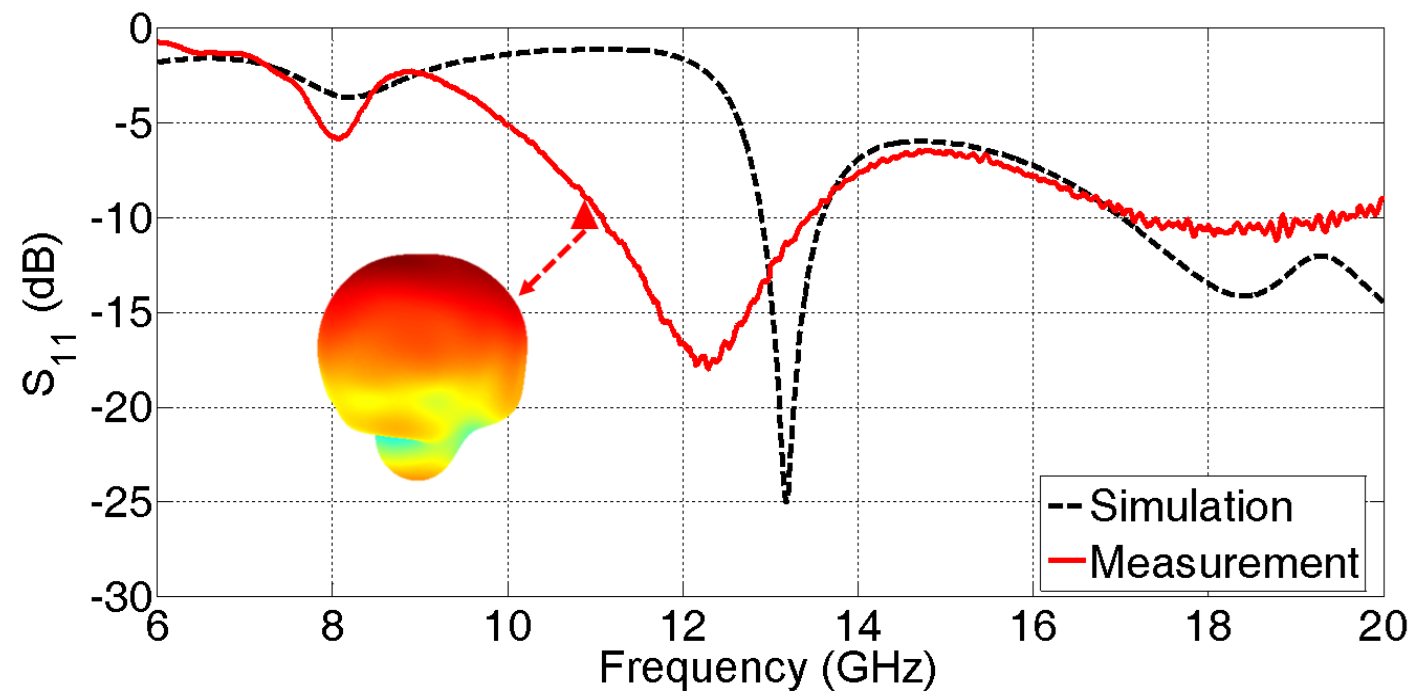

(b)

Figure 3.18. Simulated and measured $S_{11}$ of frequency-reconfigurable antenna: (a) 0.5turn loop; (b) 1.5-turn helix.
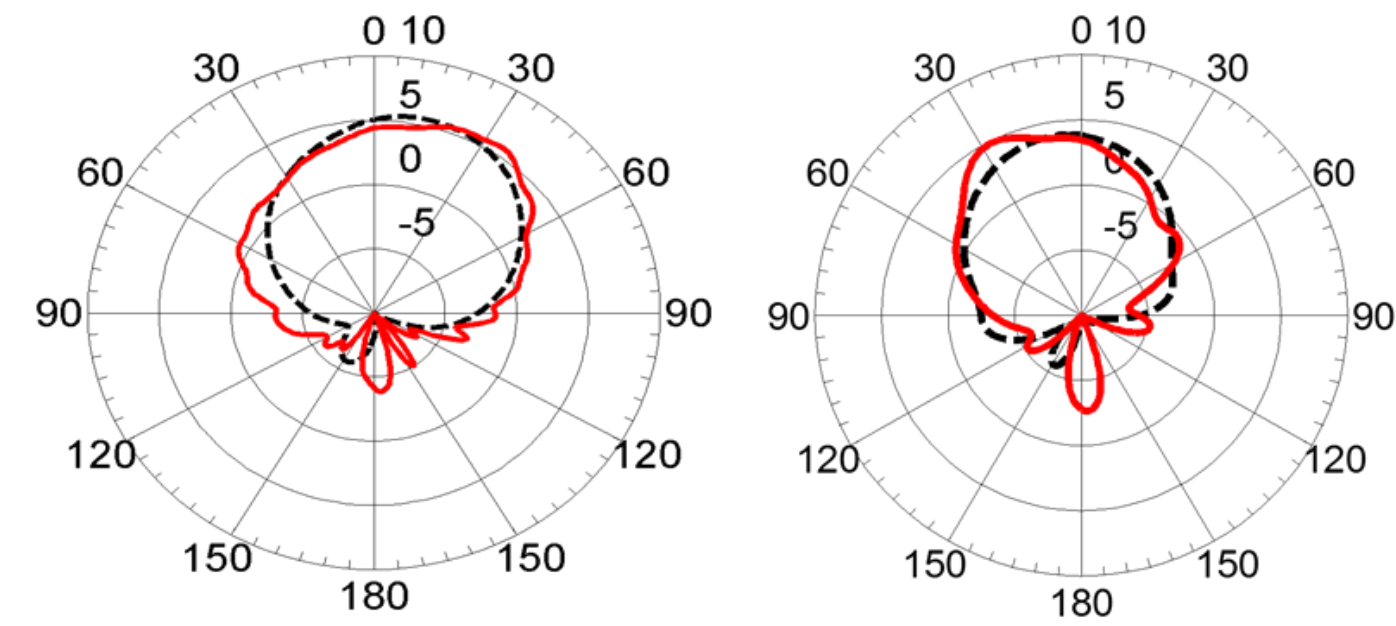

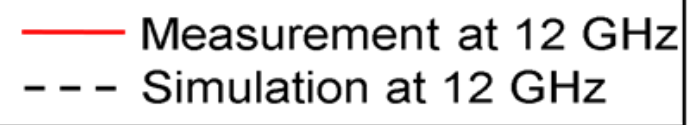

(a)

Figure 3.19. Simulated and measured elevation patterns of the frequency-reconfigurable antenna: (a) 0.5-turn loop, and (b) 1.5-turn helix. 
Table 3.3. Performance of Each State of the Frequency Reconfigurable LCE Antenna

\begin{tabular}{|l|c|c|} 
& 0.5-turn loop & 1.5-turn helix \\
\hline Operating Frequency $(\mathrm{GHz})$ & 12 & 10.7 \\
\hline Measured $\mathrm{S}_{11}(\mathrm{dBB})$ & -13.97 & -8.07 \\
\hline Simulated Realized Gain at Zenith (dB) & 5.53 & 3.79 \\
\hline Measured Realized Gain at Zenith (dB) & 5.37 & 3.53 \\
\hline Measured Axial Ratio at Zenith (dB) & 15.5 & 16.1 \\
\hline
\end{tabular}

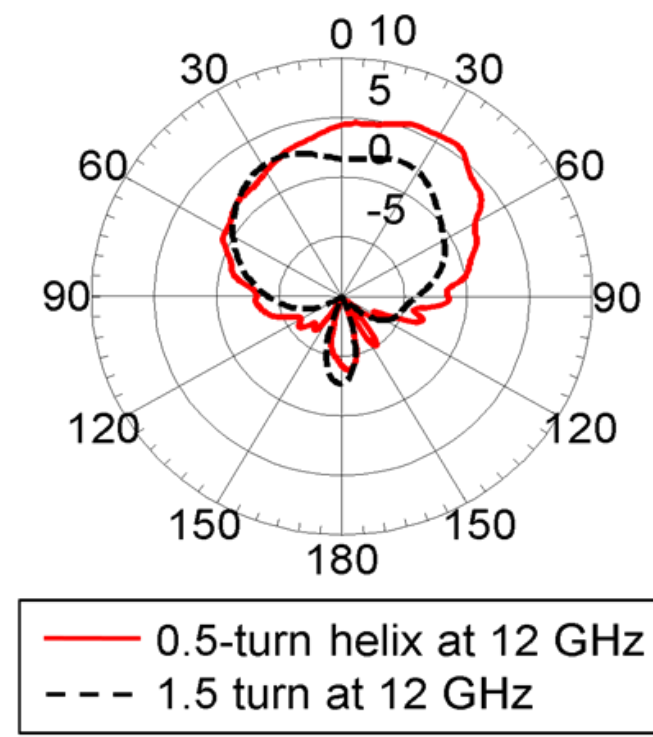

(a)

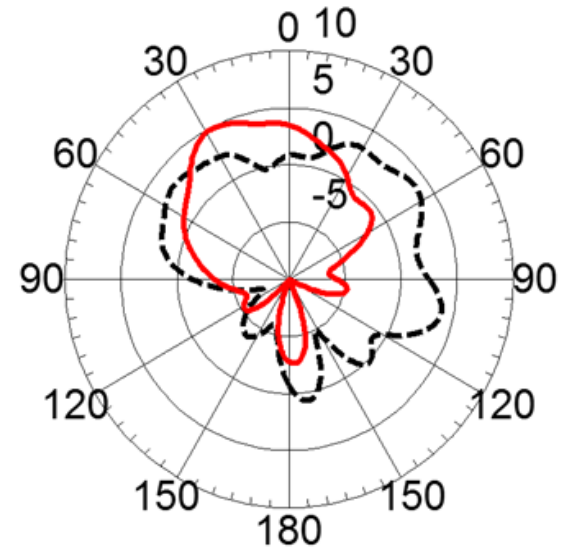
- 1.5-turn helix at $10.7 \mathrm{GHz}$ - - 0.5 turn at $10.7 \mathrm{GHz}$

Figure 3.20. Comparison of measured elevation-plane patterns of the frequency reconfigurable antenna at different states

Table 3.4. Comparison Between the Two States of the Frequency Reconfigurable LCE Antenna

\begin{tabular}{|c|c|c|c|}
\multicolumn{2}{|c|}{ Operating Frequency $(\mathrm{GHz})$} & 10.7 & 12 \\
\hline \multirow{2}{*}{ Max. Measured Realized Gain (dB) } & 0.5 -turn loop & 5.45 & 6.09 \\
\cline { 2 - 4 } & 1.5 -turn helix & 5.06 & 2.09 \\
\hline \multirow{2}{*}{ Max. Side Lobe Gain (dB) } & 0.5 -turn loop & 3.1 & 2.49 \\
\hline & 1.5 -turn helix & -0.7 & -1.37 \\
\hline
\end{tabular}


This chapter discussed the thermally induced mechanical responses from the liquid crystal elastomers (LCEs), attached to a metal layer, and are used herein to generate reconfigurable antennas that are tuned by external thermal stimuli. This is possible by programming the material's anisotropy, orientation and alignment to dictate the response. The shape change from flat to spiral and helical is shown to reconfigure either the radiation pattern and/or frequency of operation. Three different designs were developed. The first LCE antenna design achieved pattern-reconfigurability by changing its shape from straight to a 1.1-turn spiral, which in turn changed its pattern from omnidirectional to directional. The second pattern-reconfigurability LCE antenna was designed to change its shape from straight to a 1.1-turn helix, which also changed its pattern from omnidirectional to directional. The third LCE antenna design achieved frequency-reconfigurability by changing its shape from a 0.5 -turn loop to a 1.5 -turn helix, which in turn changed its frequency of operation from $12 \mathrm{GHz}$ to $10.7 \mathrm{GHz}$. LCE antennas are promising for the development of dynamically reconfigurable antennas [75]. 


\section{CHAPTER 4}

\section{SETUP DESIGN AND METALLIZATION OF DYNAMIC LCE ANTENNAS}

In Chapter 3, the pattern and frequency reconfigurable antennas based on shapemorphing LCEs were presented in a fixed (static) state [76]. In this chapter, measurement setups are developed for the characterization of reconfigurable LCE antennas in a dynamic fashion [84, 85]. Prototype LCE reconfigurable antenna designs, are fabricated and experimentally characterized through measurements of their mechanical, thermal, and electromagnetic performance. The progression of external stimuli designs used to actuate the LCE antennas are presented in Section 4.1. The designs are constructed using temperature responsive (LCE) materials. The LCEs are also metallized and attached to a connector, as shown in Figure 4.1, in order to form antennas. The effects of different metallization techniques used for the LCE antennas are investigated in Section 4.2. The skin-depth effects will be considered and analyzed. Metal morphology will be examined before and after deformation using scanning electron microscopy (SEM).

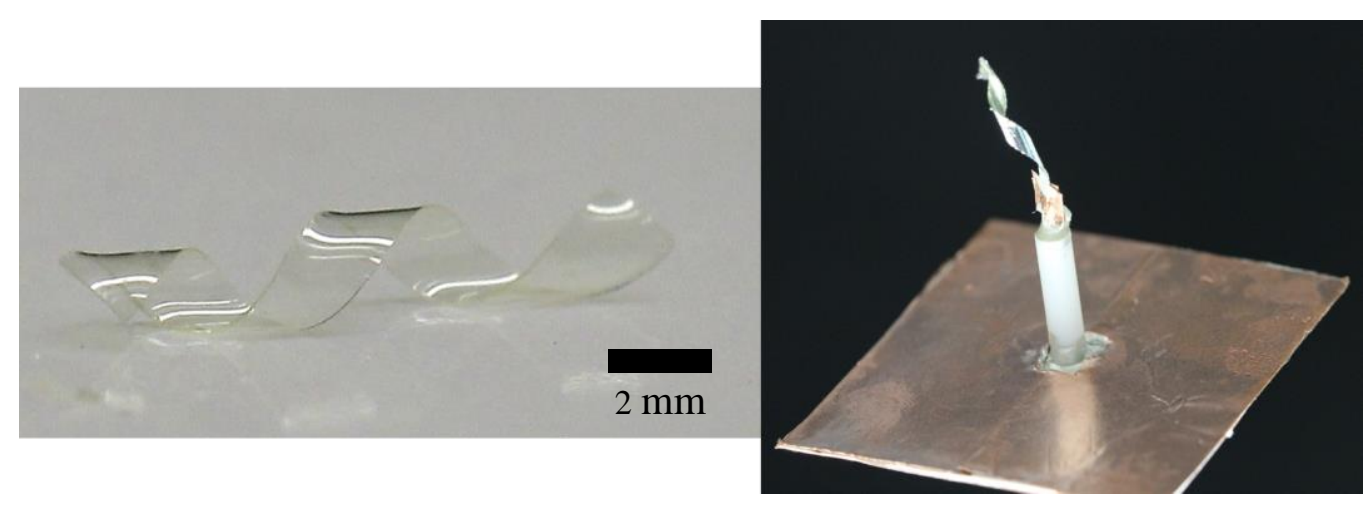

Figure 4.1. The first design of a helical antenna using LCE in response to temperature of this dissertation research. 


\subsection{External Stimulus Designs}

To achieve a reversible shape change from the metallized LCEs with response to temperature, an external temperature source is required. The external temperature source should have as little metal as possible otherwise it will change the performance of the LCE antenna during measurement. Also, the external temperature source is required to give heat, but a little amount of air pressure (psi) due to the fact that LCE materials are lightweight. For example, a microheater and a heat gun could achieve to give the heat needed, although, but their air pressure is too much. There were many different types of measurements setup designs that will be presented in this section. The main goal is to design an external stimulus source to create a certain temperature in an enclosed area around the LCE antenna in order to reversibly change its shape and simultaneously take radiation pattern

measurements inside the anechoic chamber without having to fix the antenna geometry (i.e., allow dynamic reconfiguration of the LCE antenna's shape).

\subsubsection{External Stimulus with Soldering Tool and Beaker}

For proof-of-concept, the tip of a soldering tool was used to actuate the LCE antenna, shown in Figure 4.2, because it provided the heat temperature needed without air, such as, a hot-air gun. 


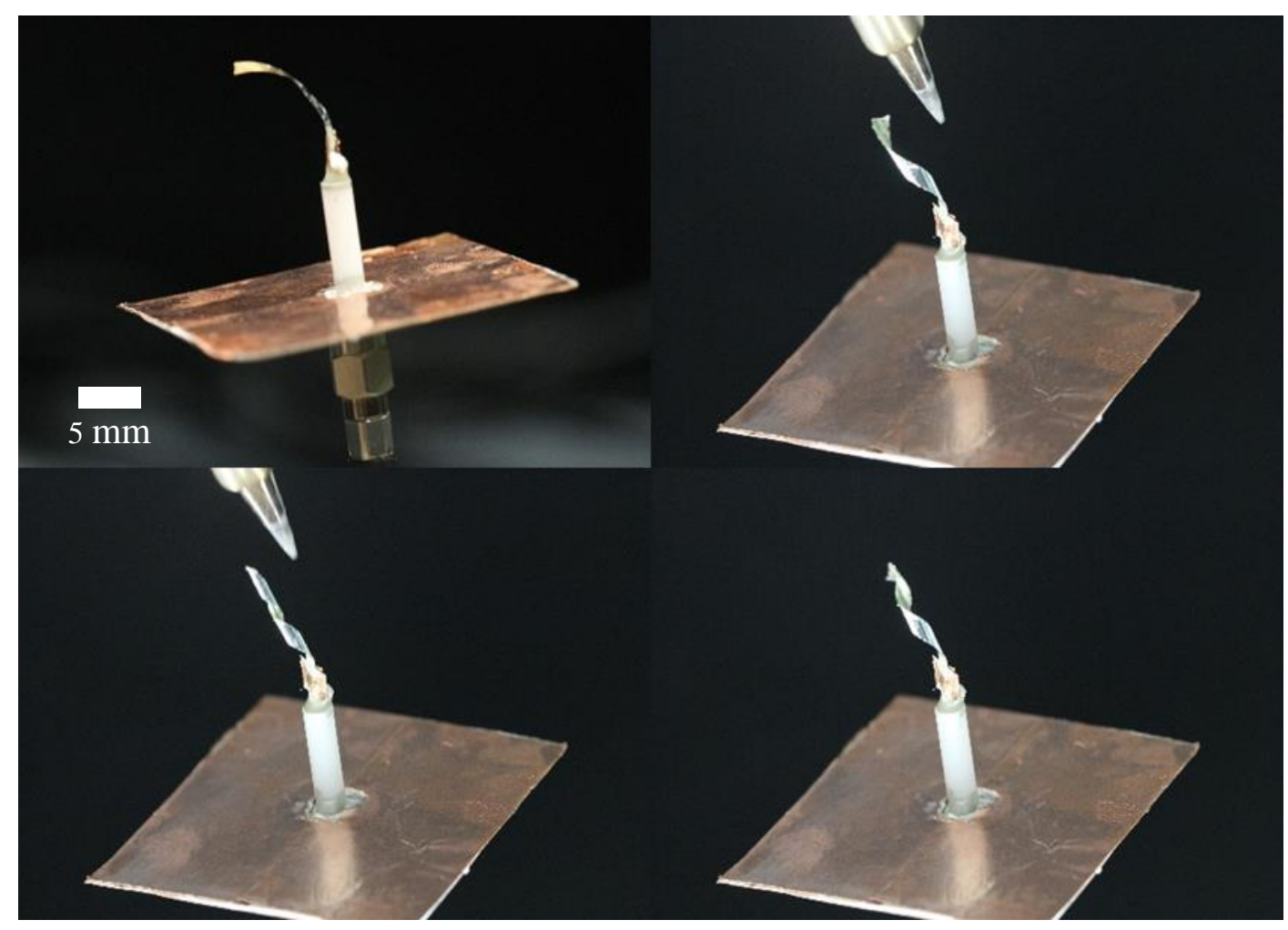

Figure 4.2. Dynamic LCE Antenna self-twisting in response to heat. The number of turns increases as the temperature increases and will return to original state once the heat is removed.

In previous research, Section 3.2, the external heat source used was a metallic insulated heat-tape wrapped around a PYREX beaker that enclosed the antenna, shown in Figure 4.3. Due to the old heating techniques affecting the LCE antenna performance, the LCE strips were fixed in different states with PLA supports to measure their radiation patterns in the StarLab anechoic chamber. These 3-D printed PLA supports were used to fix the antennas in different states after they had reshaped themselves in response to different temperatures. 


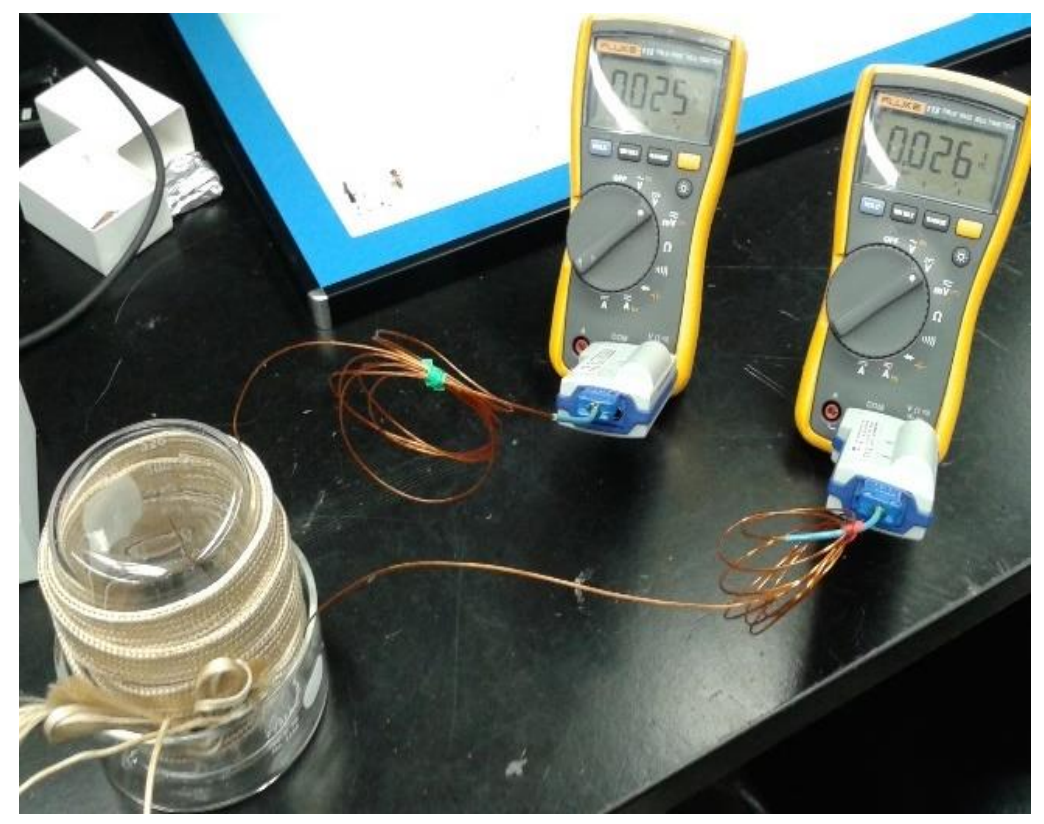

(a)

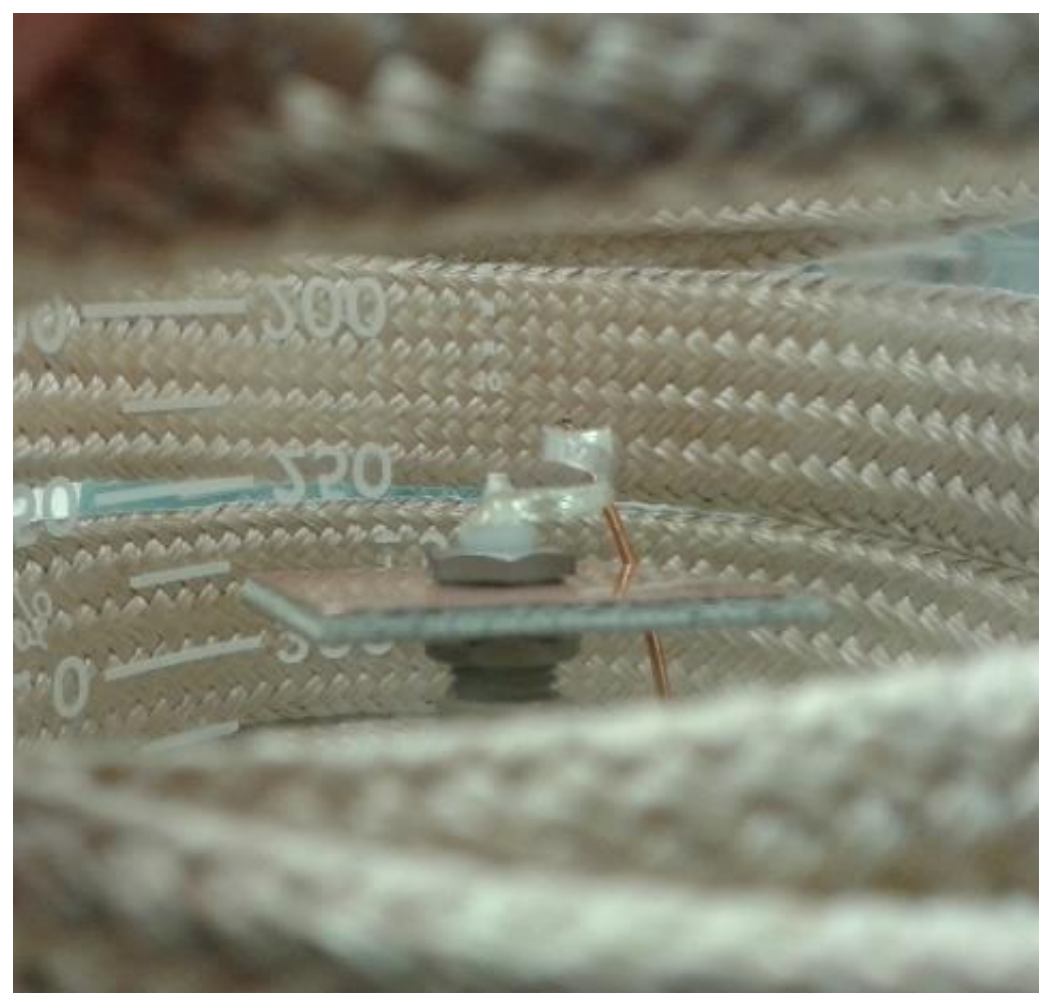

(b)

Figure 4.3. A metallic insulated heat-tape wrapped around a PYREX beaker that encloses a dynamic LCE Antenna (b), used for an external heat source. 
A design that could get heat into the anechoic chamber long enough for the antenna's structure to change without affecting the chamber during measurements was needed. Figure 4.4 shows a new design of an enclosure used for an LCE antenna to reversibly self-actuate in response to temperature. The enclosure maintains the heat long enough for the StarLab anechoic chamber to do the radiation pattern measurements (this takes 2-3 minutes). First, the antenna without the presence of heat, Figure 4.4(a), was measured and temperature was recorded in real time. A PYREX beaker is placed upside down on a hot plate, shown in Figure 4.4(b). The hot plate heats up and the beaker contains the heat inside. Then the heated beaker is placed, using thermal gloves, over the LCE antenna and the structure begins to dynamically change, as shown in Figure 4.4(c). The petri dish has a hole in the center to allow the coaxial cable to fit through; therefore, the LCE antenna is enclosed with only small heat leakage. Once the measurement is done with recorded temperature, the beaker is removed and the LCE antenna returns to its original state. A small digital temperature probe, as shown in Figure 4.4(d), was placed inside the beaker but under the antenna to monitor temperature during measurements with the LCD screen outside the chamber to verify the temperature conditions. The antenna shown in Figure 4.4 is $25 \mathrm{~mm}$ long and $2.5 \mathrm{~mm}$ wide. The overall thickness is $51.8 \mu \mathrm{m}$, with $1.8 \mu \mathrm{m}$ optically glued $\mathrm{Al}$ and a $10 \mathrm{~mm}$ ground square was used. The measurements were conducted to verify the performance of the antennas using a vector network analyzer and an anechoic chamber. 


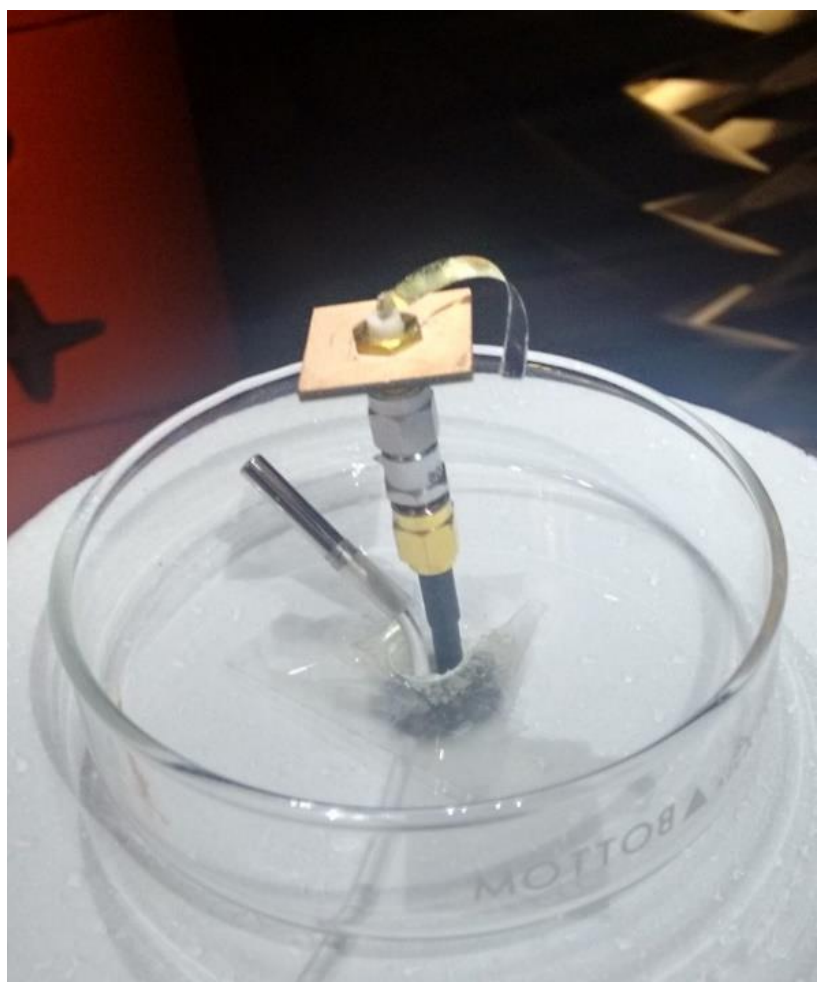

(a)

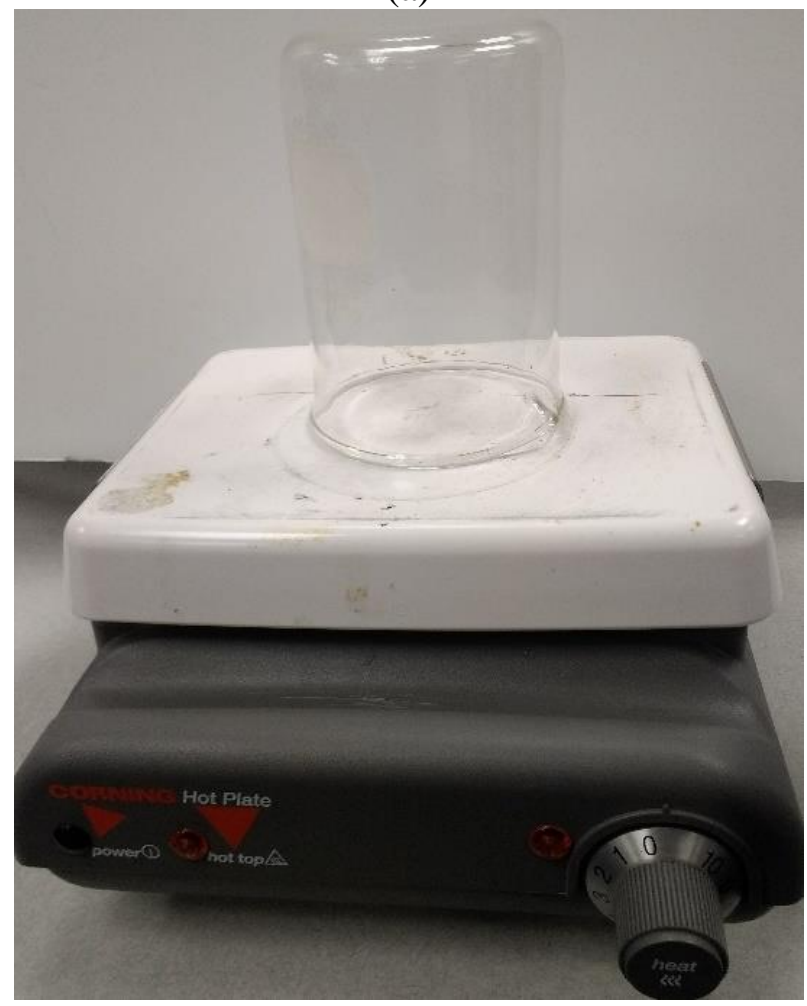

(b) 


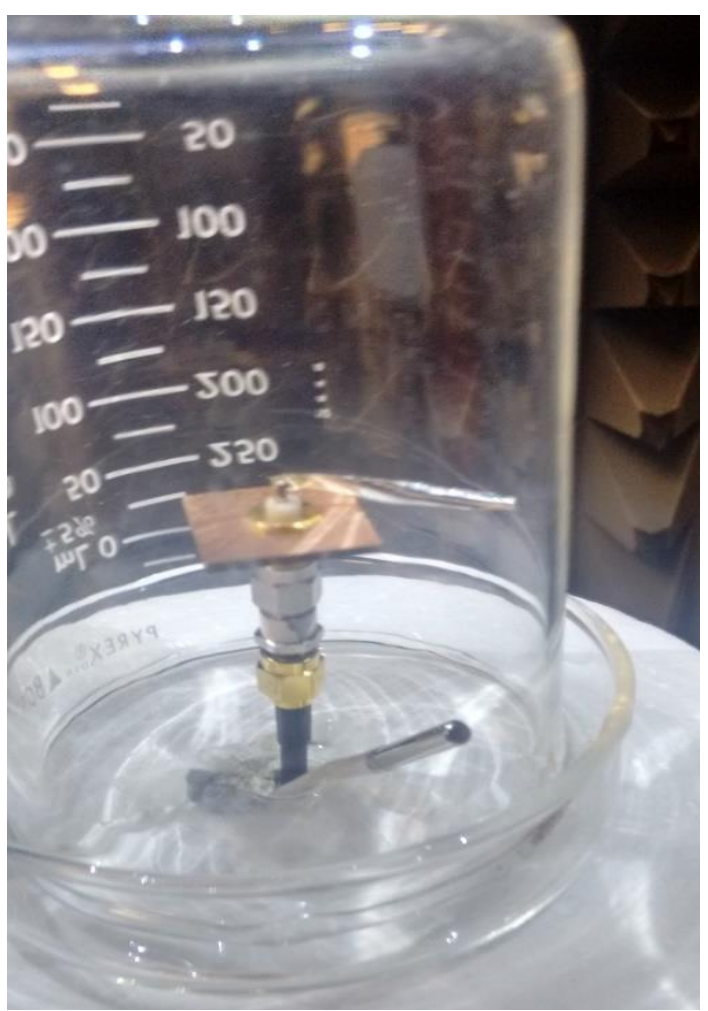

(c)

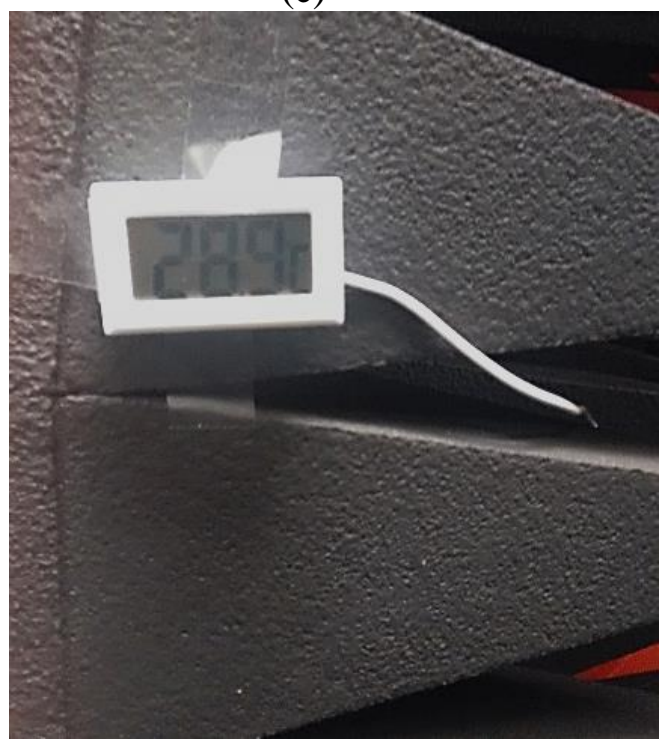

(d)

Figure 4.4. Proposed design of an external stimuli enclosure in anechoic chamber. (a) LCE antenna without heat $\left(24^{\circ} \mathrm{C}\right)$; (b) Hot plate heating beaker; (c) Hot beaker enclosure dynamically actuating LCE antenna $\left(50^{\circ} \mathrm{C}\right)$; (d) Digital thermometer monitoring temperature inside the enclosure during measurement. 
The antenna shown in Figure 4.5 is $27 \mathrm{~mm}$ long and $3 \mathrm{~mm}$ wide. The overall thickness is $51.8 \mu \mathrm{m}$, with $1.8 \mu \mathrm{m}$ optically glued $\mathrm{Al}$ and a $10 \mathrm{~mm}$ ground square was used. Figure 4.5(a) shows the antenna at room temperature. Figure 4.5(b) shows the antenna when an external heat stimulus is used. The antenna uncurled itself into a slightly twisted straight structure. Figure 4.5(c) shows the LCE antenna in the anechoic in the dynamic actuated state.

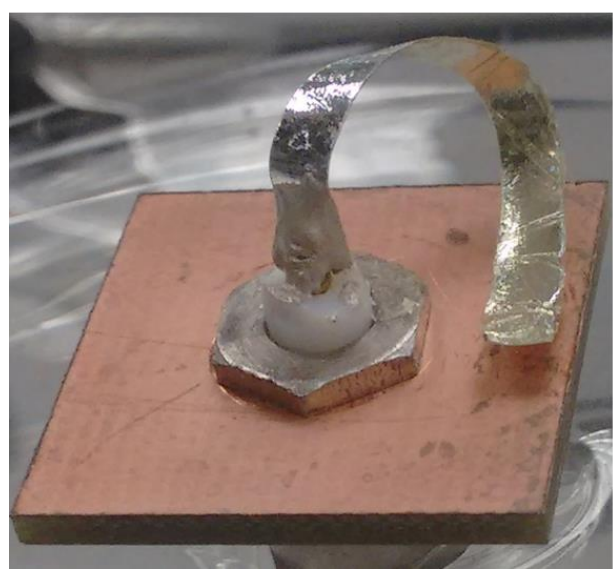

(a)

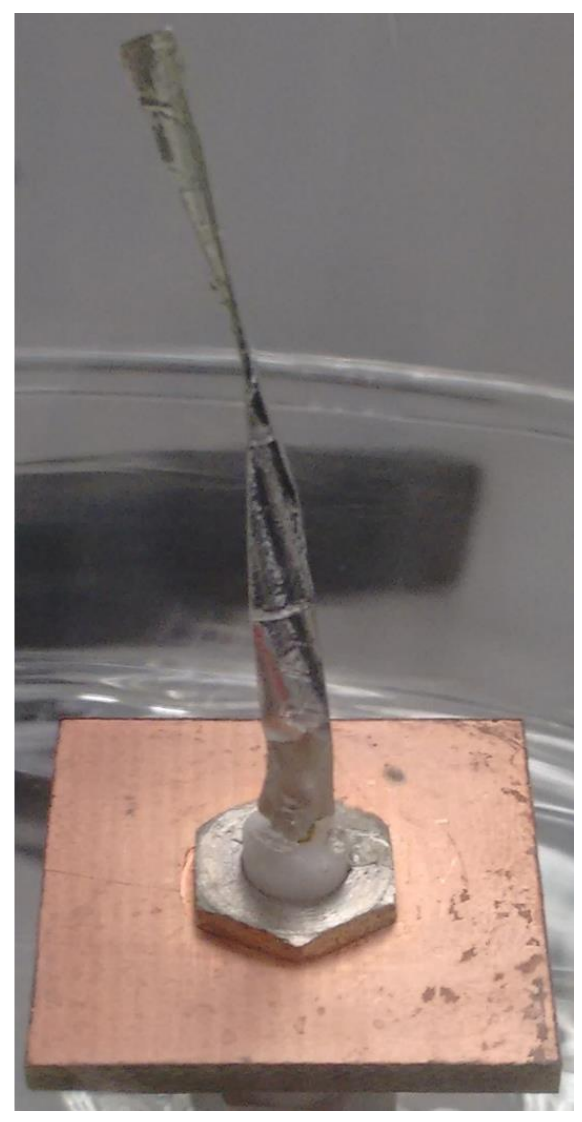

(b) 


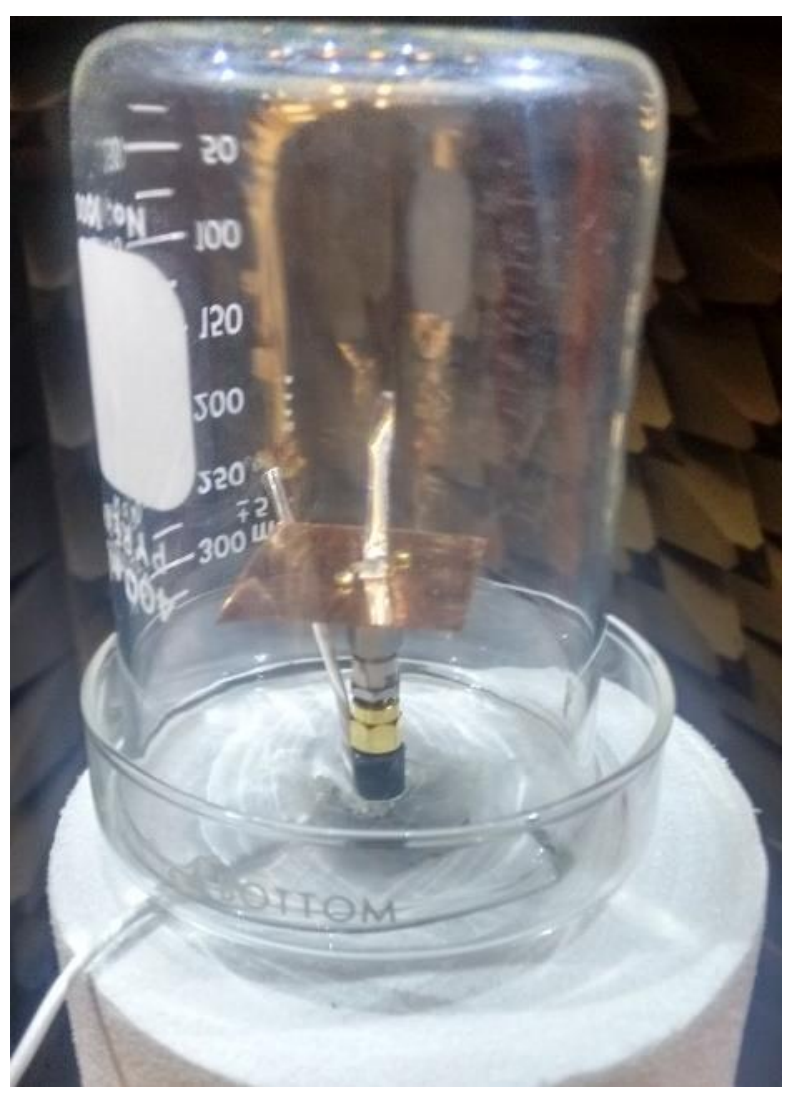

(c)

Figure 4.5. LCE antenna inside beaker enclosure at different temperature states; (a) room temperature $\left(24^{\circ} \mathrm{C}\right)$; (b) heated $\left(50^{\circ} \mathrm{C}\right)$; and (c) dynamically actuated inside the anechoic chamber.

Figure 4.6 shows the LCE antenna operating at room temperature and also inside the heated enclosure. The measured $S_{11}$ and realized gain of the LCE antenna at the operating frequencies are shown in Table 4.1, for room temperature (i.e., $24^{\circ} \mathrm{C}$ and $50^{\circ} \mathrm{C}$ ). The elevation radiation patterns for the corresponding frequencies are shown in Figure 4.7. In Figure 4.7 (a), at $6.7 \mathrm{GHz}$, the antenna is not heated and the pattern does not have a definite direction. When the LCE antenna is heated to $50^{\circ} \mathrm{C}$, the reconfigurable $\mathrm{LCE}$ antenna can operate at $2.9 \mathrm{GHz}$ or $6.8 \mathrm{GHz}$, and these patterns are directional in two different directions. 


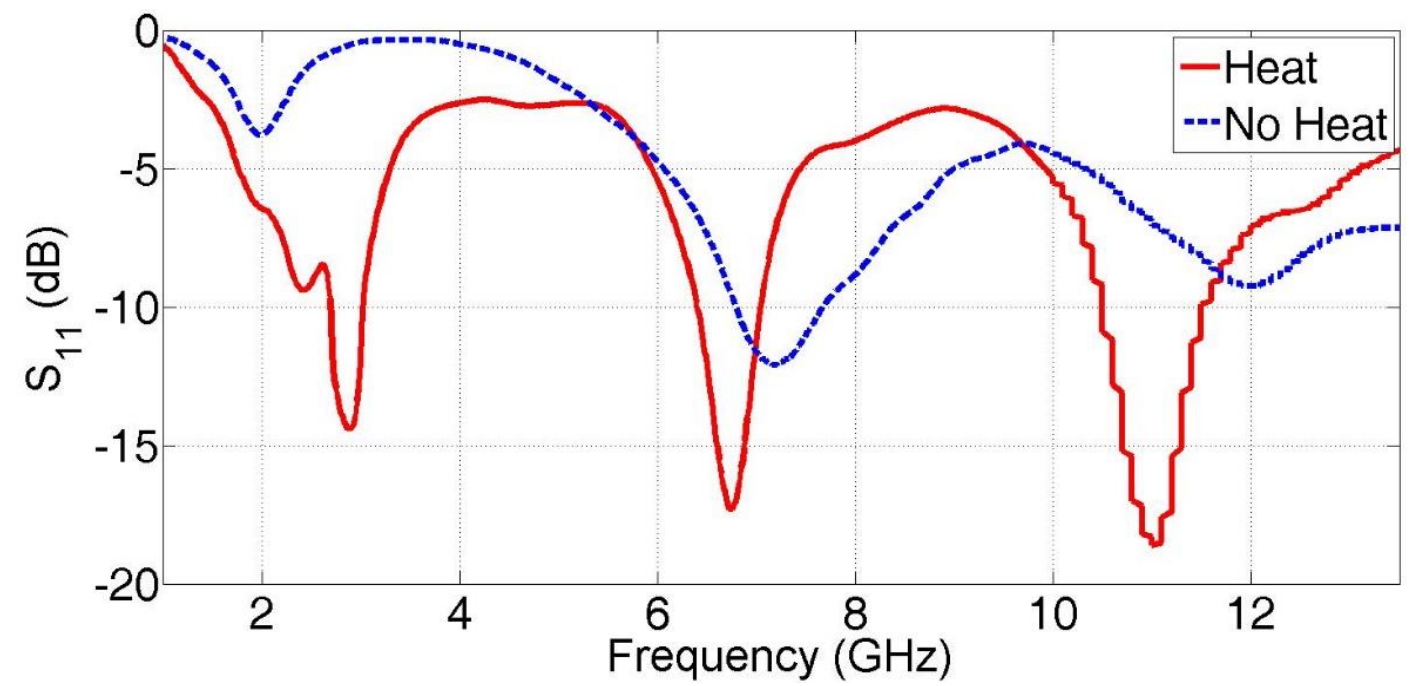

Figure 4.6. Comparison of measured $\mathrm{S}_{11}$ of multiband LCE antenna at two different temperature states.

Table 4.1 Performance of Each State of the Dynamically Reconfigurable LCE Antenna

\begin{tabular}{|c|c|c|}
\hline Operating Frequency $(\mathrm{GHz})$ & Measured S1 (dB) & Realized Gain (dB) \\
\hline No Heat 6.7 & -12 & 6.6 \\
\hline Heated 2.9 & -14 & 2.7 \\
\hline Heated 6.8 & -17 & 5.8 \\
\hline Heated 11.1 & -18 & 7.7 \\
\hline
\end{tabular}




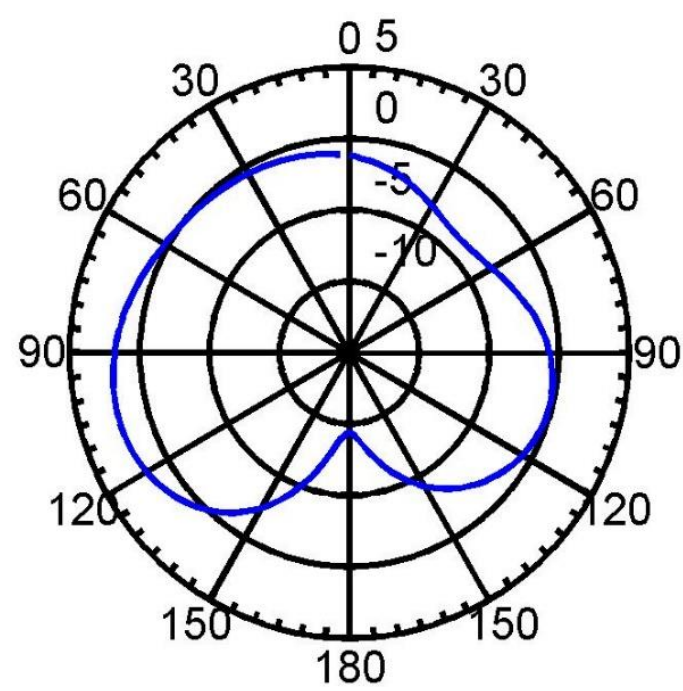

(a)

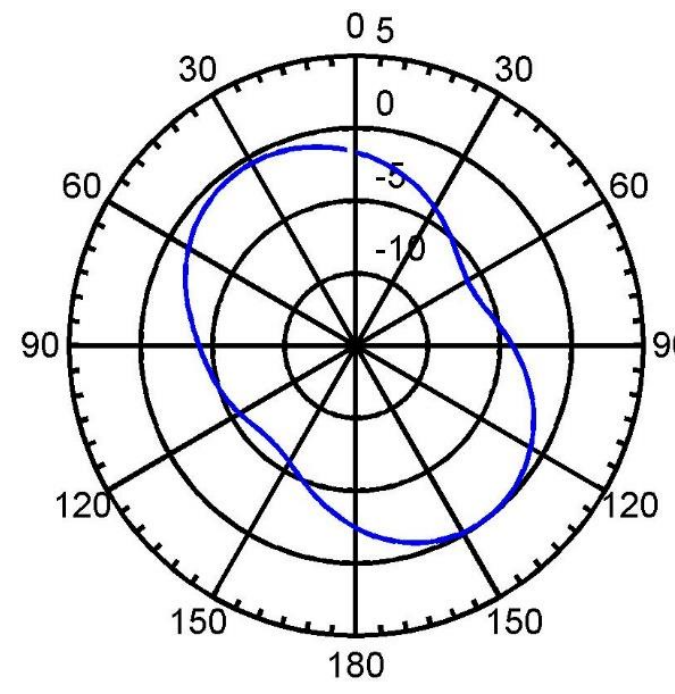

(b)

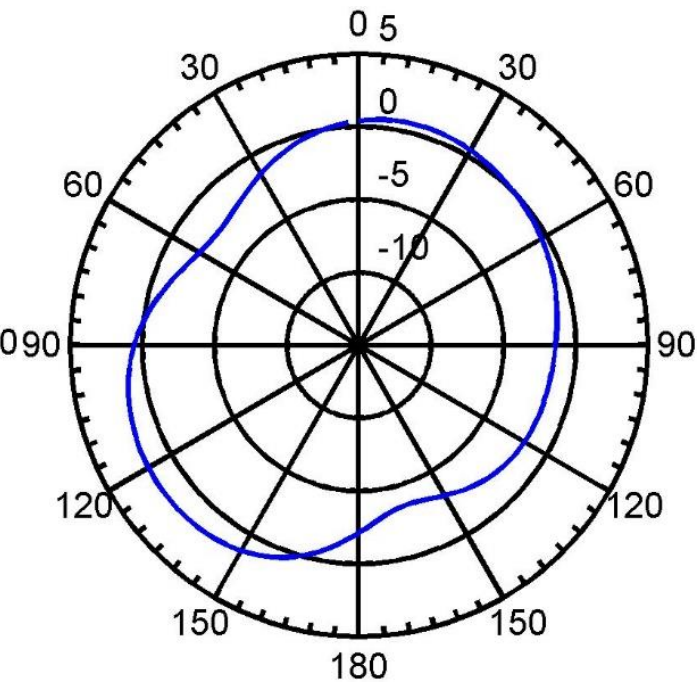

(c)

Figure 4.7. The measured radiation patterns of the reconfigurable antenna at $\theta=90^{\circ}$. (a) 6.7 GHz with no heat. (b) $2.9 \mathrm{GHz}$ and (c) $6.8 \mathrm{GHz}$ are with heat.

\subsubsection{External Stimulus with Acrylic/Plastic Box}

Although the enclosure of Figure 4.4(c) works with the LCE antenna, there are still drawbacks. One of them is the limited time for measurements before the heat leaks out and the LCE antenna recovers back to its original state. Another drawback is the temperature 
control. Only two temperatures are available that can be controlled using this process: the maximum temperature from the hot plate needed for actuation and the recovering temperature as the heat leaks out of the beaker.

To better control the heating of the LCE antennas, acrylic or polystyrene (plastic) boxes along with a solder reworking station were used to construct the new enclosure shown in Figure 4.8. The boxes have holes drilled out for the coaxial cable and for the solder reworking station hose. The rework station is helpful because of the airflow (psi) and temperature control. Therefore, the hot air is pumped into the enclosed box at the desired temperature and airflow setting, and the LCE antenna can be measured in the chamber at different stable temperatures instead of only two from the previous design. In addition, because the hose from the rework station is long, it can easily be setup in the chamber without the whole system being inside affecting the antenna radiation pattern measurement, as shown in Figure 4.9. The amount of the hot air pumped into the box is controlled by either a nozzle or the size of the drilled hole. Again, a digital thermometer is used to monitor the temperature inside the enclosure. This setup allows the dynamic actuation of LCE antennas and real-time measurements. 


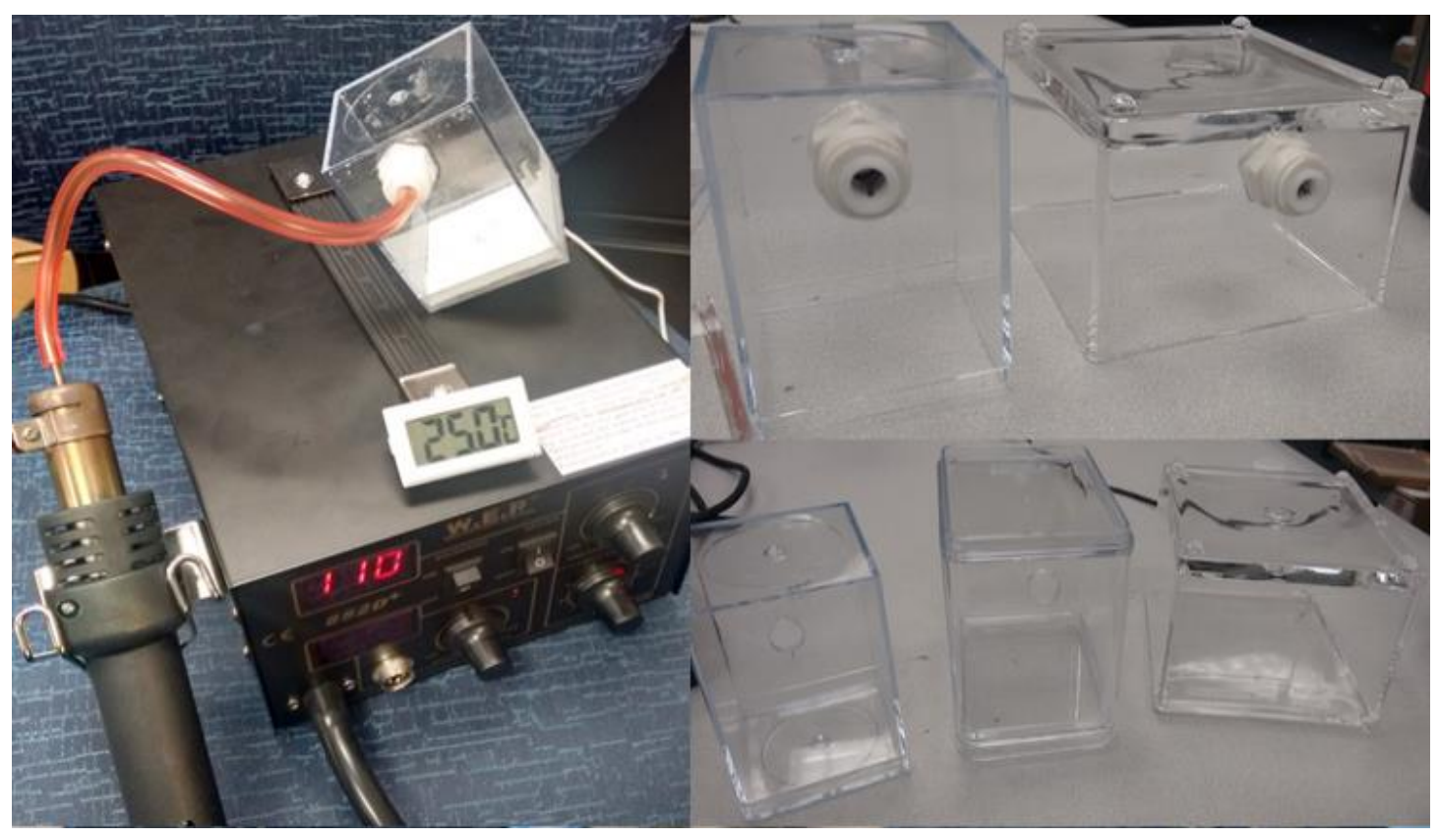

Figure 4.8. Examples of acrylic or polystyrene (plastic) boxes with drilled holes and solder reworking station external stimuli setup.

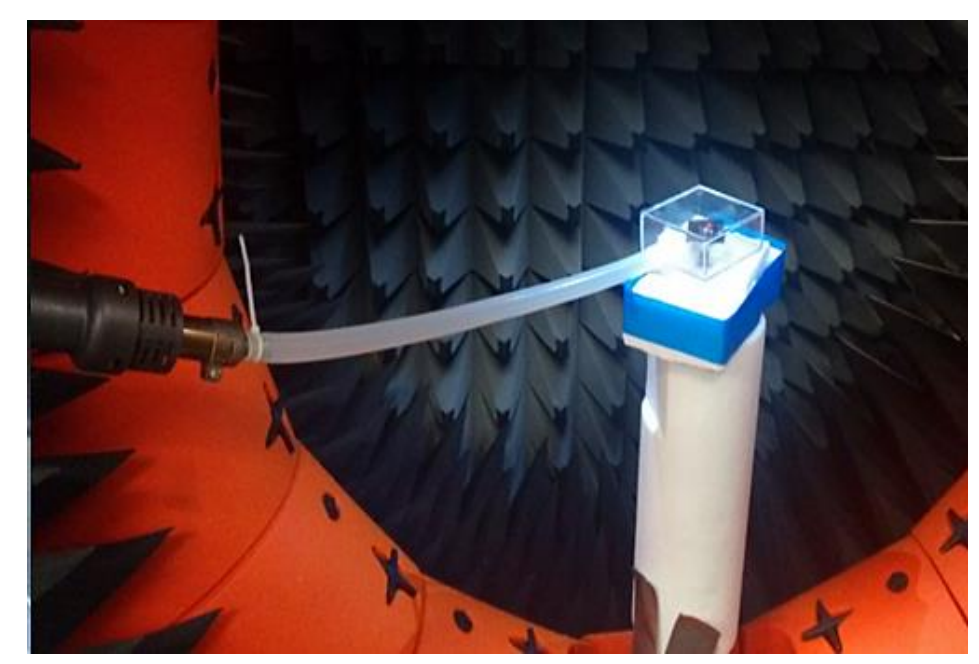

Figure 4.9. External stimuli enclosure setup in the chamber with reworking station hose.

A frequency-reconfigurable LCE antenna is proposed here based on using external stimuli with the acrylic box. The LCE antenna is $20 \mathrm{~mm}$ long and $2 \mathrm{~mm}$ wide. The overall thickness is $50.5 \mu \mathrm{m}$, with $500 \mathrm{~nm}$ evaporated $\mathrm{Al}$ and a $30 \mathrm{~mm}$ ground square was used. The 
simulation and prototype models are shown in Figures 4.10 and 4.11. The simulated and measured $\mathrm{S}_{11}$ for the three states are shown in Figures 4.12 and 4.13. All patterns were measured with the external stimuli setup in the StarLab antenna measurement system. The simulated and measured elevation radiation patterns of the different states are shown in Figure 4.14 at their corresponding frequencies. Figures 4.12 to 4.14 show that as the temperature changes, the antenna changes its shape and operates at a different frequency.

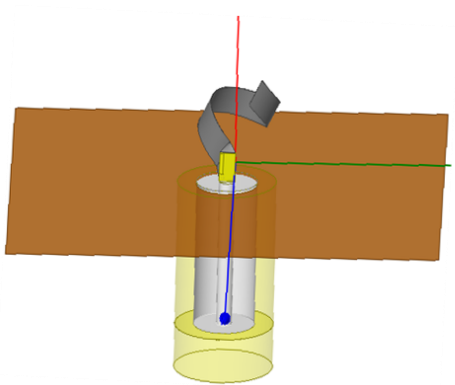

(a)

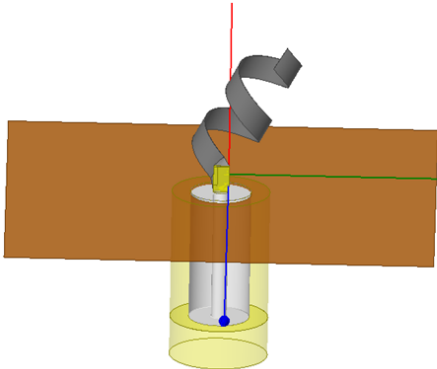

(b)

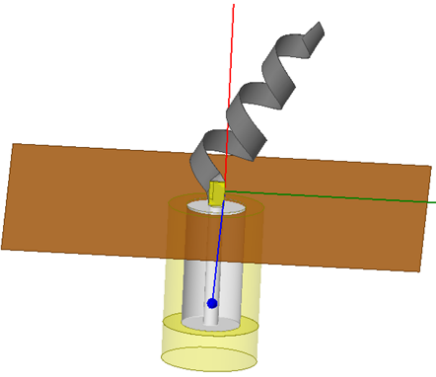

(c)

Figure 4.10. Simulated model of LCE frequency-reconfigurable antenna that reshapes itself from (a) 1-turn helix to (b) 2-turn helix to (c) 3 turn helix.

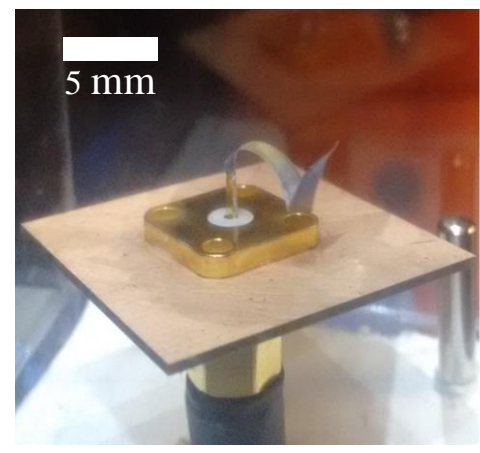

(a)

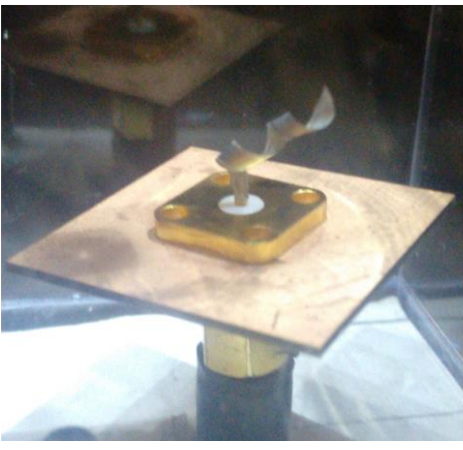

(b)

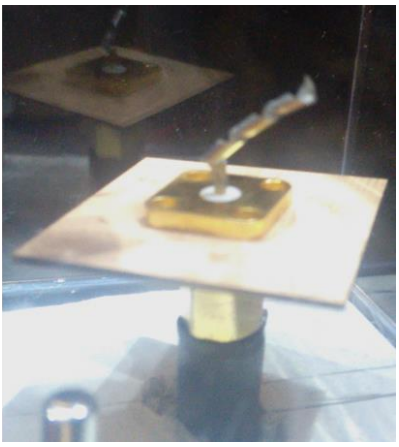

(c)

Figure 4.11. Dynamic prototype LCE frequency-reconfigurable antenna at different temperatures: (a) 1-turn helix at $45^{\circ} \mathrm{C}$, (b) 2-turn helix at $60^{\circ} \mathrm{C}$, and (c) 3-turn helix at $80^{\circ} \mathrm{C}$. 


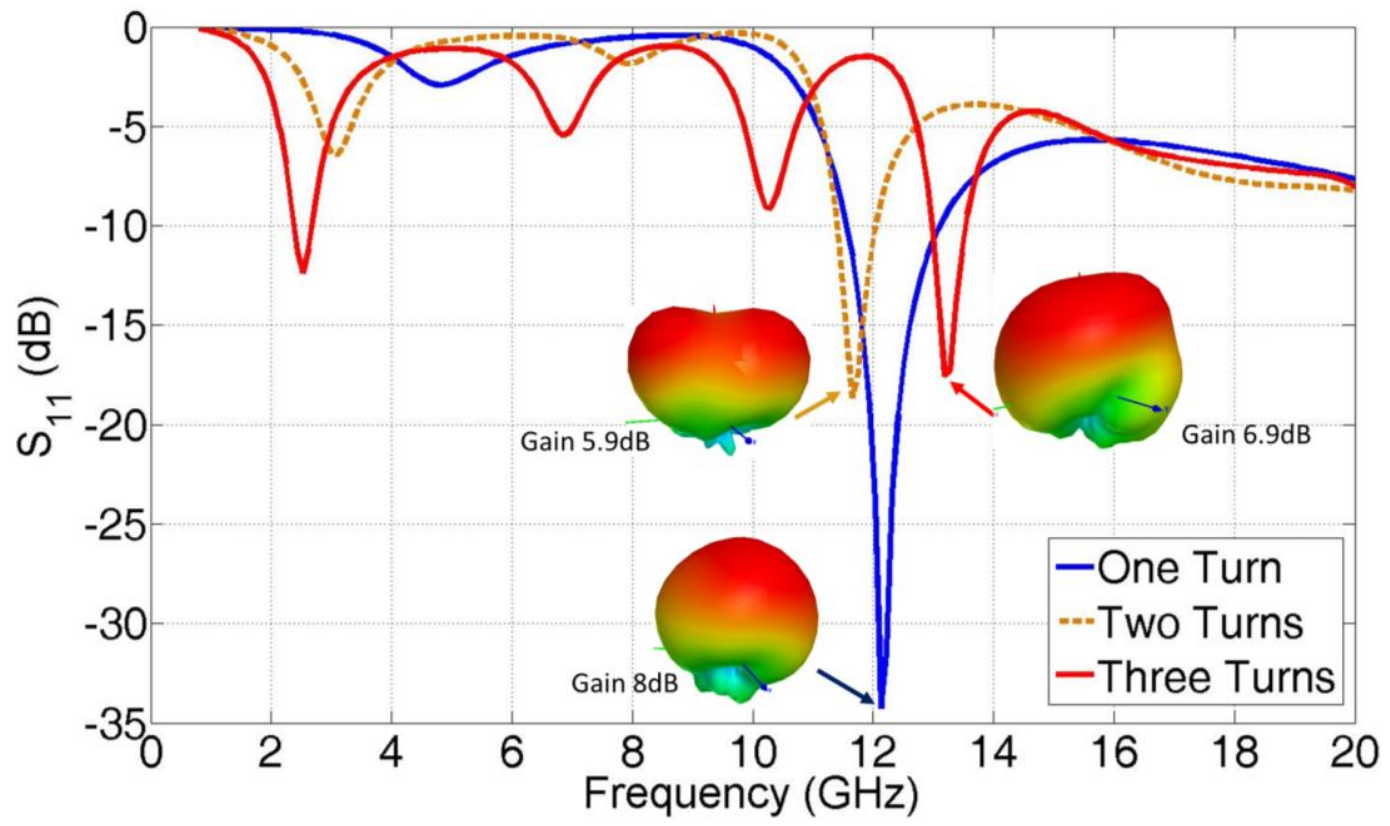

Figure 4.12. Simulated $S_{11}$ of frequency-reconfigurable antenna for three states with a simulated 3D radiation gain.

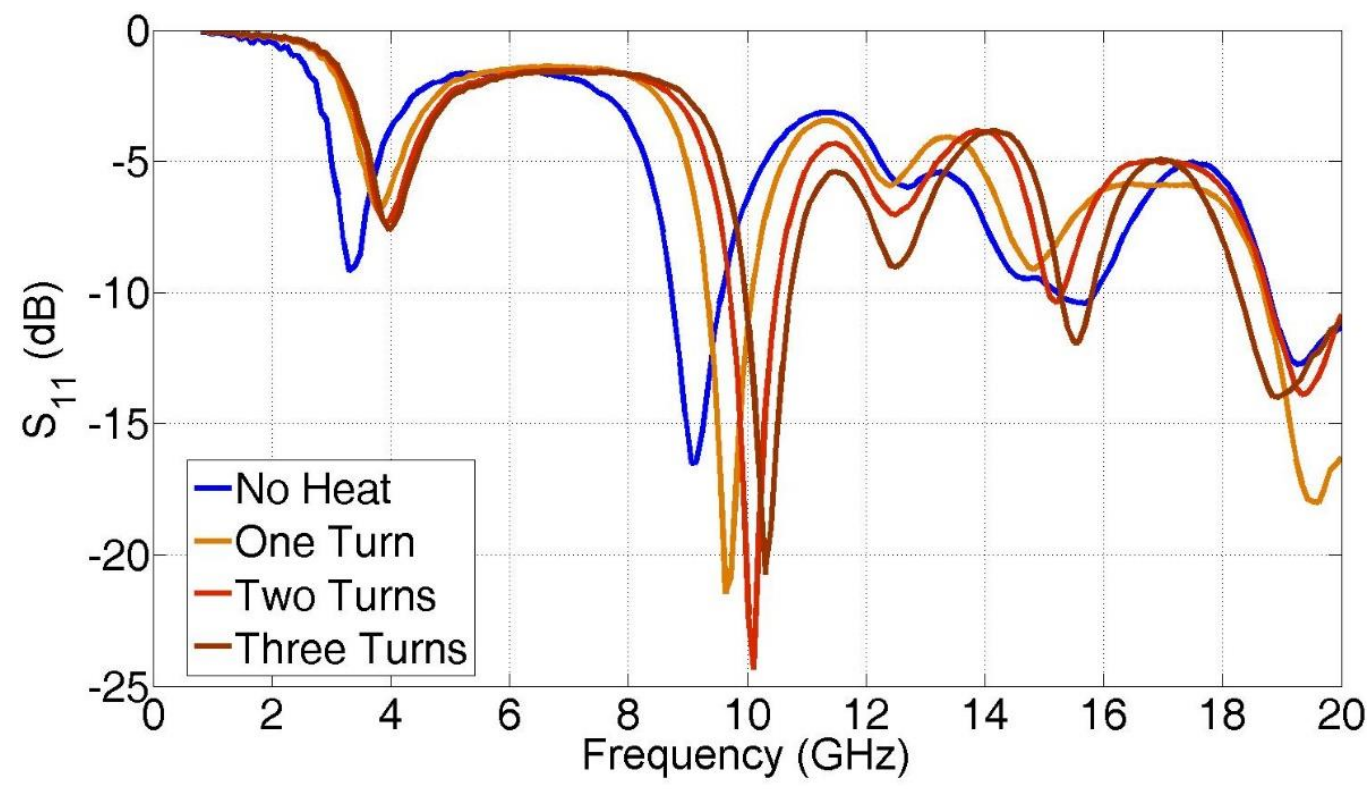

Figure 4.13. Measured $S_{11}$ of frequency-reconfigurable antenna four three states 


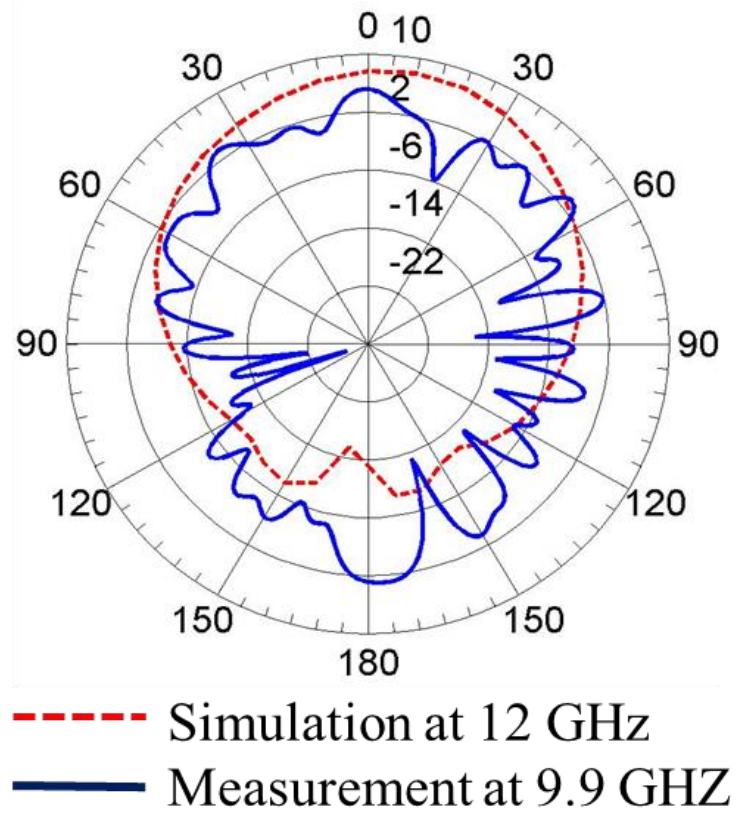

(a)

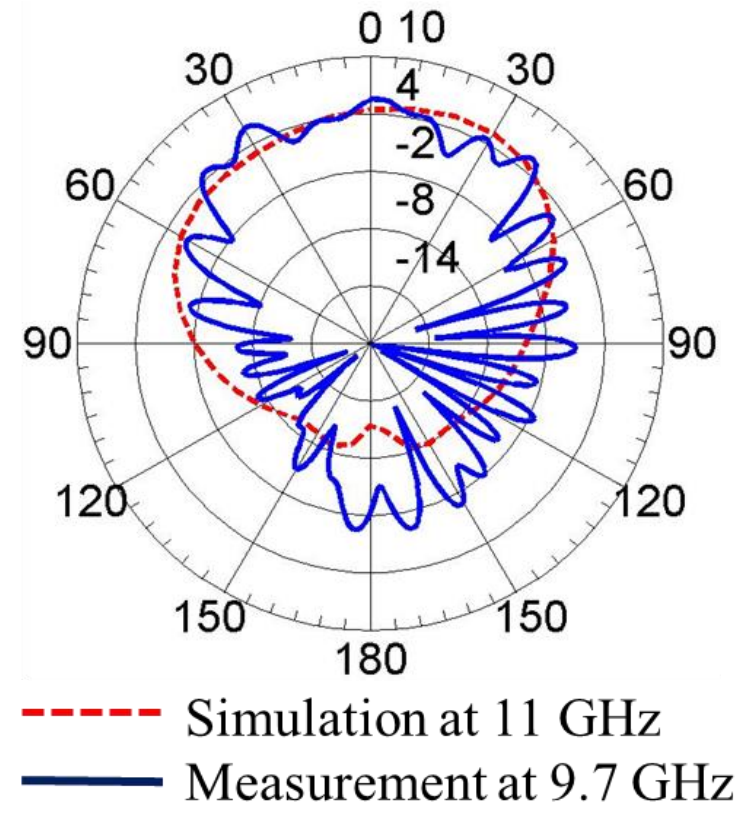

(b)

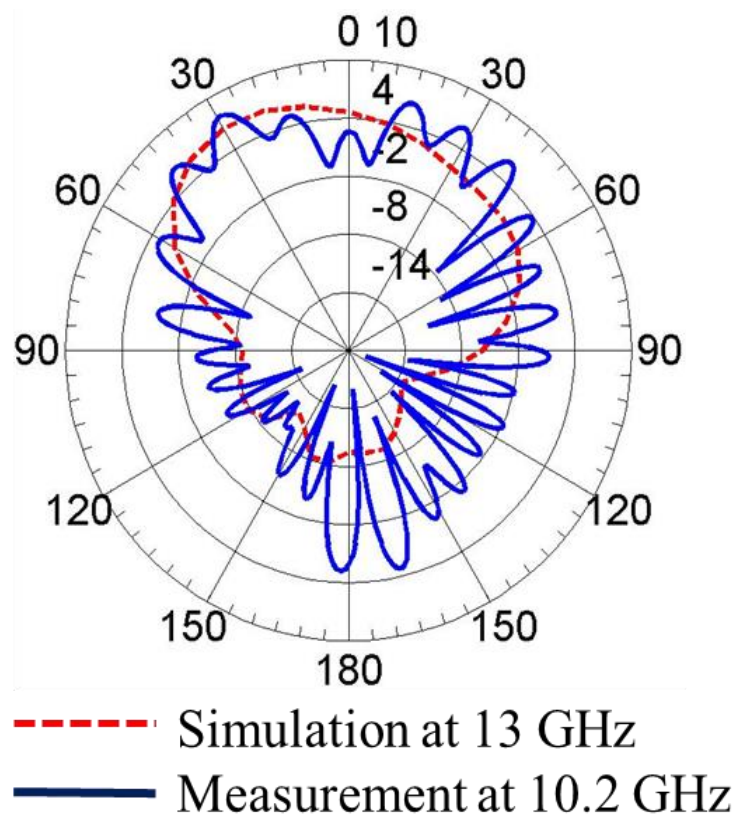

(c)

Figure 4.14. Simulated and measured elevation patterns of the frequency-reconfigurable antenna at different states: (a) 1-turn helix, (b) 2-turn helix, and (c) 3-turn helix. 


\subsubsection{Cylinder Brace for Larger LCE Antennas}

A problem that was faced in Section 4.1.2 with the antenna setup in the anechoic chamber was that when as the LCE antenna becomes longer, its weight increases and gravity forces pull it down. Therefore, in certain long LCE antennas at room temperature the antenna can potentially be pulled down by gravity to the point that it touches the ground plane and shorts itself. One way to prevent this from happening and simultaneously measure the antenna as it responds to temperature changes, is to measure it upside down, as shown in Figure 4.15. To measure the radiation pattern, the LCE antenna would have to be connected to the connector at $90^{\circ}$ degrees, which will not show the whole pattern towards the azimuth (see Figure 4.16); therefore, this is not practical. The LCE antenna shown in Figure 4.15 is $25 \mathrm{~mm}$ long and $2.5 \mathrm{~mm}$ wide with $50 \mu \mathrm{m}$ thick LCE substrate metallized with $200 \mathrm{~nm}$ of Titanium/Copper (25nm Ti/175nm CU). Titanium was used as an adhesion layer for the cooper. When heated, the LCE antenna changes from a lefthanded helical state to a right-handed helical state and back to its original state after the heat is removed.

To address the problem regarding the potential shorting of the LCE antenna, a 3-D printed PLA cylinder brace was designed to support the antenna upwards at room temperature. This support prevents the LCE antenna from dropping and touching the ground plane and has a sufficiently large diameter to allow the antenna to change its shape when it is heated. Figure 4.16 shows the LCE antenna with the PLA cylinder. The LCE antenna is $20 \mathrm{~mm}$ long and $2 \mathrm{~mm}$ wide. The overall thickness is $51 \mu \mathrm{m}$, with $1 \mu \mathrm{m}$ evaporated $\mathrm{Al}$ and a $30 \mathrm{~mm}$ ground square was used. The PLA cylinder is designed at an 
angle because the antenna spirals at an angle. The simulation and prototype models are shown in Figures 4.17 and 4.18. Figure 4.18 shows the LCE antenna with different turns inside the cylinder brace as the temperature increases. The LCE antenna dynamically changes its number of turns according to the temperature as follows: 0 -turns at $25^{\circ} \mathrm{C}, 1$ turn at $40^{\circ} \mathrm{C}, 2$-turns at $63^{\circ} \mathrm{C}$, and 3-turns at $80^{\circ} \mathrm{C}$. The simulated and measured $\mathrm{S}_{11}$ for each state are shown in Figure 4.19 (a)-(c), respectively. All patterns were measured with the external stimuli setup in the StarLab antenna measurement system. The simulated and measured elevation radiation patterns of the different states are shown in Figure 4.20 at their corresponding frequencies.

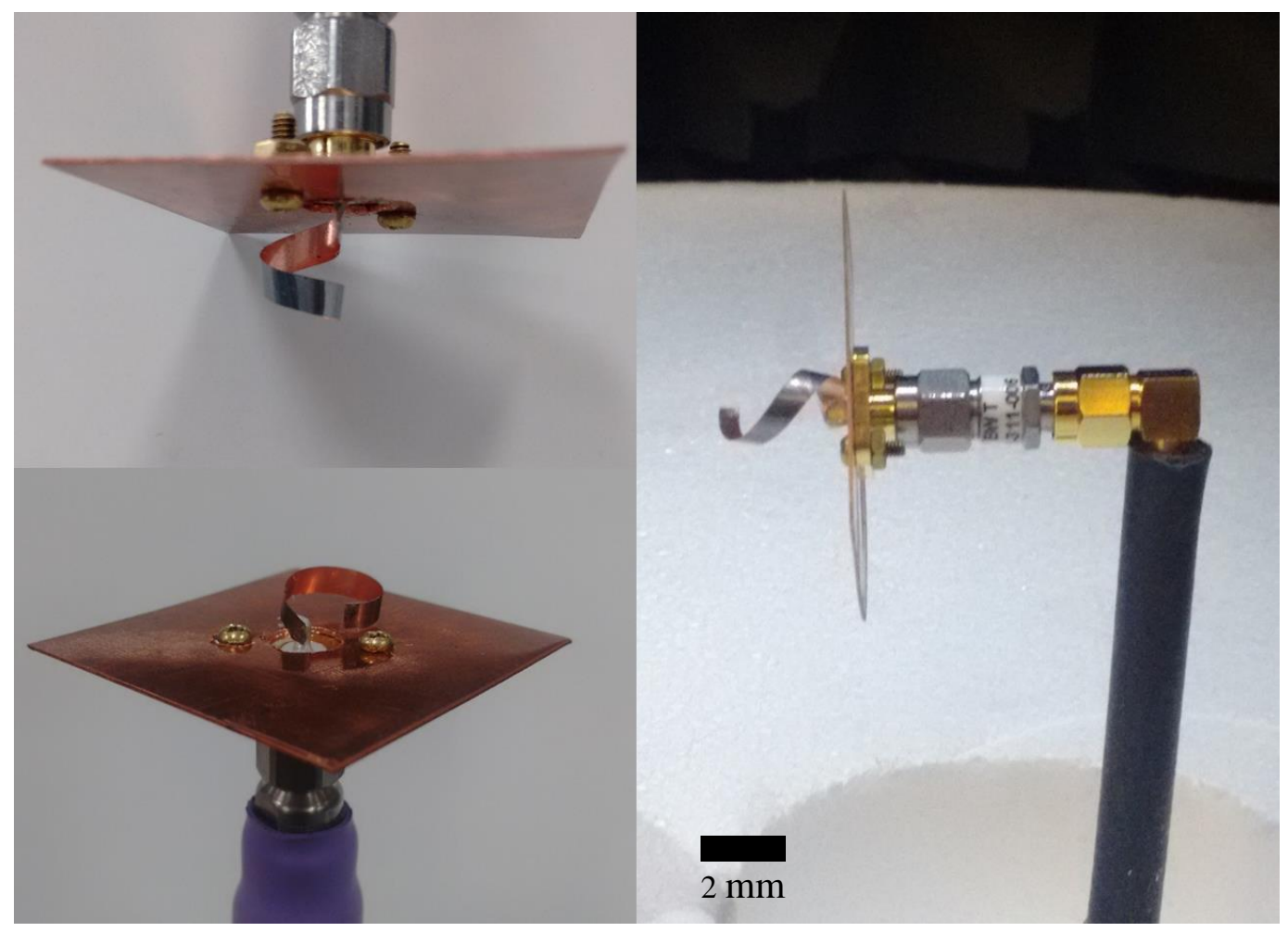

Figure 4.15. Prototype of LCE antenna for dynamic measurements at different orientations: upside down, right side up, and $90^{\circ}$ degrees inside the anechoic chamber. 


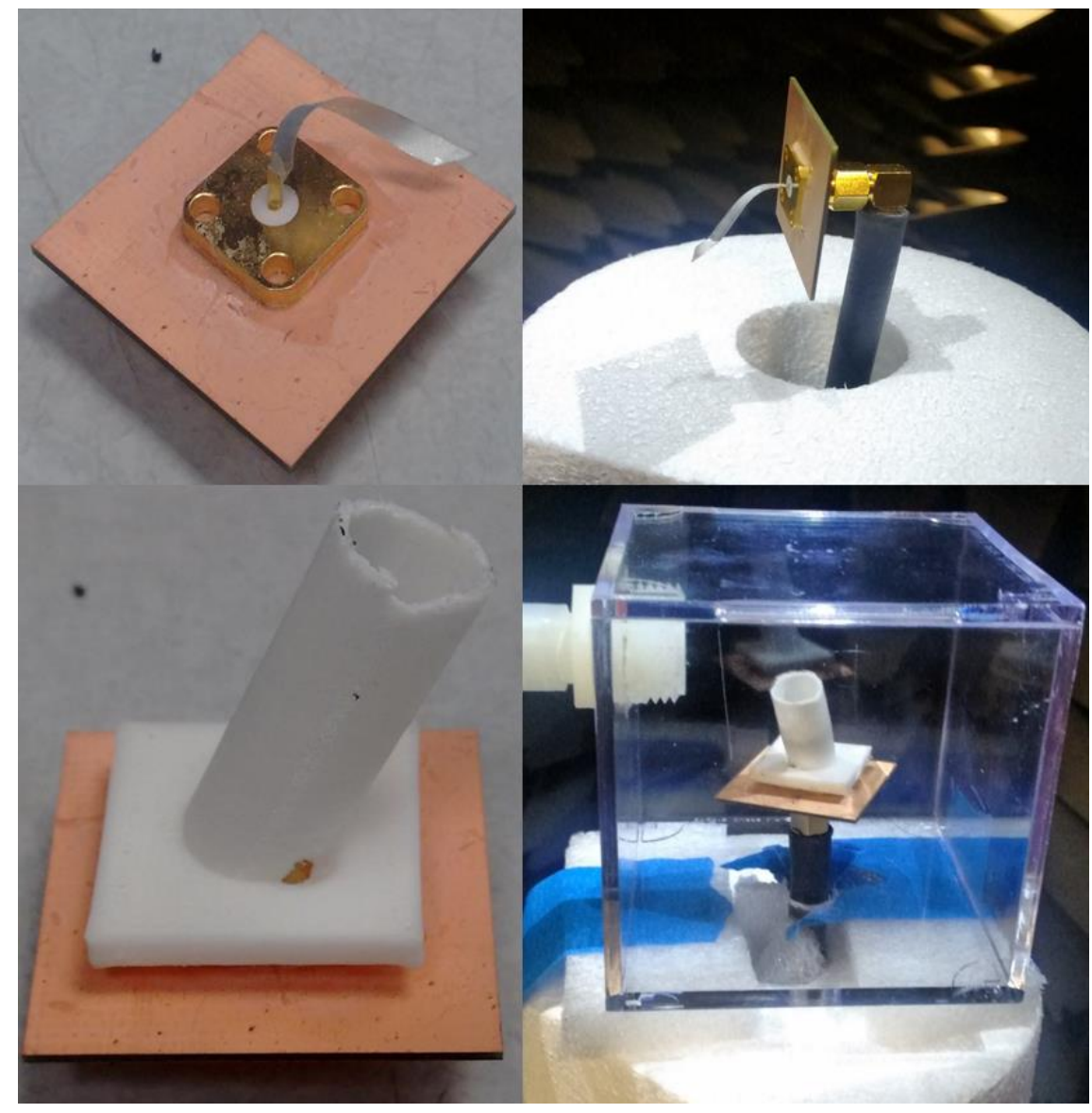

Figure 4.16. Dynamic prototype LCE Antenna with and without the Polylactic Acid (PLA) cylinder brace.

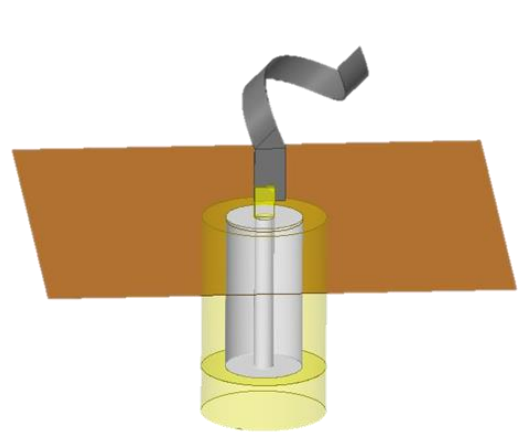

(a)

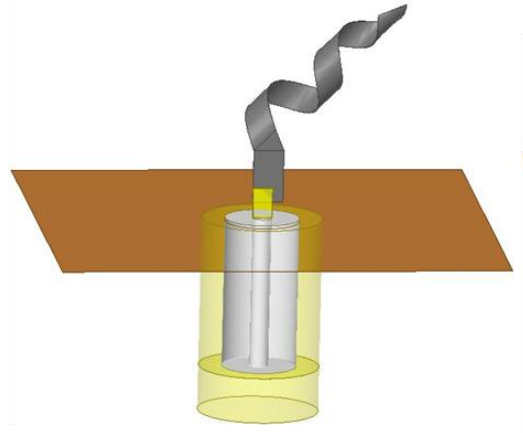

(b)

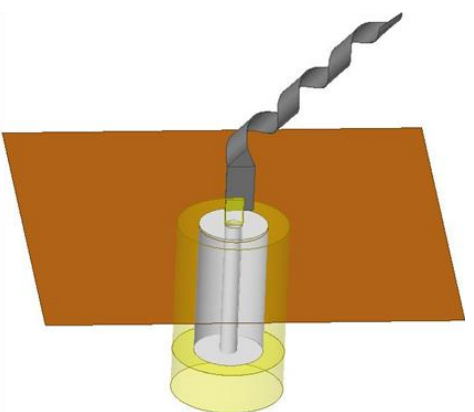

(c)

Figure 4.17. Simulated model of LCE frequency-reconfigurable antenna that reshapes itself from (a) 1-turn helix to (b) 2-turn helix to (c) 3 turn helix. 


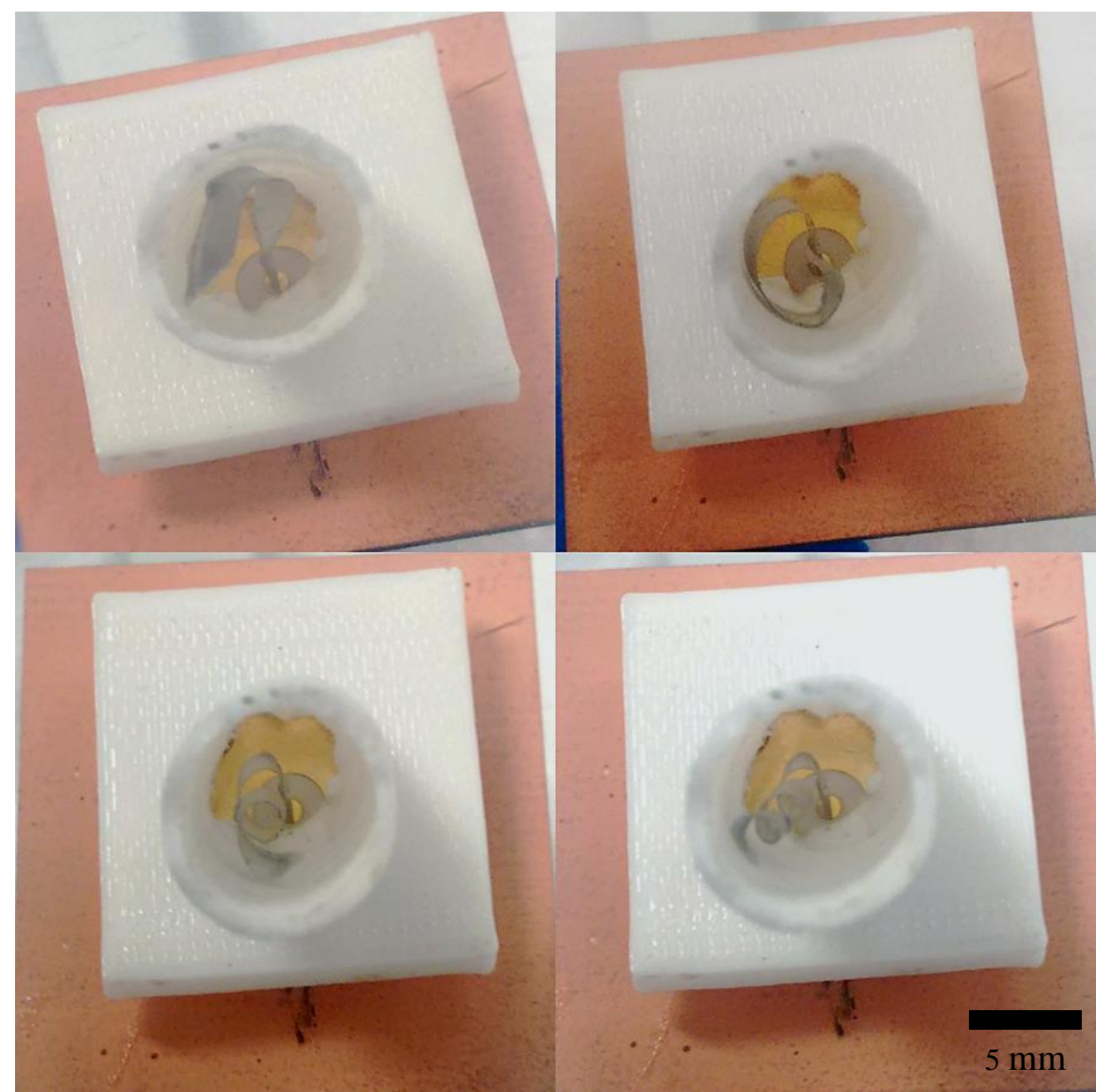

Figure 4.18. Dynamic prototype LCE Antenna inside the cylinder brace at different states: no turns at $25^{\circ} \mathrm{C}, 1$-turn at $40^{\circ} \mathrm{C}, 2$-turn helix at $63^{\circ} \mathrm{C}$, and 3-turn helix at $80^{\circ} \mathrm{C}$. 


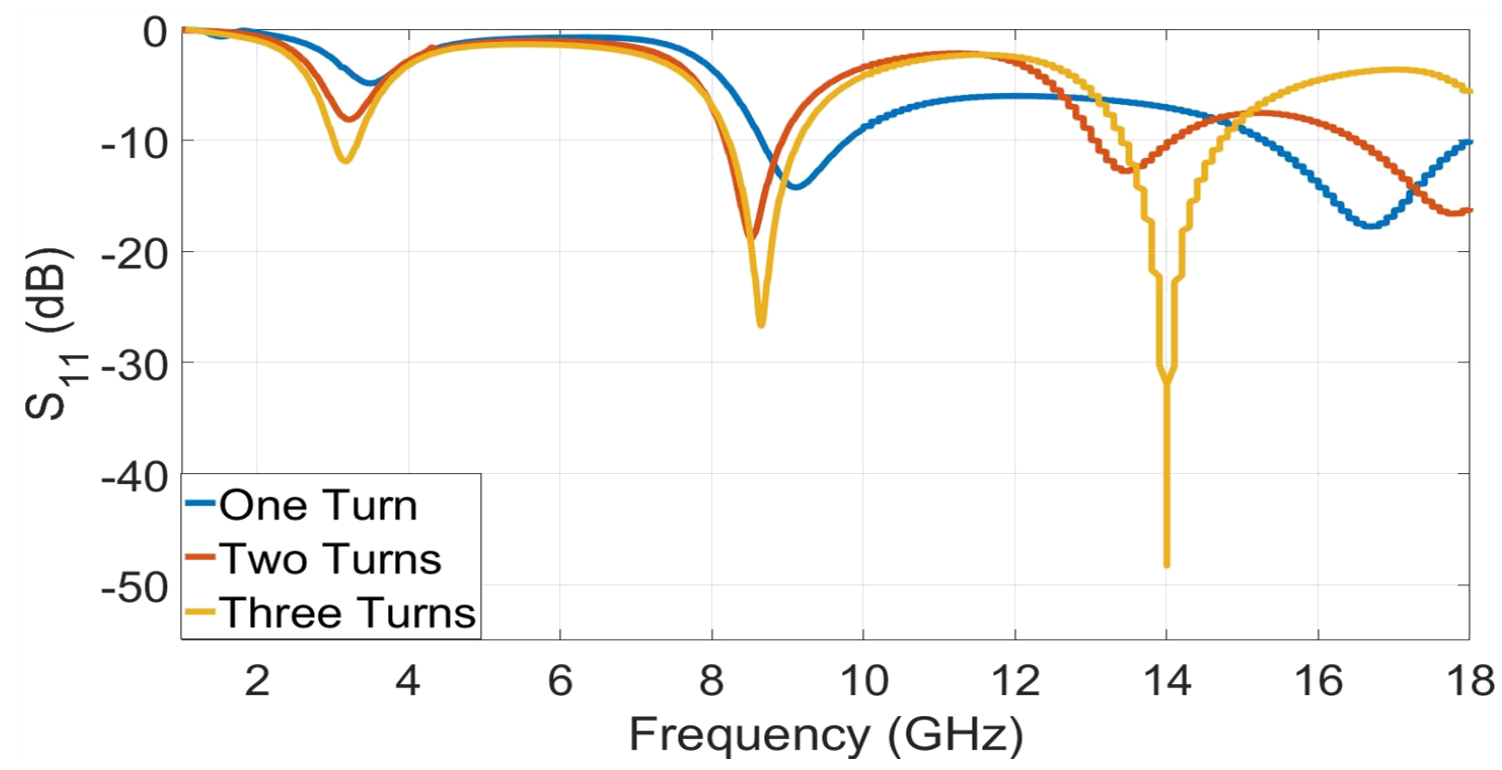

(a)

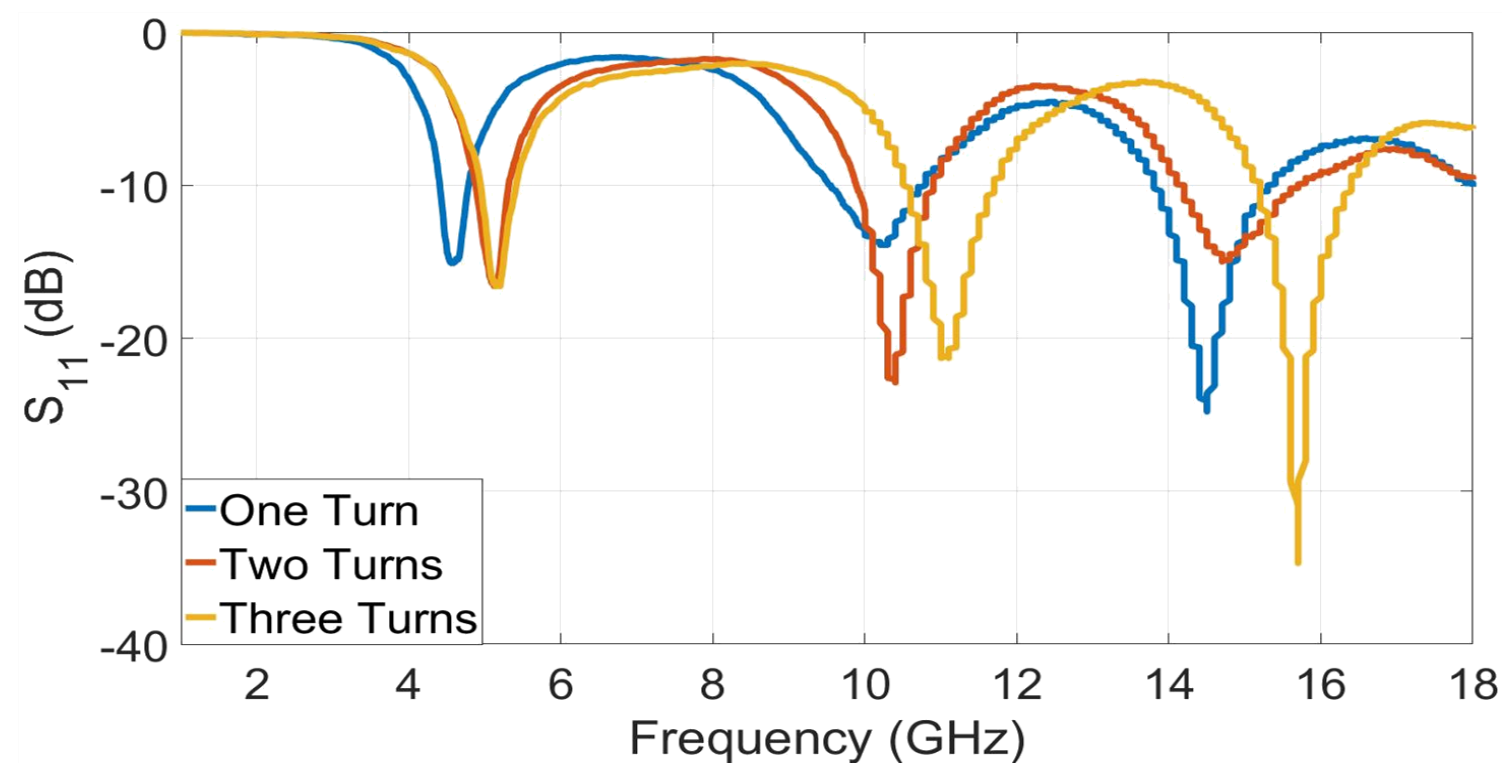

(b)

Figure 4.19. (a) Simulated and (b) measured $\mathrm{S}_{11}$ of dynamic frequency-reconfigurable LCE antenna at each different state 


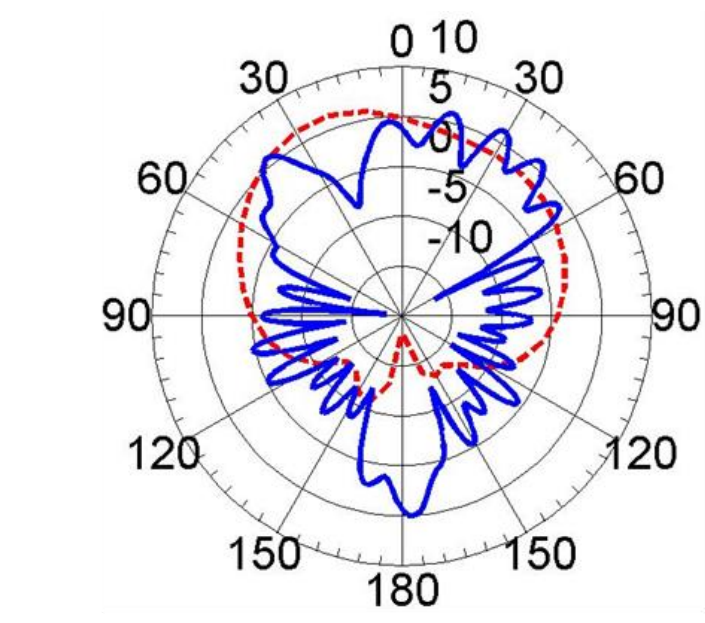

----- Simulation at $10 \mathrm{GHz}$

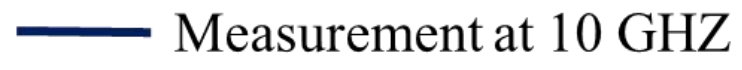

(a)

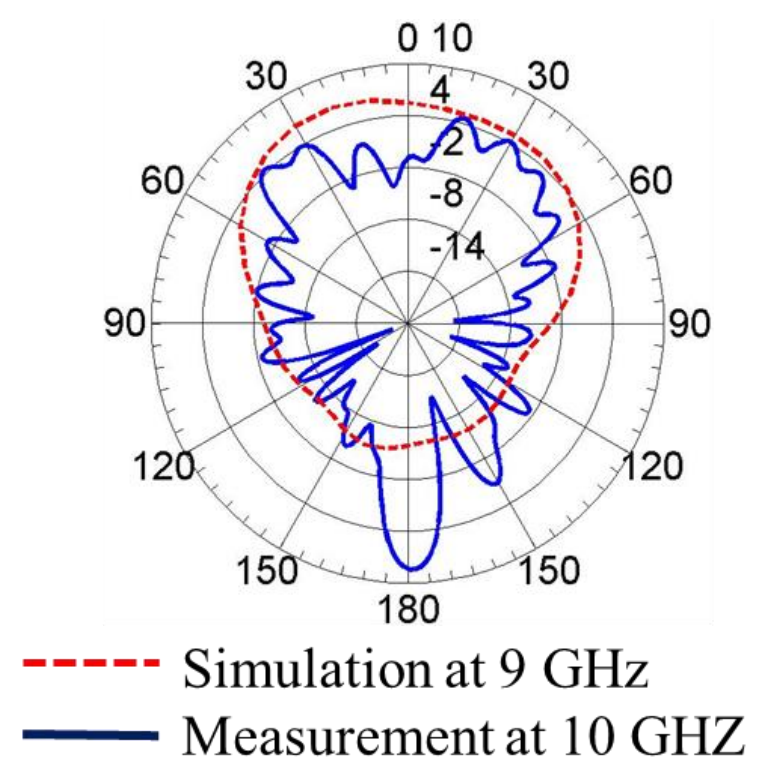

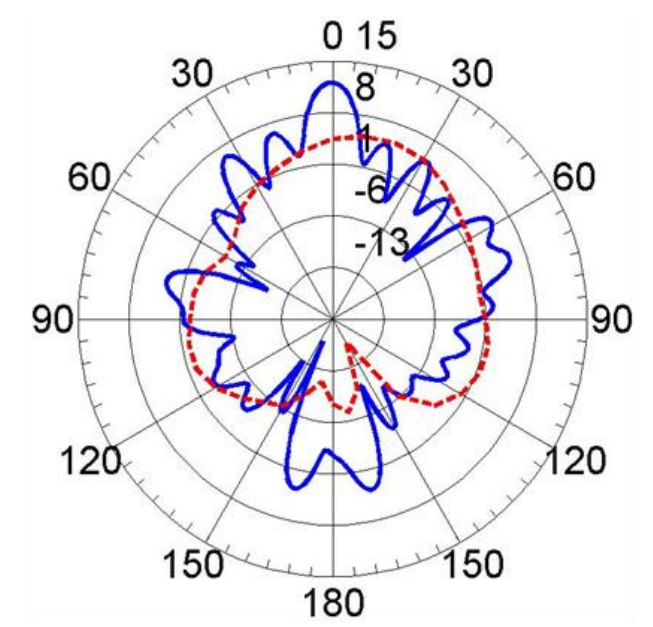

----- Simulation at $14 \mathrm{GHz}$

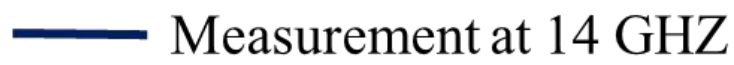

(b)

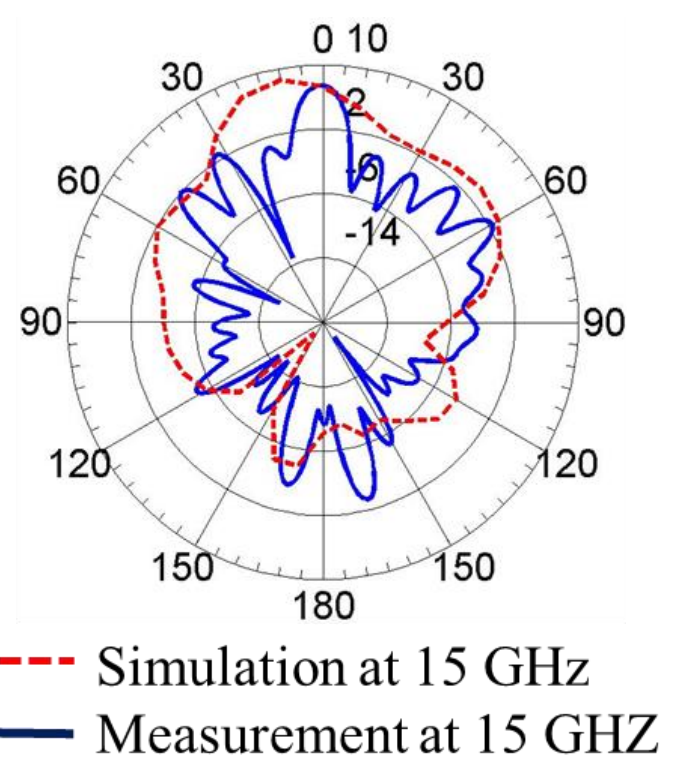

(d)

Figure 4.20. Simulated and measured elevation patterns of the dynamic frequencyreconfigurable LCE antenna at different states: (a) 1-turn helix at $10 \mathrm{GHz}$, (b) 2-turn helix at $\sim 10 \mathrm{Ghz}$, (c) 2-turn helix at $14 \mathrm{GHz}$, and (d) 3-turn helix at $15 \mathrm{GHz}$. 
In summary, there were many different types of measurement setups, each setup addresses a problem that was identified in the previous setup. The designs were constructed for lightweight responsive (LCE) materials to smoothly change their structure without ambient temperature interference. The main goal was to design an external stimuli source mechanism to set a certain temperature in an enclosed area for LCE antennas to allow the dynamic characterization of their mechanical, thermal, and electromagnetic performance without fixing the antenna.

\subsection{Different Metallization Techniques used for LCE Antennas}

LCE substrates need to be metallized in order to function as antennas [73]. However, optimal metallizations should be developed that do not crack or delaminate when LCE antennas reversibly actuate. Here, the metallization of LCEs film will be studied for different conductors and fabrication processes. Specifically, optical glue or electron beam physical vapor deposition (E-Beam evaporation) will be used to attach the conductor to LCE films. Although there are many other metallization techniques available [17], the limitations of metallizing a temperature sensitive thin film must be considered. Once the metal is attached to the polymer, the ability of the metalized LCE to reversibly change its shape was tested. The thickness of the metallization can range from a few nanometers to hundreds of nanometers. It is expected that the metal thickness by evaporation will not exceed the skin-depth in the RF range. The effects of the material thickness to the selfmorphing ability of LCE antennas will be also considered and performance trade-offs (i.e., thinner materials are easier to fold, whereas thicker materials exhibit less resistive losses) will be studied. Electroplating can be used to increase the metal thickness and provide 
thicknesses that are greater than $1 \mu \mathrm{m}$. The metal morphology of the conductor will be characterized before and after actuation using scanning electron microscopy (SEM).

At high frequencies, the current density is concentrated into the region near the surface of a good conductor. This is commonly called the skin effect. Skin depth or penetration depth is defined as the depth below the surface of the conductor at which the amplitude at an incident electric field (E) has decreased by factor 1/e (approximately 0.37) [86]. The skin depth, $\delta$, is defined by

$$
\delta=\sqrt{\frac{\rho}{\pi f \mu_{r} \mu_{0}}}
$$

Where $\rho$ is the resistivity, $f$ is the frequency, $\mu_{r}$ is the permeability of free space and $\mu_{0}$ is the magnetic permeability of the conductor material. The metal thickness of our LCE antennas will not to exceed the skin-depth at the corresponding frequencies of operation since thick metallizations will not allow these antennas to change their shape. Therefore, thick metallizations will be avoided.

The method for fabricating Aluminum-coated LCEs is described below. Two LCE antennas were prepared using two different metallization techniques. Antenna 1 used an optically glued aluminum ( $\mathrm{Al})$ and Antenna 2 used electron beam evaporation. To prepare Antenna 1, the LCE films on the glass slides were spin-coated with a thin layer of optical glue and immediately attached to $1.8 \mu \mathrm{m}$ thick Al film. After UV curing the optical glue ( $\sim 5 \mathrm{~min})$, the films were cut into strips. Antenna 2 was prepared using a thin film deposition process called electron beam physical vapor deposition or E-Beam evaporation (CHA SAP 
600). The deposition rate in this process was set to $0.1 \mathrm{~nm}$ per second with incremental deposition of $250 \mathrm{~nm}$ of $\mathrm{Al}$ to avoid overheating the LCEs. After evaporating $1 \mu \mathrm{m}$ of $\mathrm{Al}$, the films were also cut into strips. The deposition rate in this process can be as low as $1 \mathrm{~nm}$ per minute to as high as few micrometers per minute. The material utilization efficiency is high relative to other methods and the process offers structural and morphological control of films. The Al thickness used in Antenna 2 was $1 \mu \mathrm{m}$. Both antennas 1 and 2 were made on glass slides, shown in Figure 4.21 (a) and (b). Surface profiles of the LCEs and images of the Al films were taken using scanning electron microscopy (SEM, Jeol JSM7000F/JIB-4500). The metallized LCE films prepared for SEM measurements; were $5 \mathrm{~mm}$ by $2 \mathrm{~mm}$ samples of the two $\mathrm{Al}$ metallized LCEs. The samples were sputtered with a thin layer $(\sim 5 \mathrm{~nm})$ of gold by using a Pelco SC-7 auto sputter coater prior to SEM imaging to obtain a conductive surface. The $\mathrm{Al}$ film used with the optical glue was a foil type material, which displayed wrinkles and non-uniformity when it was attached to the LCE substrate. Figure 4.22 shows SEM images of the metallized LCE films at $100 \mu \mathrm{m}$ scale, illustrating the wrinkles of the glued $\mathrm{Al}$ and the uniformity of the E-beam evaporated Al. Figure 4.23 shows the surface roughness of the two metallizations before and after heat. 


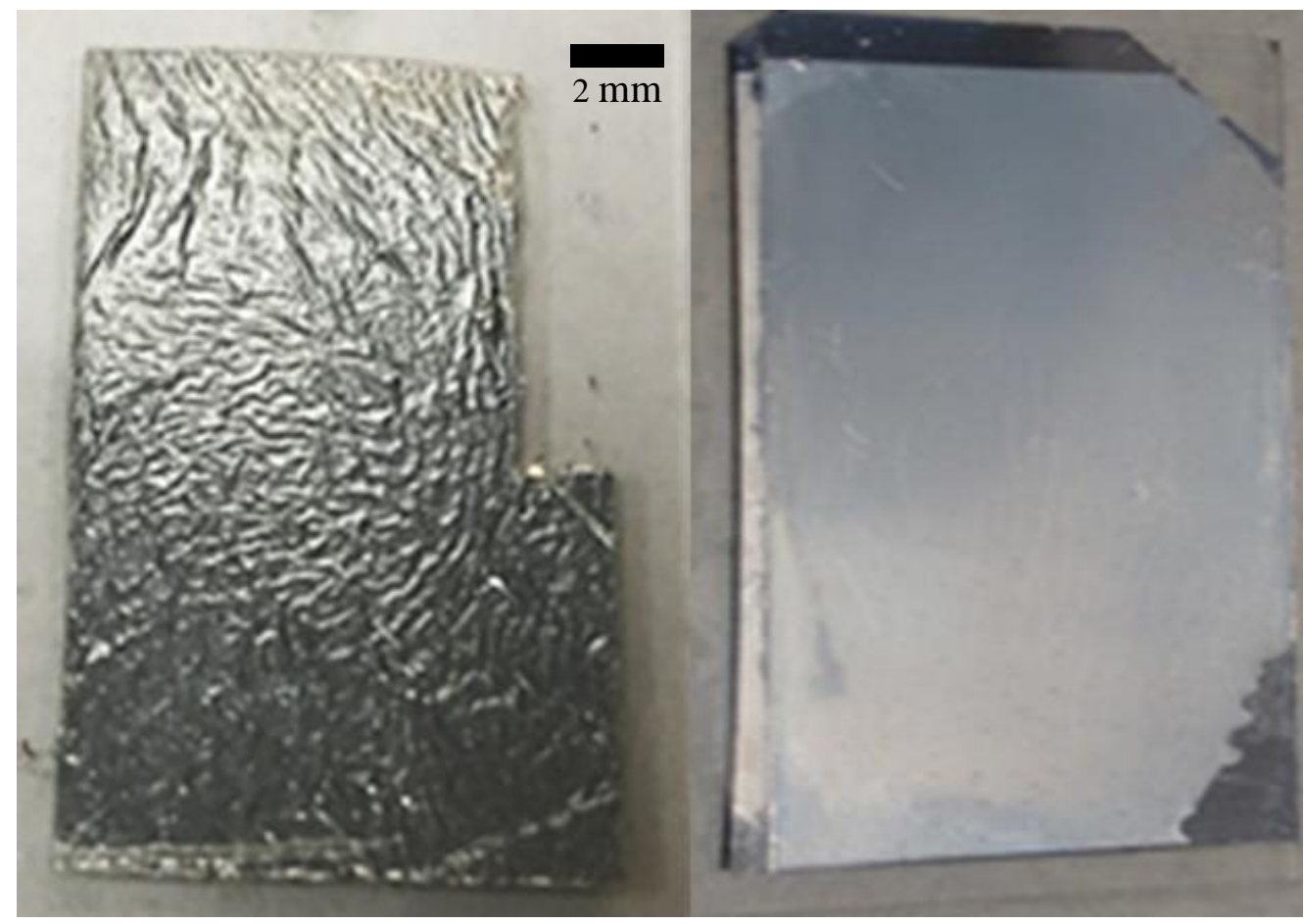

(a)

(b)

Figure 4.21. Metallized LCEs on glass slides with: (a) glued Al and (b) E-beam evaporated Al.

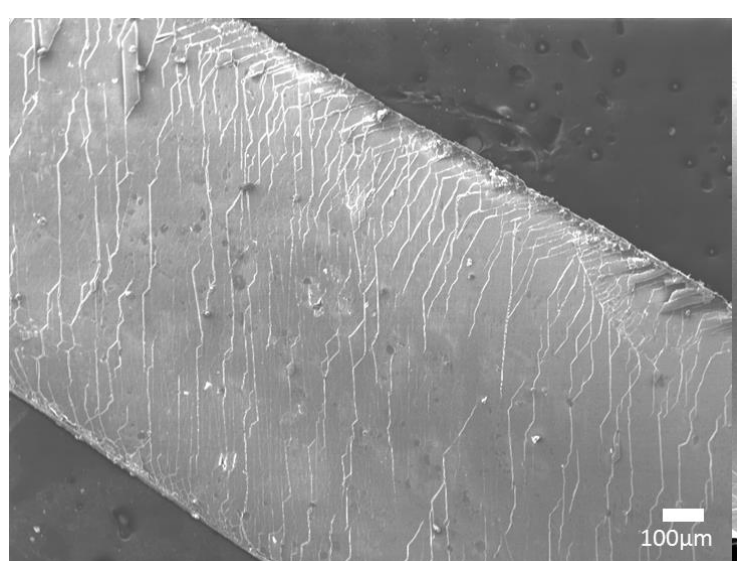

(a)

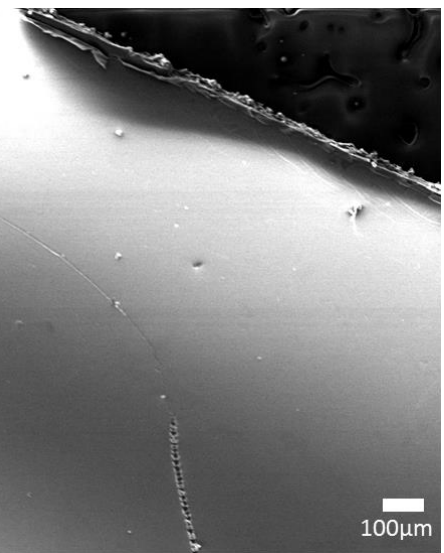

(b)

Figure 4.22. SEM images of metallized LCE films before heat cycles with: (a) glued Al and (b) E-beam evaporated Al. 


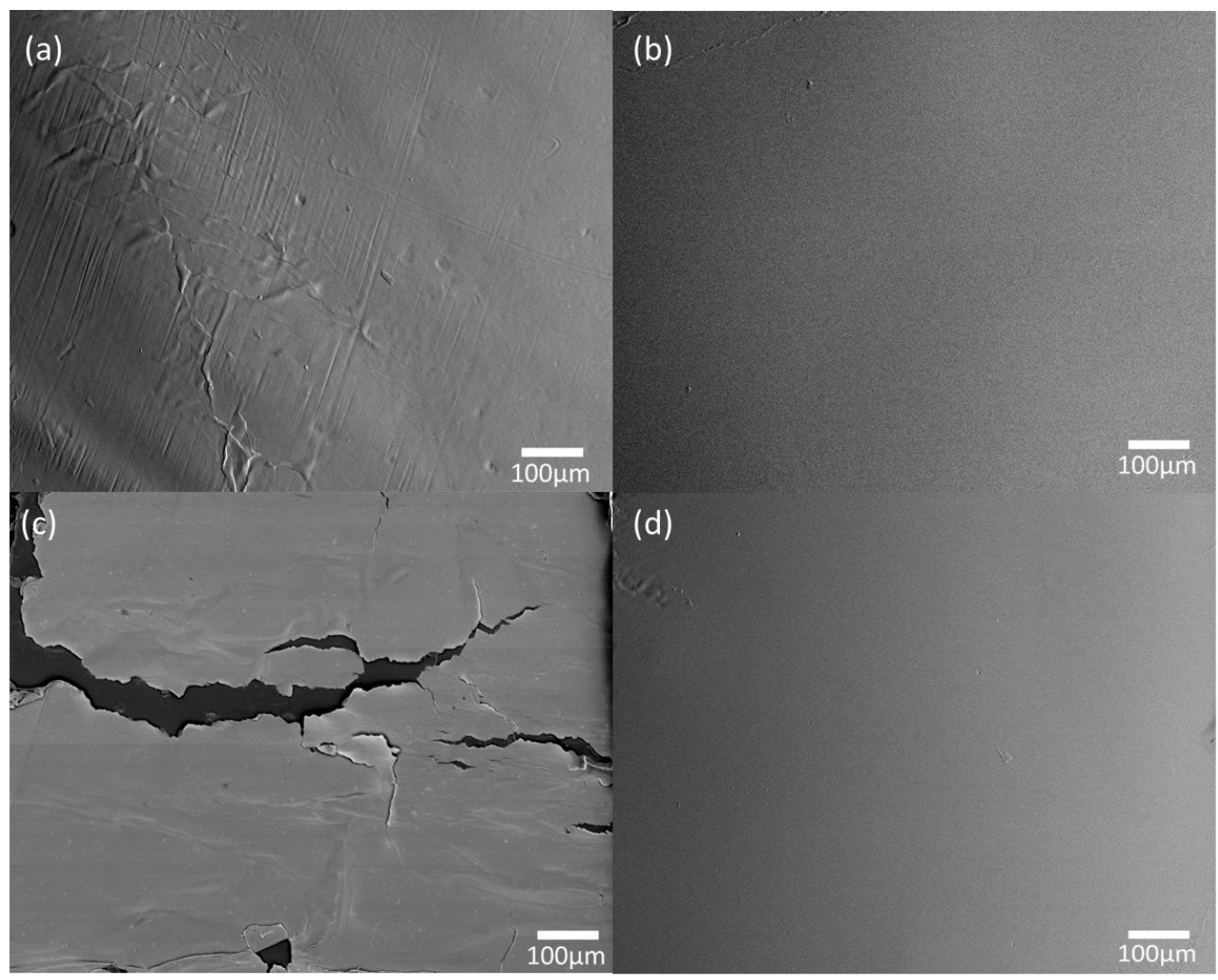

Figure 4.23. SEM images of metallized LCE films: (a) glued Al before heat, (b) E-beam evaporated $\mathrm{Al}$ before heat, (c) glued $\mathrm{Al}$ after heat, and (d) E-beam evaporated $\mathrm{Al}$ after heat.

Antenna 1 is shown in Figure 24(a) and it is $20 \mathrm{~mm}$ by $2 \mathrm{~mm}$ by $51 \mu \mathrm{m}$ thick with $1 \mu \mathrm{m}$ of $\mathrm{Al}$ using the E-beam evaporation. Antenna 2 is shown in Figure 24(b) and it is $20 \mathrm{~mm}$ by $2 \mathrm{~mm}$ by $51.8 \mu \mathrm{m}$ with $1.8 \mu \mathrm{m}$ thick $\mathrm{Al}$ film attached to the LCE substrate using an optical glue. An LPKF ProtoMat S103 was used to make 30mm square ground planes from FR-4 substrate $\left(\varepsilon_{\mathrm{r}}=4\right)$ with copper thickness of $0.035 \mathrm{~mm}$ and $1.5 \mathrm{~mm}$ thick substrate. Both antennas were attached to SMA connectors using Alumina thermal adhesive and the ground planes were attached using super glue. After 25 50 heat cycles, the glued Al LCE antenna began to display cracks and peeling, as shown in Figure 4.25. 


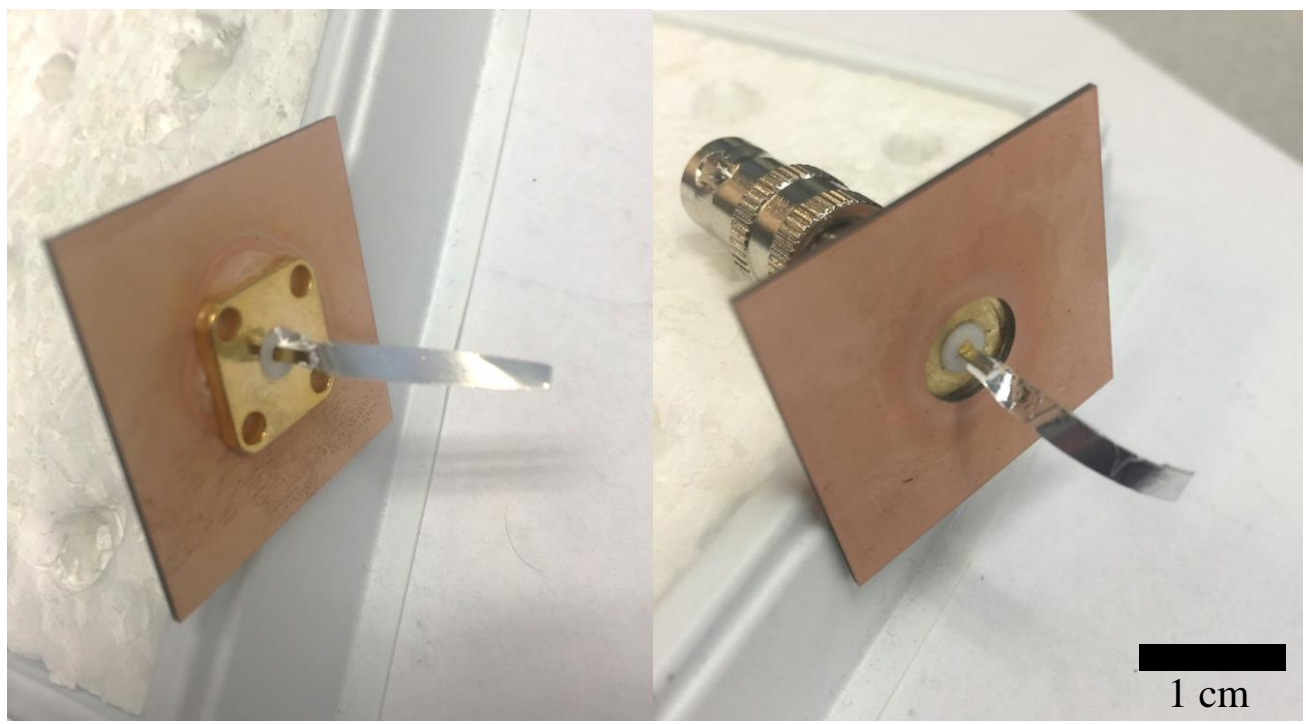

(a)

(b)

Figure 4.24. Two LCE antennas were prepared using two different metallization methods: (a) Antenna 1 used Al attached to the LCE with optical glue, and (b) Antenna 2 used electron beam evaporation.

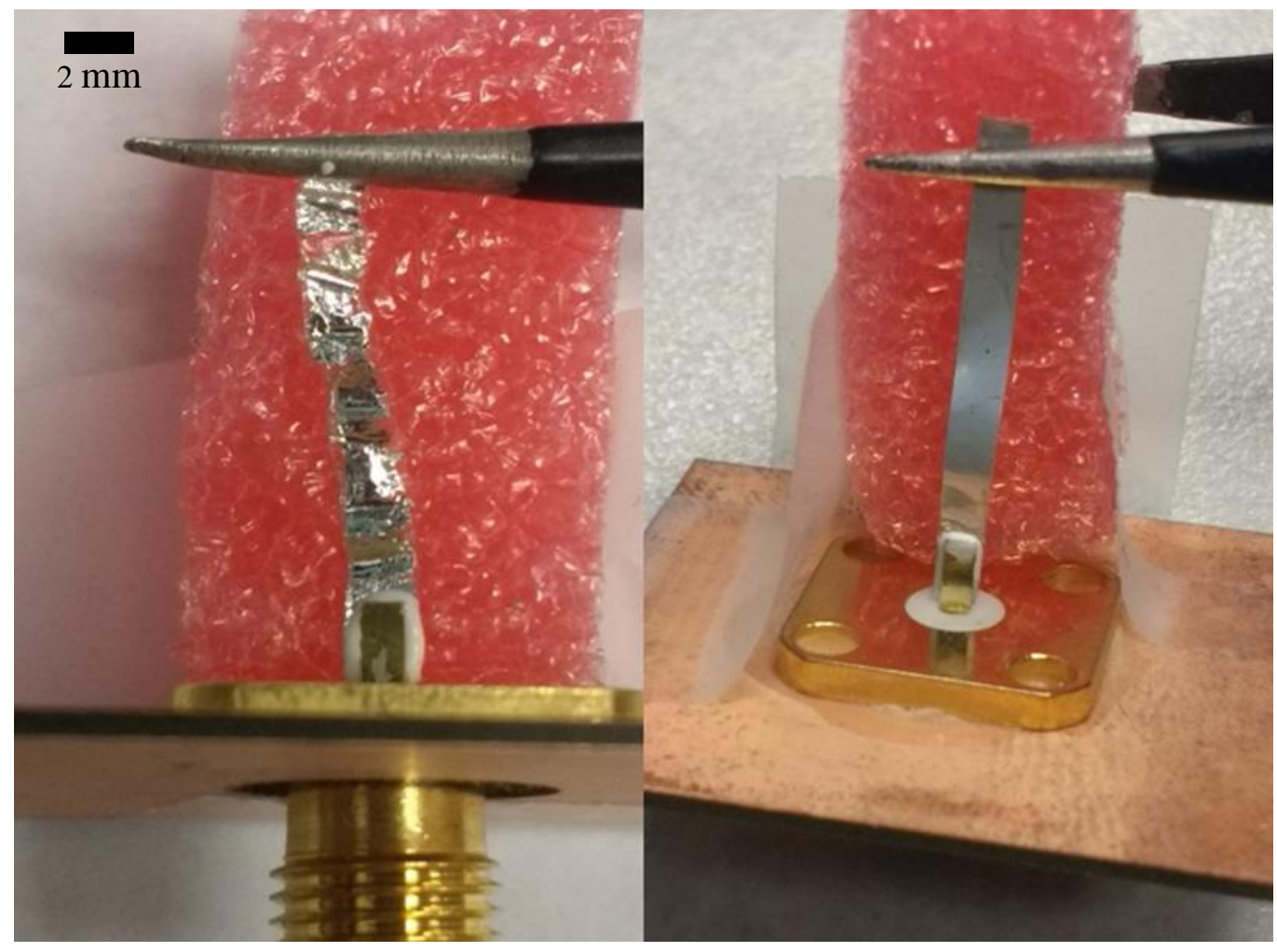

Figure 4.25. Two LCE antennas after 50 heat cycles. 
Atomic Force Microscopy (AFM) images of the glued Al confirmed that the surface roughness of the metallization increased after heating LCEs, as shown in Figure 4.26. Figure 4.27 shows the metallized LCE samples that will be actuated through a different number of heat cycles. These samples were $5 \mathrm{~mm}$ by $2 \mathrm{~mm}$ samples. The SEM micrographs shown in Figure 4.28 illustrate the differences in the metallization of the LCEs with increasing heat cycles $(0,25,50,100$ respectively). These images clearly demonstrate the changes in the surface roughness and increased buckling created on the films as the number of heat cycles increases. Each film comes from the same sample slide and has not been affected with heat cycles previously. Buckling and cracking of glued Al increased at various sites after heating due to the geometrical change of the LCEs.

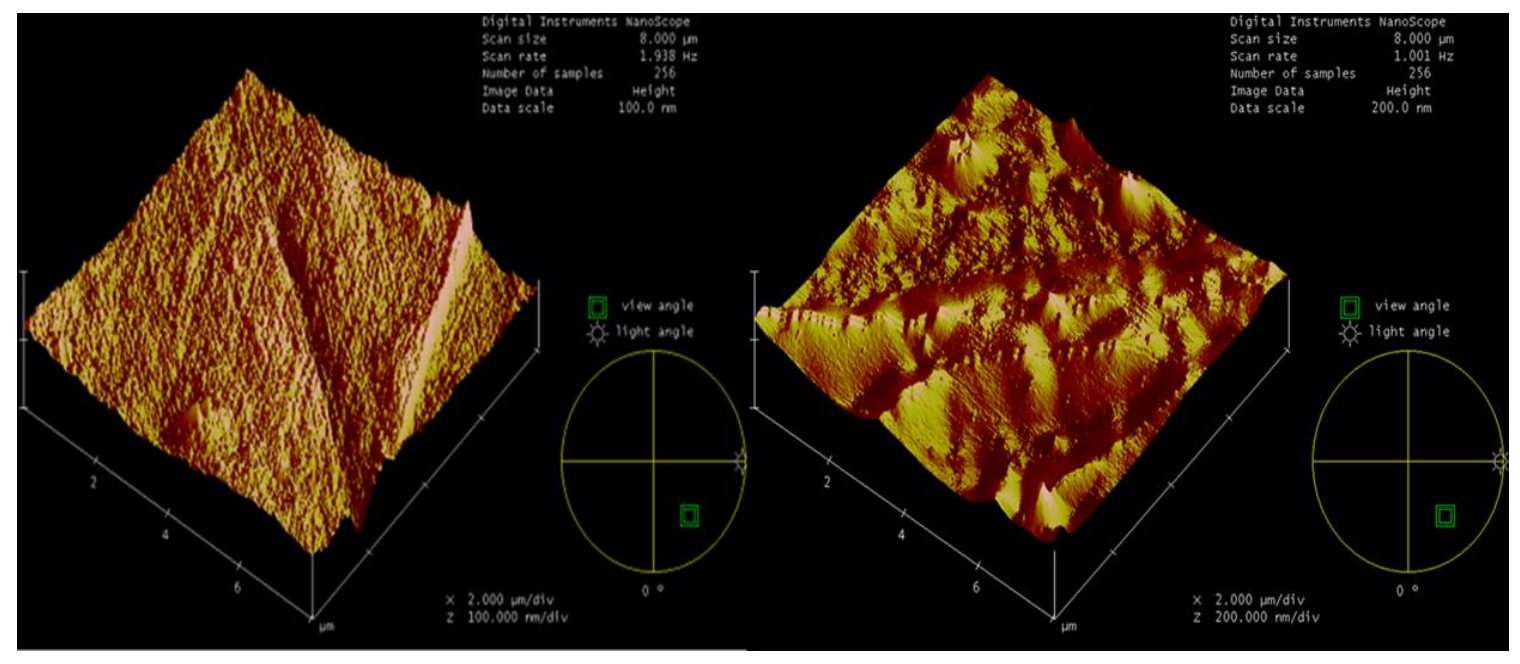

Figure 4.26. AFM images of glued Al before and after 50 heat cycles. 


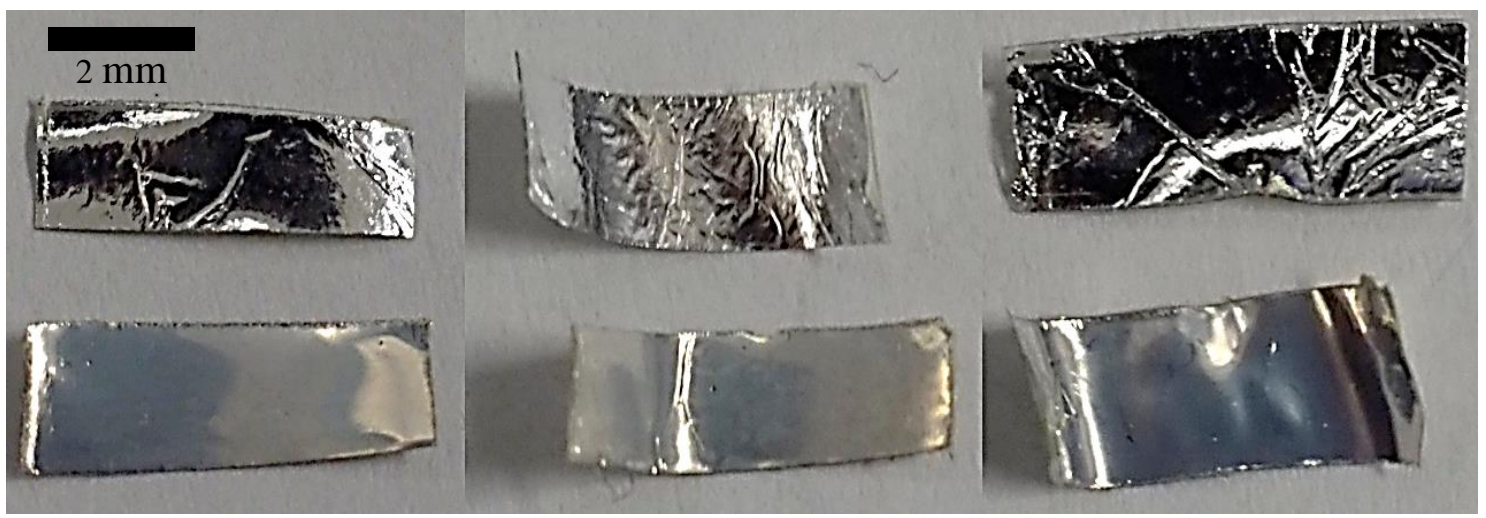

(a)

(b)

(c)

Figure 4.27. Metallized LCE samples that will be actuated through a different number of heat cycles: (a) 25 cycles, (b) 50 cycles, and (c) 100 cycles. 

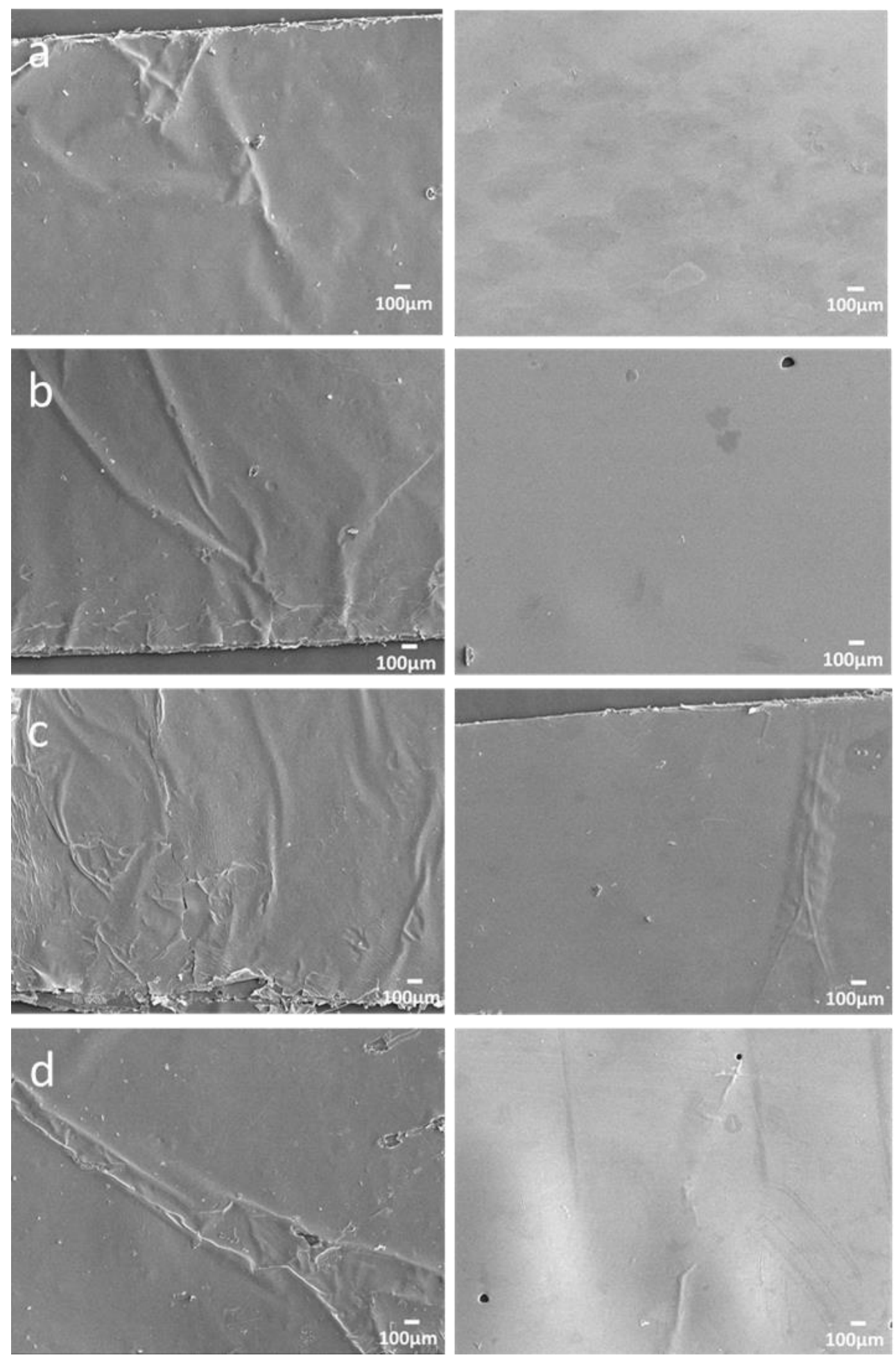

Figure 4.28. SEM images showing Al glued (left side) and evaporated (right side) with (a) no heat, (b) 25 , (c) 50 , and (d) 100 heat $\left(25^{\circ} \mathrm{C}-90^{\circ} \mathrm{C}\right)$ cycles from top to bottom respectively. 


\section{CHAPTER 5}

\section{DUAL-BAND SELF-MORPHING LIQUID CRYSTALLINE ELASTOMER (LCE) ANTENNAS AT DYNAMIC COLD STATES}

In this chapter, two LCE antennas based on cold temperature sensing, which can dynamically self-morph from a monopole to a helical antenna as temperature decreases below room temperature, are presented. The synthesis and preparation of the TN LCE used for the antennas are described in Section 5.1. The results of the LCE antennas reversibly changing frequency in response to temperatures are presented in Section 5.2. In order to design an external stimuli enclosure for cold temperatures for that given range; a cooling bath (Dry Ice/Isopropyl Alcohol) is needed, bringing the temperature down to $-77^{\circ} \mathrm{C}$. The deeper the LCE antenna goes in, the lower the temperature will be as well as increased number of turns. As the temperature decrease, the LCE antennas will change their state on demand from flat to a helical shape with the number of turns increasing.

\subsection{Synthesis and preparation of TN LCES}

TN LCE preparation by photoalignment was performed by adapting a previously described method [26]. Glass slides $(50 \mathrm{~mm} \times 25 \mathrm{~mm} \times 1 \mathrm{~mm})$ were cleaned with acetone, isopropyl alcohol, and deionized water and dried with nitrogen. The cleaned glass slides were exposed to oxygen plasma at $100 \mathrm{mTorr}$ pressure and $50 \mathrm{~mW}$ power for 1 minute by Technics Series 85-RIE. A solution of $1 \%$ brilliant yellow in DMF was filtered through 0.2 $\mu \mathrm{m}$ filter. The dye solution was then spin coated on glass slides at $1500 \mathrm{rpm}$ for 30 seconds. After coating, photoalignment of the dye was achieved by exposing the slides with linearly 
polarized broad-band light at an intensity of $50 \mathrm{~mW} / \mathrm{cm}^{2}$. Then, the cells were constructed by two glass slides with $12.5 \mu \mathrm{m}$ spacers to set film thickness.

The equivalent molar ratio of liquid crystal monomer RM82 and chain extender nbutylamine were mixed with 1.5 wt. \% of photoinitiator I-369, shown Figure 5.1(a). Twisted aligned cells were filled with a monomer mixture with capillary force and stored overnight at $65^{\circ} \mathrm{C}$ for oligomerization. After the oligomerization, the sample was cooled to room temperature and polymerized in the nematic state by $365 \mathrm{~nm}$ UV irradiation (Omnicure ${ }^{\circledR}$ LX400+, Lumen Dynamics) at an intensity of $200 \mathrm{~mW} / \mathrm{cm}^{2}$ for 5 minutes. After the crosslinking, glass cell was opened for metal evaporation, shown in Figure 1(b).

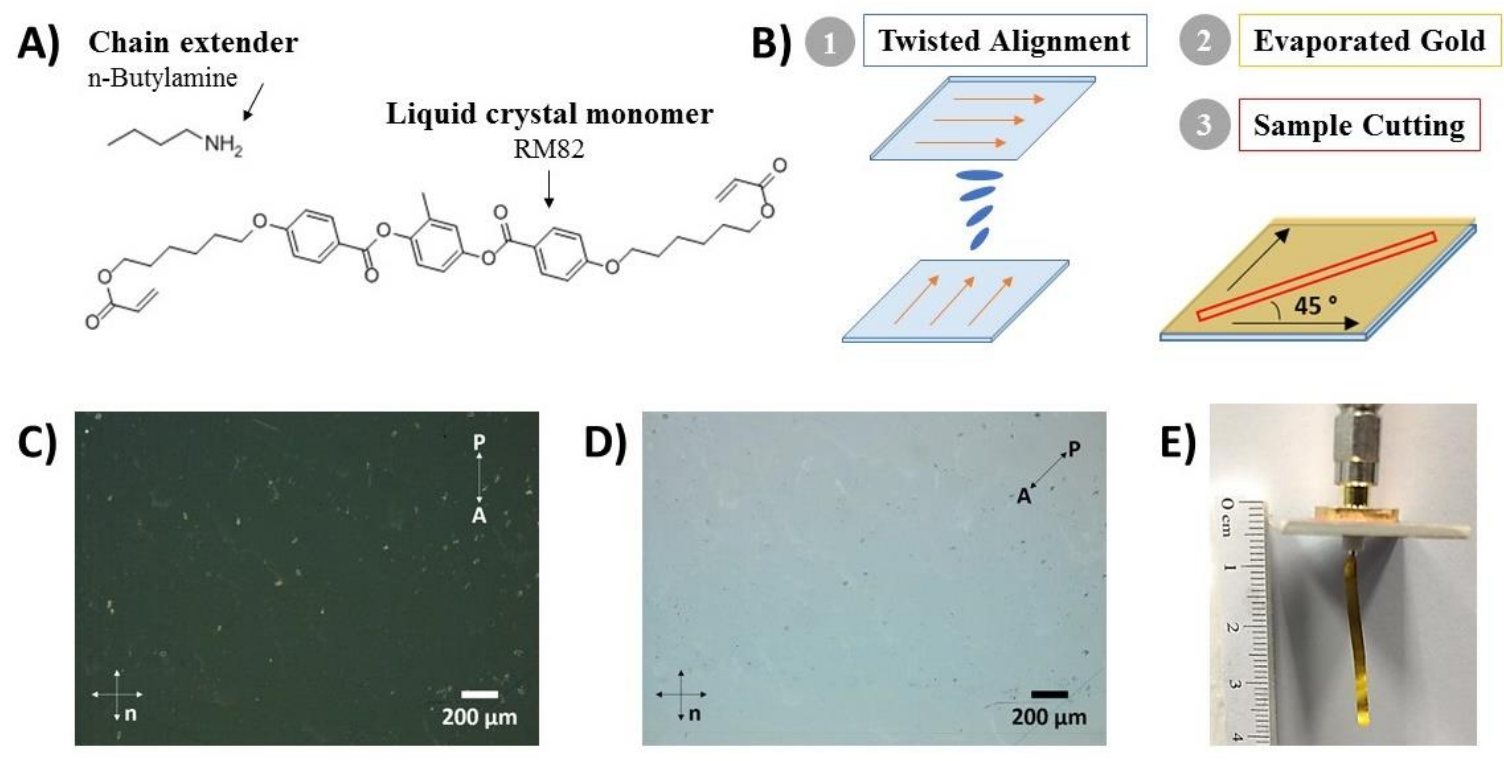

Figure 5.1. (a) RM82 and $n$-butylamine used to synthesize the reactive LCEs and (b) The fabrication process of LCE sample metallized with gold. POM images to confirm twisted alignment: (c) front (d) back. (e) An evaporated Au LCE antenna at room temperature. 
The LCE antenna dimensions are $30 \mathrm{~mm} \times 2 \mathrm{~mm} \times 12.7 \mu \mathrm{m}$, as shown in Figure 1(e). The aspect ratio (i.e., length/width) of the LCE strips had to be large enough $(>10)$ to achieve the needed shape transformations, such as, helices or spirals. The aspect ratio for our film is 15 . The LCE antenna will be used as a sensor by relating the change of its shape to a detectable change in its electrical properties.

The TN LCE film alignment was confirmed by birefringence from polarized optical microscopy (POM) (BX51, Olympus), shown in Figure 5.1(c) and (d). Scanning Electron Microscopy (SEM) was conducted using an SEM, Jeol JSM-7000F/JIB-4500 operated a $12 \mu \mathrm{A}$ current and $15 \mathrm{kV}$ accelerating voltage, shown in Figure 5.3. Samples were of 12.5 $\mu \mathrm{m}$ thick LCE with $200 \mathrm{~nm} \mathrm{Au}$. The the skin depth of the gold metallization is $0.940 \mu \mathrm{m}$ at $7 \mathrm{GHz}$ and it was calculated using the following parameters: $\rho=2.44 \mu \Omega \mathrm{cm}, \mu_{0}=4 \pi \mathrm{x}$ $10^{-7} \mathrm{H} / \mathrm{m}$, and $\mu_{r}=1$ [87]. The two operating frequencies of the LCE antenna at room temperature were $2.7 \mathrm{GHz}$ and $\sim 7 \mathrm{GHz}$. The thickness of the evaporated gold, $t$, is $200 \mathrm{~nm}$, which is $13 \%$ and $21 \%$ of the skin depth, $\delta$, at $2.7 \mathrm{GHz}$ and $\sim 7 \mathrm{GHz}$, respectively. The RF sheet resistance, $R_{s}$, of the $200 \mathrm{~nm}$-thick conductive gold layer is $0.13 \Omega / \mathrm{sq}$ and $0.135 \Omega / \mathrm{sq}$, respectively at $2.7 \mathrm{GHz}$ and $6.95 \mathrm{GHz}$ according to the following

$$
R_{S}=\frac{\rho}{\delta} \frac{1}{1-\exp ^{-t / \delta}}
$$

Equation (2) shows that as the thickness of the gold layer increases the RF sheet resistance decreases, thereby decreasing the RF losses of the antenna. In turn, increased RF losses in the antenna decrease its radiation efficiency; therefore, the metal layer should not be made too thin. However, the thicker the metallization becomes the more difficult the self- 
morphing of the metallized LCE becomes. The metallization should not be chosen too thick as this will restrict the ability of the LCE to change its shape. There is a performance tradeoff in the design of the LCE antennas is controlled by the thickness of the metallization between RF losses and mechanical ability to self-morph. It was observed that LCEs with thinner metallization can change shape more easily, whereas LCEs with thicker metallization exhibit less RF resistive losses. The two probe resistance measurements were performed using Keithley 4200-SCS to obtain an I-V curve with a voltage sweep from -1V to $1 \mathrm{~V}$ and a sweep step of $0.01 \mathrm{~V}$. The resistance is calculated as the gradient (change in voltage divided by the change in current) of the I-V curve. All samples were $5 \mathrm{~mm}$ by $2 \mathrm{~mm}$, measured at room temperature in ambient air and probed at the same distance. The $5 \mathrm{~mm}$ by $2 \mathrm{~mm} \mathrm{Au}$ film resistance measurements after 50 cold cycles was $4.4 \Omega$.

The AR70-38 [88] regulation is concerned primarily with the mechanical operation or functioning of materiel under the extremes of climate to which it is likely to be exposed. Climatic design types. Four climatic design types are differentiated on the basis of worldwide temperature regimes. They are- (1) Hot climatic design type. (2) Basic climatic design type. (3) Cold climatic design type. (4) Severe cold climatic design type The areas designated as cold, and severe cold, primarily northern North America, Greenland, northern Asia, and the Tibetan Highlands of China, were delimited because of the occurrence of low temperatures. In the area of the cold design type, temperature during the coldest month in a normal year may be colder than the basic cold extreme of $-32^{\circ} \mathrm{C}$. In the severe cold areas, the temperature during the coldest month in a normal year may be colder than the cold extreme of $-46^{\circ} \mathrm{C}$, but colder than $-51^{\circ} \mathrm{C}$ no more than 20 percent of 
the hours in the coldest month in the coldest part of the area (northern Siberia where absolute minimum temperatures are lower than $-65^{\circ} \mathrm{C}$ ).

The LCE antennas were immersed and measured at temperatures below $0^{\circ} \mathrm{C}$. The apparatus and procedure used were in accordance with the standards: AR70-38 [88], MILSTD-883E [89], and MIL-STD-810F [90]. The apparatus used for the severe cold environmental test consist of a large temperature controlled flask of cold bath filled with dry ice and isopropyl alcohol (IPA). The temperature of the cold bath was set to $-77^{\circ} \mathrm{C}$. A thermocouple was used to measure the bath temperature and additional fresh, dry ice was added to the bath periodically, to maintain a constant temperature, $-77^{\circ} \mathrm{C}$. The antennas were subjected to the cold condition and ambient temperature for at least 10 cycles, with a transfer time of $10 \mathrm{~s}$ and a dwell time of 2 min according to [89]. Figure 5.2 shows the cooling bath's temperature regions. The coldest temperature at which this LCE antenna is measured at is $-65^{\circ} \mathrm{C}$. This specific test temperature was determined according to [90] Method 502.4, based on the worldwide areas in which the material will be used with extended storage periods. If material is to be stored for extended periods (years) without shelter or protection in areas that experience very low temperatures such as the "cold pole" of northeast Siberia or central Greenland, there is an increased chance that the material may experience much lower temperatures (approaching $-65^{\circ} \mathrm{C}$ ). The LCE antenna needs to be able to function in such prolonged exposure to the extreme low temperatures. 

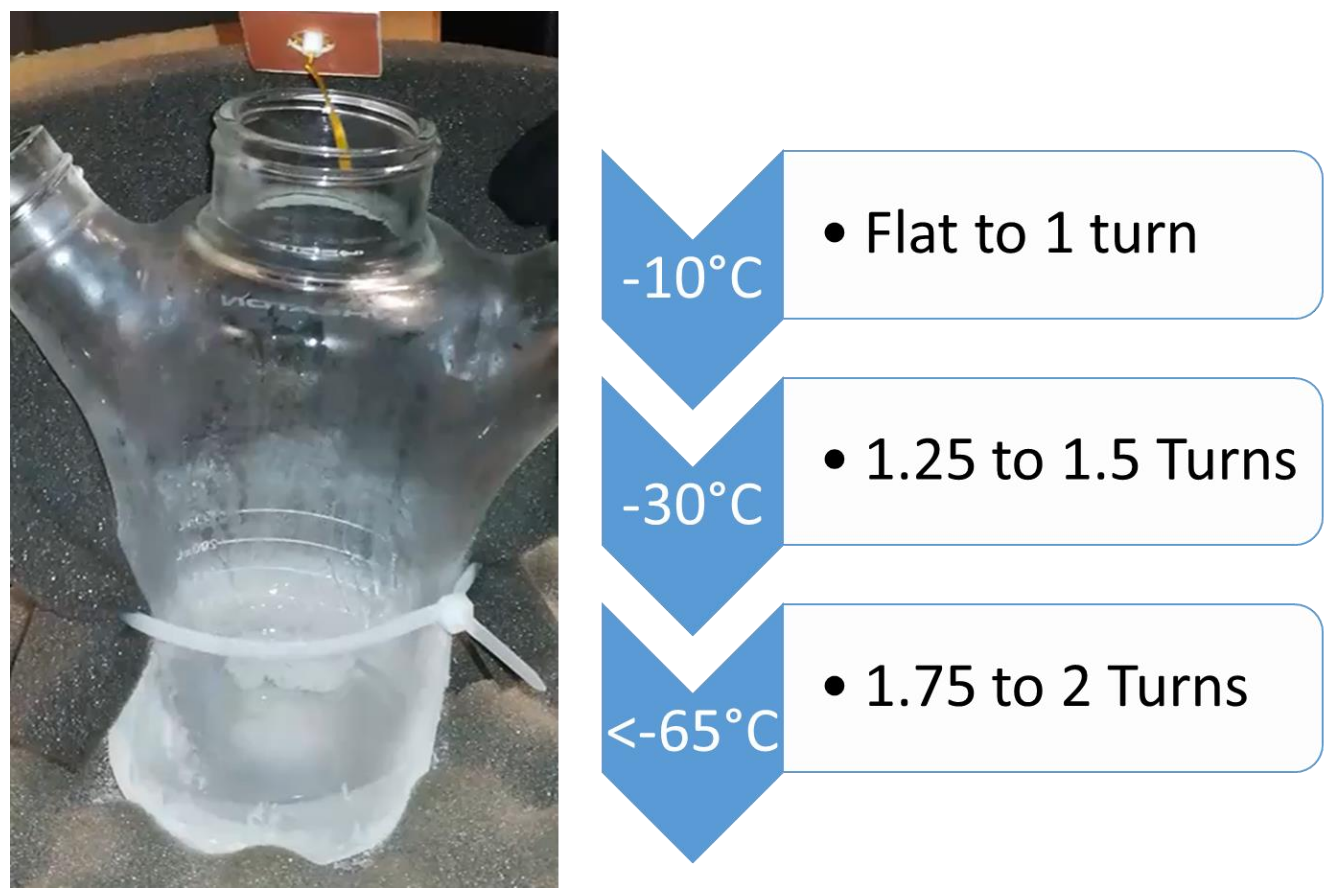

Figure 5.2. The cooling bath's temperature regions

\subsection{Results and Discussion}

Two LCE antennas were fabricated and evaluated through measurements for their mechanical, thermal, and EM performance. Figure 5.3 depicts SEM micrographs of evaporated Au LCE film. The results show the roughness of the film formed by E-Beam evaporation. The metallized surface morphology of the films showed buckling at x1000 magnification due to stretching of the LCE when lifting/handling, as shown in, Figure 5.3(a). This LCE deformation causes the Au film to contract, producing visible cracks in the film, Figure 5.3(b). The shape of helical LCE with one turn shown in Figure5.3(c) and top view of the diameter, Figure 5.3(d), where the Au film is on the inside of the helical. 

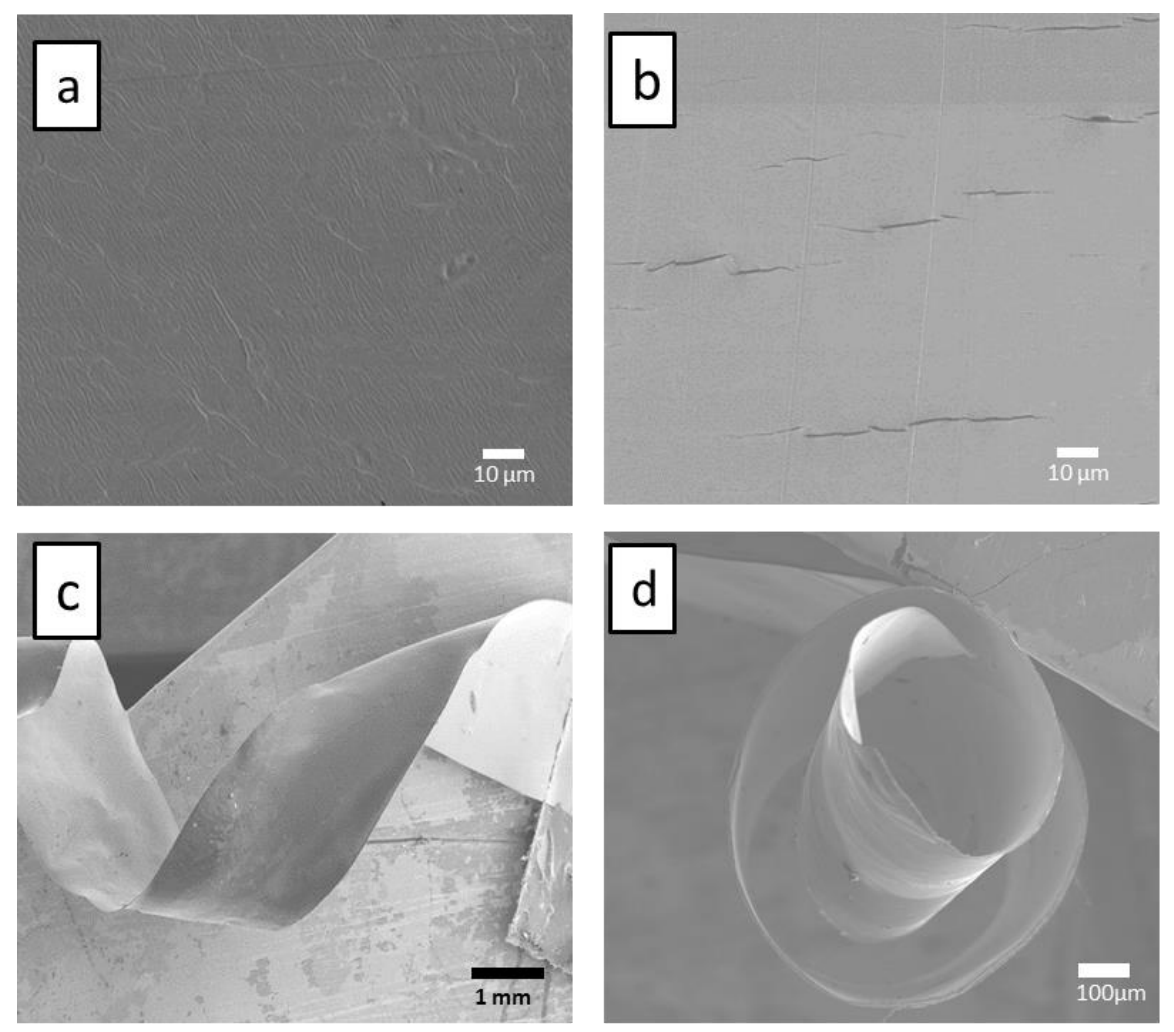

Figure 5.3. SEM micrographs of: (a) evaporated Au LCE film after lift-off; (b) evaporated Au LCE film after 50 cycles; (c) evaporated Au LCE helical at one turn; and (d) top view of evaporated Au LCE film.

Figure 5.4 and 5.6 show verification of the LCE antennas changing inside the cooling bath flask in response to the temperature lowering. As the LCE antenna is lowered into the flask, the temperature decreases, which changes the shape of the antenna from flat to a helical shape. It is important to note that as the temperature decreases the number of turns of the helix formed by the LCE increases. The RF tunability of the self-twisting LCE antenna was investigated and showed that the reflection coefficient, $S_{11}$, was measured using a vector network analyzer while the temperature became colder simultaneously. This indicates the novelty of the reversible tunability of the LCE antennas with temperature. The mechanical deformation of our LCE antennas is caused by the mechanical response of the LCE substrate to different temperatures. 
The reflection coefficient was measured using an E5071C ENA Series Network Analyzer to identify the resonant frequency, $S_{11}$, (i.e., the frequency where the antenna exhibits best match to $50 \Omega$ ). Figure 5.5 and 5.7 reflection coefficient of the LCE antenna 1 and 2, respectively, for different number of helical turns corresponding to different temperatures. Specifically, the LCE antenna with zero, one and two turns correspond to room temperature $\left(25^{\circ} \mathrm{C}\right),-30^{\circ} \mathrm{C}$ and $-65^{\circ} \mathrm{C}$, respectively. Both figures illustrate that in the frequency range between 1-10 GHz the LCE antennas have two operating frequency bands, which are summarized in both Tables 5.1 and 5.2. The bandwidth is defined as the frequencies where $S_{11} \leq-10 \mathrm{~dB}$ and the $S_{11}$ is shown at the center frequency. It should be noted that at room temperature $\left(25^{\circ} \mathrm{C}\right)$ the LCE antenna has 0 turns and performs as a monopole antenna. Whereas, when the antenna is cooled, it forms a 3D helical antenna. Also, the operating frequency of the antennas increases as the temperature decreases (i.e., number of helical turns increases). This frequency shift occurs because as the number of LCE antenna turns increases, this changes its current distribution and location of these currents in space, which in turn changes its input impedance, reflection coefficient and operating frequency. It is this frequency shift that can be used to detect different temperature by using a transmitter that sends an interrogating signal to the LCE antenna to determine its the operating frequency. By knowing the operating frequency, then we can infer the temperature. Specifically, when the interrogating transmitter determines that the frequency of operation of the LCE antenna is $2.7 \mathrm{GHz}, 2.96 \mathrm{GHz}$ or $3.3 \mathrm{GHz}$ then the inferred sensed temperature will be $25^{\circ} \mathrm{C},-10^{\circ} \mathrm{C}$ or $-65^{\circ} \mathrm{C}$, respectively (according to Table 5.1 and 5.2). 
Figure 5.8 shows the measured reflection coefficient at room temperature after the LCE antenna has been actuated through a different number of temperature cycles (each cycle takes the antenna from $25^{\circ} \mathrm{C}$ to $-65^{\circ} \mathrm{C}$ and back to $25^{\circ} \mathrm{C}$. Figure 4 (b) illustrates that the LCE antenna after 100 cycles exhibits approximately the same resonant frequency in both bands of operation, which robustness of this design.

A)

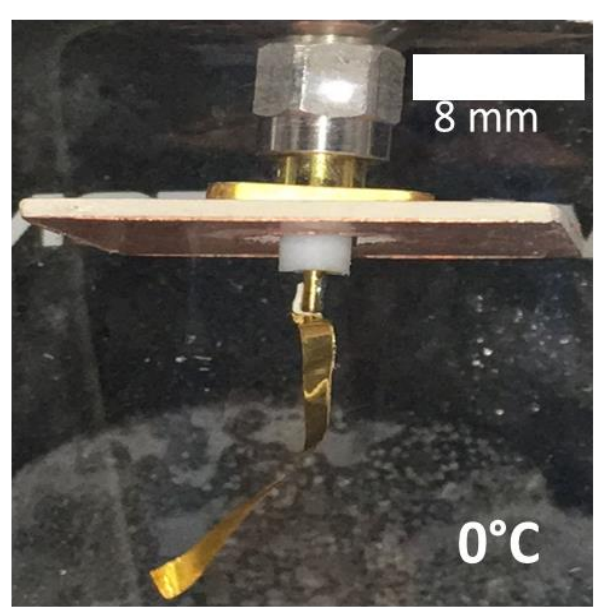

C)

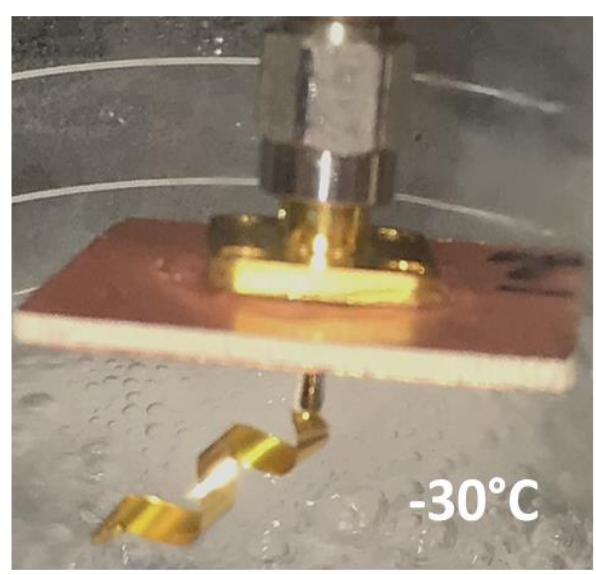

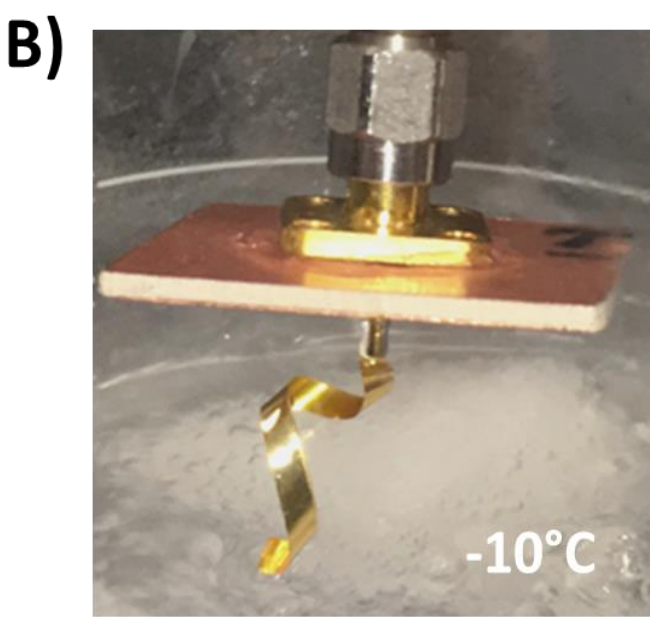

D)

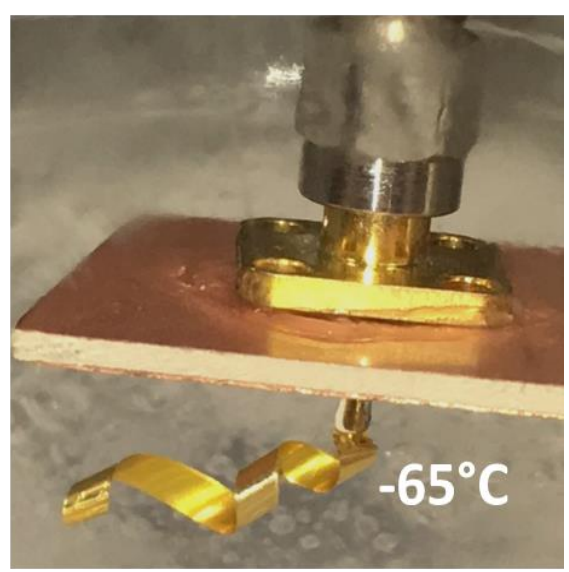

Figure 5.4. Au LCE antenna 1's number of turns increase as the temperature decrease. 


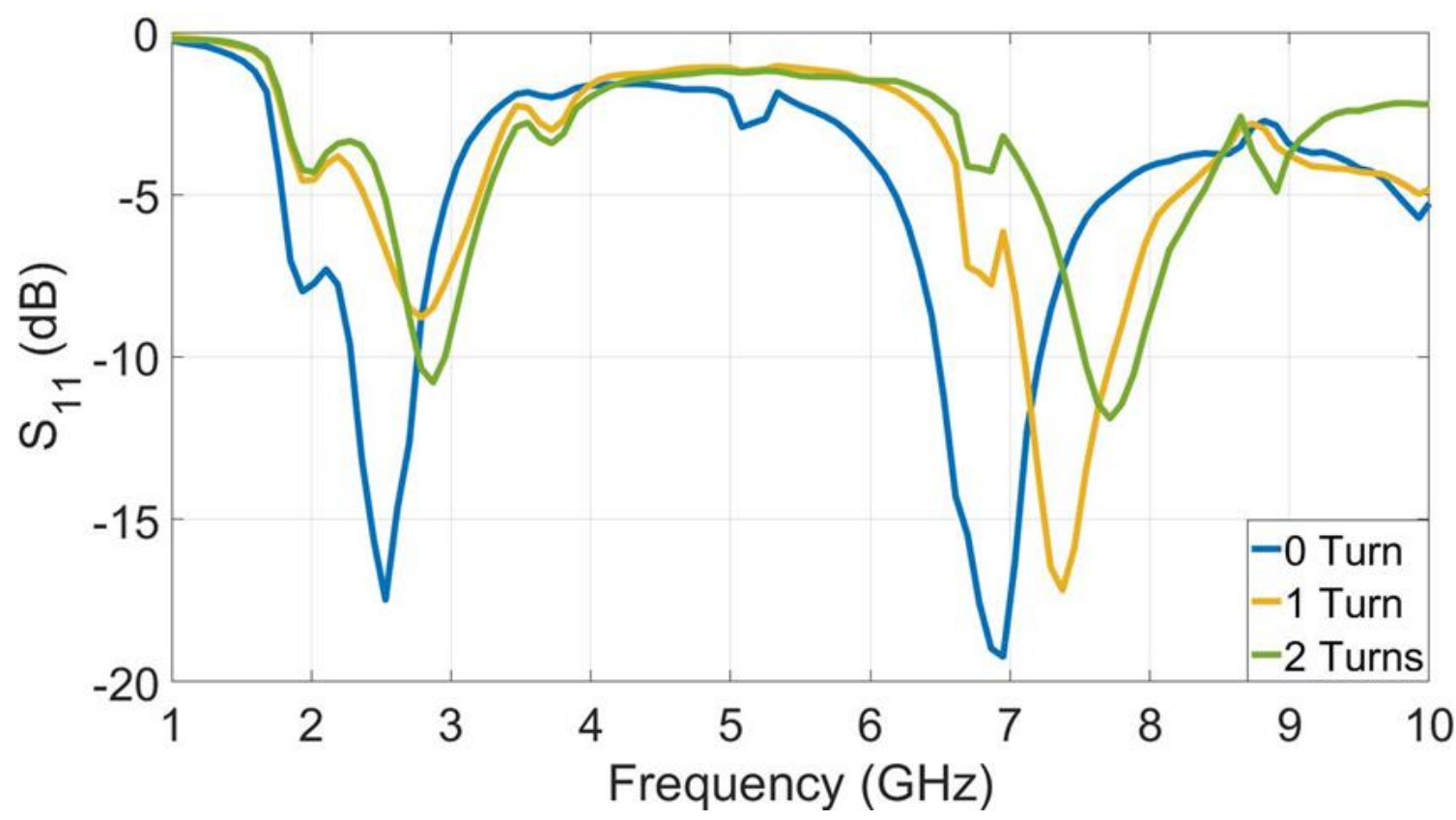

Figure 5.5. Measured reflection coefficient $\left(\mathrm{S}_{11}\right)$ of the Au LCE antenna 1 as the number of turns increased as temperature decreases.

Table 5.1. Measured Resonant Frequency and Bandwidth of Dual-band Au LCE Antenna 1 at Each Number of Turns in Response to Temperature.

\begin{tabular}{|c|c|c|c|c|c|c|c|}
\multicolumn{2}{|c|}{ LCE Antenna } & \multicolumn{3}{c|}{ Band 1 } & \multicolumn{3}{c|}{ Band 2 } \\
\hline \# of turns & $\begin{array}{c}\text { Temp } \\
\left({ }^{\circ} \mathrm{C}\right)\end{array}$ & $\begin{array}{c}\text { Frequency } \\
(\mathrm{GHz})\end{array}$ & $\begin{array}{c}\text { S11 } \\
(\mathrm{dB})\end{array}$ & $\begin{array}{c}\text { BW10dB } \\
(\mathrm{MHz})\end{array}$ & $\begin{array}{c}\text { Frequency } \\
(\mathrm{GHz})\end{array}$ & $\begin{array}{c}\text { S11 } \\
(\mathrm{dB})\end{array}$ & $\begin{array}{c}\text { BW10dB } \\
(\mathrm{MHz})\end{array}$ \\
\hline 0 Turn & 25 & 2.53 & -17.5 & 420 & 6.95 & -19.2 & 710 \\
\hline 1 Turn & -10 & 2.78 & -8.8 & - & 7.38 & -17.2 & 600 \\
\hline 2 Turns & -65 & 2.87 & -10.8 & 200 & 7.72 & -11.9 & 360 \\
\hline
\end{tabular}


A)

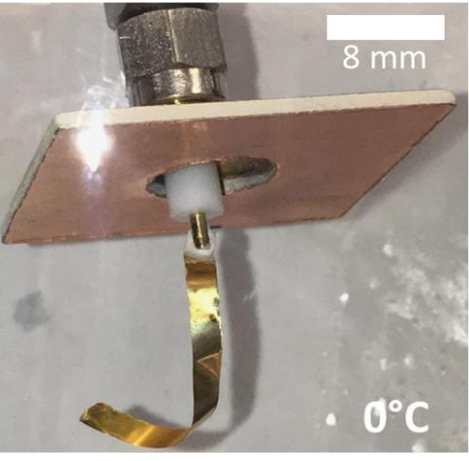

C)

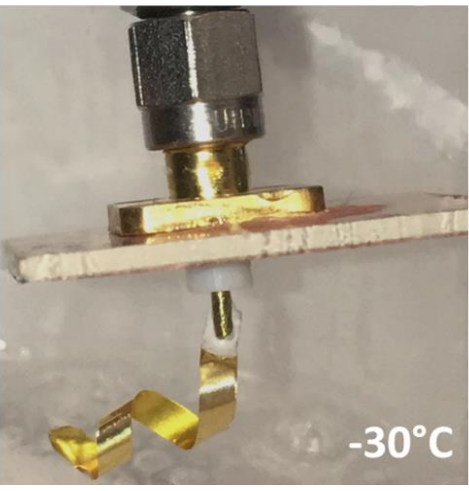

B)

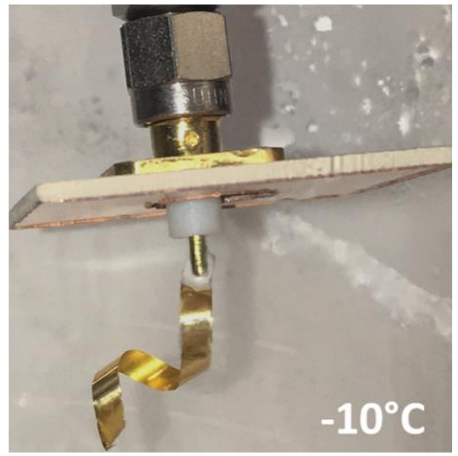

D)

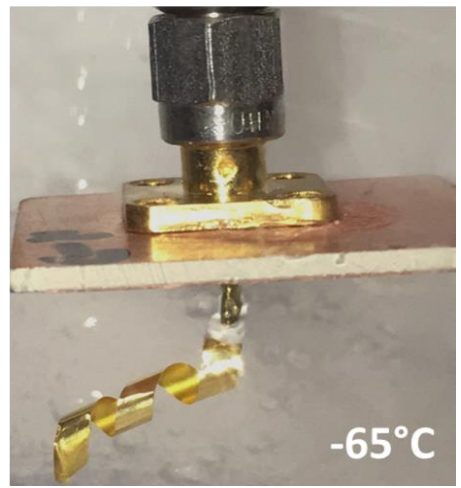

Figure 5.6. Au LCE antenna 2's number of turns increase as the temperature decrease.

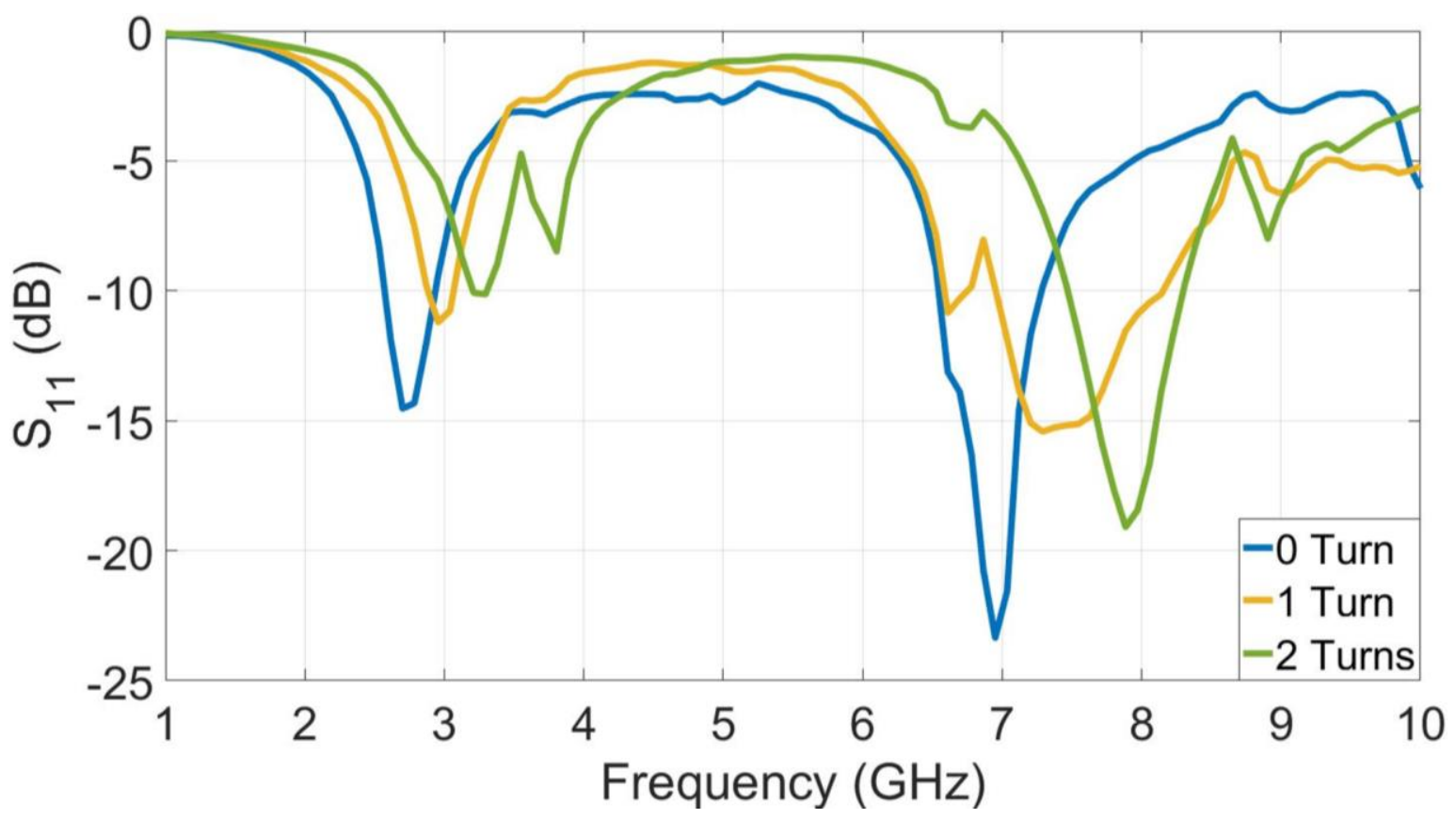

Figure 5.7. Measured reflection coefficient $\left(\mathrm{S}_{11}\right)$ of the Au LCE antenna 2 as the number of turns increased as temperature decreases. 
Table 5.2. Measured Resonant Frequency and Bandwidth of Dual-band Au LCE Antenna 2 at Each Number of Turns in Response to Temperature.

\begin{tabular}{|c|c|c|c|c|c|c|c|}
\multicolumn{2}{|c|}{ LCE Antenna } & \multicolumn{3}{|c|}{ Band 1 } & \multicolumn{3}{c|}{ Band 2 } \\
\hline \# of turns & $\begin{array}{c}\text { Temp } \\
\left({ }^{\circ} \mathrm{C}\right)\end{array}$ & $\begin{array}{c}\text { Frequency } \\
(\mathrm{GHz})\end{array}$ & $\begin{array}{c}\text { S11 } \\
(\mathrm{dB})\end{array}$ & $\begin{array}{c}\text { BW10dB } \\
(\mathrm{MHz})\end{array}$ & $\begin{array}{c}\text { Frequency } \\
(\mathrm{GHz})\end{array}$ & $\begin{array}{c}\text { S11 } \\
(\mathrm{dB})\end{array}$ & $\begin{array}{c}\text { BW10dB } \\
(\mathrm{MHz})\end{array}$ \\
\hline 0 Turn & 25 & 2.7 & -14.5 & 370 & 6.95 & -23.3 & 750 \\
\hline 1 Turn & -10 & 2.96 & -11.2 & 180 & 7.29 & -15.4 & 1190 \\
\hline 2 Turns & -65 & 3.3 & -10.1 & 10 & 7.89 & -19.1 & 850 \\
\hline
\end{tabular}

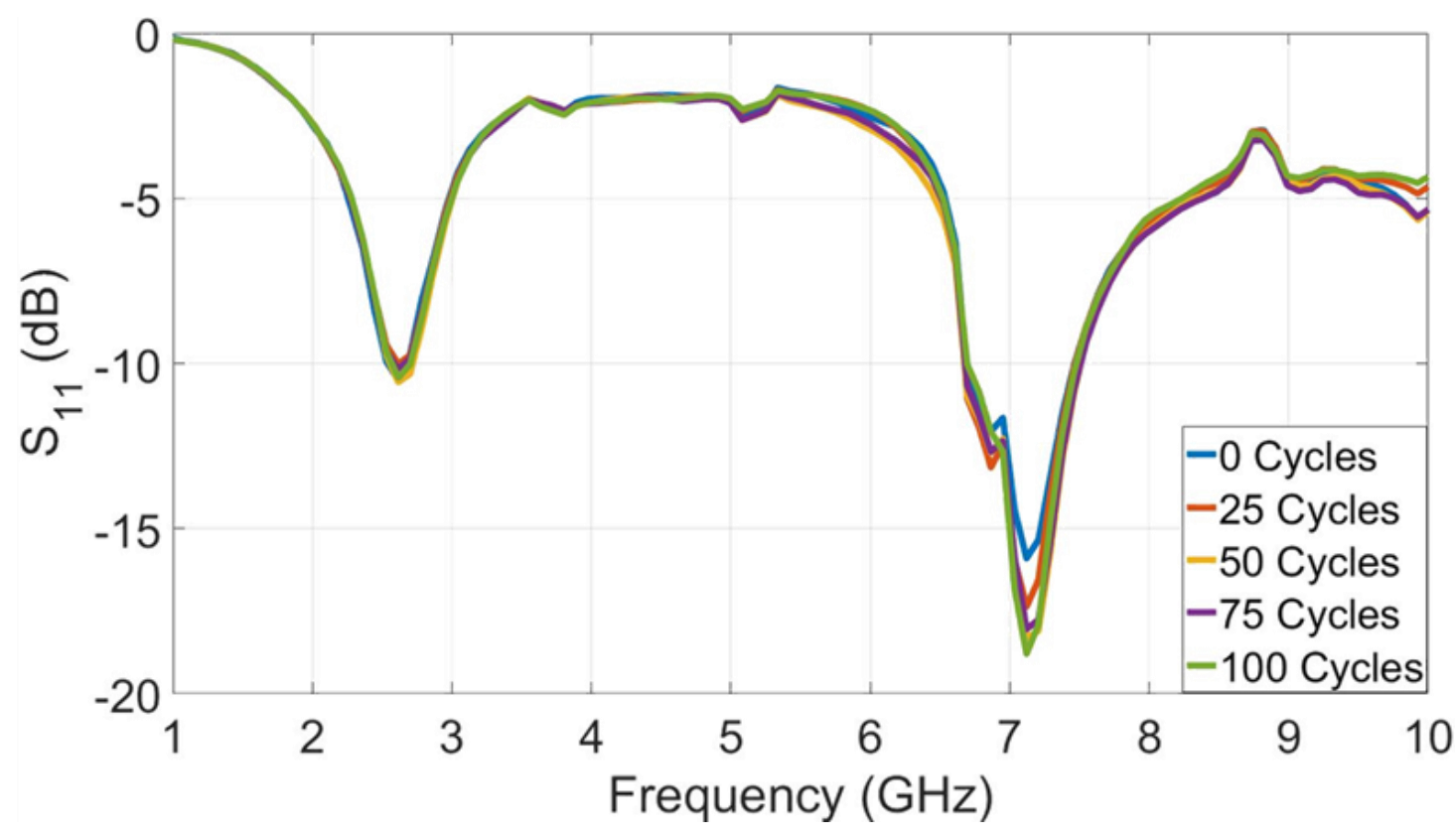

Figure 5.8. Measured frequency response of the reflection coefficient $\left(S_{11}\right)$ after the $\mathrm{Au}$ LCE antenna has been reversibly actuated through cold temperatures from 0 to 100 cycles. 
This chapter discusses two reversible self-morphing novel LCE antennas that can dynamically change the electromagnetic performance in response to cold temperatures. These types of antennas are well suited for passive sensing of temperatures. Specifically, these LCE antenna sensors changes its shape from straight to helical as the temperature decreases from room temperature to cold temperatures thereby shifting their frequency of operation. These antennas are ideal to detect temperature that has reached a certain threshold. These antennas have an advantage over previous designs and it is due to the advanced shape-programmable LCEs that are temperature responsive. There are many metallization techniques available, however the limitations of metalizing the temperature sensitive LCEs must be considered. The LCE antennas were able to obtain temperatures as low as $-77^{\circ} \mathrm{C}$ using a dry ice/IPA cooling bath. 


\section{CHAPTER 6}

\section{CONCLUSION AND FUTURE WORK}

\subsection{Conclusions}

This dissertation discussed the design of reversibly self-morphing novel LCE antennas that can dynamically change electromagnetic performance in response to temperature. Design and manufacturing processes of reconfigurable antennas on LCE polymer substrates were demonstrated for the first time.

In Chapter 3, the pattern and frequency reconfigurable antennas based on shapemorphing LCEs were presented in a fixed (static) state [76]. The pattern-reconfigurable antenna can reshape itself at different temperatures to radiate: (1) omnidirectionally when it is straight, and (2) directionally when it is coiled into a helix due to heating. On the other hand, the frequency-reconfigurable antenna can change its number of turns at varying temperatures to radiate directionally at different frequencies. Although, the results clearly demonstrated the reconfigurability, due to the external stimulus equipment limitations, only fixed states of the antennas were examined. Chapter 4 improved upon previous measurement limitations, by optimizing the design of external stimulus to allow dynamic shape change in response to temperature. The goal was to control the temperature in an enclosed area around the LCE antenna so that the antenna reversibly freely changes its shape. Also, this setup needed to allow simultaneous radiation pattern measurements inside the anechoic chamber without having to fix the geometry of the antenna to a static state. Different types of measurement setups were developed, each one addressing a problem from the previous one (i.e., decreasing metal interference, increasing the temperature time 
allowed for measurements, avoiding larger LCE antennas from shorting out due to gravity. Also, two different metallization schemes for LCE materials were characterized. Finally, two reversible self-morphing novel LCE antennas that can dynamically change the electromagnetic performance in response to cold temperatures were developed.

LCE materials can have significant impact on sensing applications due to their selfactuation, which is reversible and can happen multiple times. This research is expected to contribute to future advances in morphing electronics, including sensors, passive antennas, arrays, and frequency selective surfaces (FSS).

\subsection{Future Work}

The future work of this research is to develop LCE materials for potential use for RFID applications. Different design approaches will be used, namely: 1) the RFID antenna will be totally constructed using metallized LCEs, 2) the RFID antenna will be constructed partly using LCEs and partly using traditional antenna materials (i.e., metalized PCBs, RFID tags), and 3) the RFID antenna will be constructed using a standard RFID antenna (dipole) and parasitic LCE elements that will tune the antenna at different frequencies at different temperatures. 


\section{REFERENCES}

[1] S.J. Mazlouman, A. Mahanfar, C. Menon and R.G. Vaughan, "Reconfigurable AxialMode Helix Antennas Using Shape Memory Alloys," Tap, vol. 59, pp. 1070-1077, 2011.

[2] J. Kowalewski, T. Mahler, L. Reichardt and T. Zwick, "Shape Memory Alloy (SMA)Based Pattern-Reconfigurable Antenna," IEEE Antennas and Wireless Propagation Letters, vol. 12, pp. 1598, 2013.

[3] J. Kiriazi, H. Ghali, H. Ragaie and H. Haddara, "Reconfigurable dual-band dipole antenna on silicon using series MEMS switches," pp. 406 vol.1, 2003.

[4] H. Inan, M. Poyraz, F. Inci, M.A. Lifson, M. Baday, B.T. Cunningham and U. Demirci, "Photonic crystals: emerging biosensors and their promise for point-of-care applications," Chem. Soc. Rev, vol. 46, pp. 366-388, Jan 23,. 2017.

[5] H. Subbaraman, D.T. Pham, X. Xu, M.Y. Chen, A. Hosseini, X. Lu and R.T. Chen, "Inkjet-Printed Two-Dimensional Phased-Array Antenna on a Flexible Substrate," Lawp, vol. 12, pp. 170-173, 2013.

[6] M. Kubo, X. Li, C. Kim, M. Hashimoto, B.J. Wiley, D. Ham and G.M. Whitesides, "Stretchable microfluidic radiofrequency antennas," Advanced Materials (Deerfield Beach, Fla.), vol. 22, pp. 2749-2752, Jul 6, 2010.

[7] C. Yu, Z. Duan, P. Yuan, Y. Li, Y. Su, X. Zhang, Y. Pan, L.L. Dai, R.G. Nuzzo, Y. Huang, H. Jiang and J.A. Rogers, "Electronically Programmable, Reversible Shape Change 
in Two- and Three- Dimensional Hydrogel Structures (Adv. Mater. 11/2013)," Advanced Materials, vol. 25, pp. 1540, Mar 20,. 2013.

[8] T. Ware, D. Simon, D.E. Arreaga-Salas, J. Reeder, R. Rennaker, E.W. Keefer and W. Voit, "Fabrication of Responsive, Softening Neural Interfaces," Advanced Functional Materials, vol. 22, pp. 3470-3479, Aug 21,. 2012.

[9] M.D. Dickey, R.C. Chiechi, R.J. Larsen, E.A. Weiss, D.A. Weitz and G.M. Whitesides, "Eutectic Gallium-Indium (EGaIn): A Liquid Metal Alloy for the Formation of Stable Structures in Microchannels at Room Temperature," Advanced Functional Materials, vol. 18, pp. 1097-1104, 2008.

[10] P.T. Mather, X. Luo and I.A. Rousseau, "Shape Memory Polymer Research," Annual Review of Materials Research, vol. 39, pp. 445-471, Aug 4,. 2009.

[11] C. Ohm, M. Brehmer and R. Zentel, "Liquid crystalline elastomers as actuators and sensors," Advanced Materials (Deerfield Beach, Fla.), vol. 22, pp. 3366-3387, Aug 17,. 2010.

[12] M. Warner and E.M. Terentjev, Liquid Crystal Elastomers, OUP Oxford, 2003, .

[13] T.A. Tervoort, P. Smith, N. Stutzmann and K. Bastiaansen, "Patterning of polymersupported metal films by microcutting," Nature, vol. 407, pp. 613, 2000. 
[14] V. Svorcik, J. Zehentner, V. Rybka, P. Slepicka and V. Hnatowicz, "Characterization of thin gold layers on polyethyleneterephthalate: transition from discontinuous to continuous, homogenous layer," Appl.Phys.A, vol. 75, pp. 541, 2002.

[15] O.K. Oyewole, D. Yu, J. Du, J. Asare, D.O. Oyewole, V.C. Anye, A. Fashina, M.G. Zebaze Kana and W.O. Soboyejo, "Micro-wrinkling and delamination-induced buckling of stretchable electronic structures," Journal of Applied Physics, vol. 117, pp. 235501, Jun $21, .2015$.

[16] M.J. Cordill and A.A. Taylor, "Thickness effect on the fracture and delamination of titanium films," Thin Solid Films, vol. 589, pp. 209, 2015.

[17] J. Siegel and V. Kotál, "Preparation of Thin Metal Layers on Polymers," Acta Polytechnica, vol. 47, Jan 1,. 2007.

[18] C.P. Barker, K.-. Kochem, K.M. Revell, R.S.A. Kelly and J.P.S. Badyal, "The interfacial chemistry of metallized, oxide coated, and nanocomposite coated polymer films," Thin Solid Films, vol. 257, pp. 77-82, February 15,. 1995.

[19] T. Defraeye, P. Cronjé, T. Berry, U.L. Opara, A. East, M. Hertog, P. Verboven and B. Nicolai, "Towards integrated performance evaluation of future packaging for fresh produce in the cold chain," Trends Food Sci.Technol., vol. 44, pp. 201, 2015.

[20] R. Bhattacharyya, C. Floerkemeier and S. Sarma, "RFID tag antenna based temperature sensing," pp. 8-15, 2010. 
[21] T.J. White and D.D. Broer, "Programmable and adaptive mechanics with liquid crystal polymer networks and elastomers," Nature Materials, vol. 14, pp. 1087-1098, 2015.

[22] Anonymous "ANSYS HFSS: High Frequency Electromagnetic Field Simulation," vol. 2018, .

[23] R.L. Haupt and M. Lanagan, "Reconfigurable Antennas," Ap-M, vol. 55, pp. 49-61, 2013.

[24] C.G. Christodoulou, Y. Tawk, S.A. Lane and S.R. Erwin, "Reconfigurable Antennas for Wireless and Space Applications," Proc IEEE, vol. 100, pp. 2250, 2012.

[25] N. Haider, D. Caratelli and A.G. Yarovoy, "Recent Developments in Reconfigurable and Multiband Antenna Technology." International Journal of Antennas and Propagation, vol. 2013, pp. 1, 2013.

[26] J. Costantine, Y. Tawk, S.E. Barbin and C.G. Christodoulou, "Reconfigurable Antennas: Design and Applications," Proc IEEE, vol. 103, pp. 424, 2015.

[27] D.E. Anagnostou, G. Zheng, M.T. Chryssomallis, J.C. Lyke, G.E. Ponchak, J. Papapolymerou and C.G. Christodoulou, "Design, Fabrication, and Measurements of an RF-MEMS-Based Self-Similar Reconfigurable Antenna," IEEE Transactions on Antennas and Propagation, vol. 54, pp. 422, 2006.

[28] G. N. NIELSON, M. J. SHAW, O. B. SPAHN, G. R. BOGART, M. R. WATTS, R. H. OLSSON III, P. RESNICK, D. LUCK, S. BREWER, C. TIGGES, G. GROSSETETE, 
"High-Speed, Sub-Pull-in Voltage MEMS Switching," SANDIA REPORT., pp. 17-21, 2008.

[29] N. Biyikli, Y. Damgaci and B.A. Cetiner, "Low-voltage small-size double-arm MEMS actuator." Electron.Lett., vol. 45, pp. 354, 2009.

[30] P. Qin, Y.J. Guo, A.R. Weily and C. Liang, "A Pattern Reconfigurable U-Slot Antenna and Its Applications in MIMO Systems," IEEE Transactions on Antennas and Propagation, vol. 60, pp. 516, 2012.

[31] B. Kim, B. Pan, S. Nikolaou, Y. Kim, J. Papapolymerou and M.M. Tentzeris, "A Novel Single-Feed Circular Microstrip Antenna With Reconfigurable Polarization Capability," IEEE Transactions on Antennas and Propagation, vol. 56, pp. 630, 2008.

[32] J. Sarrazin, Y. Mahe, S. Avrillon and S. Toutain, "Pattern Reconfigurable Cubic Antenna," IEEE Transactions on Antennas and Propagation, vol. 57, pp. 310, 2009.

[33] Y. Bai, S. Xiao, C. Liu, X. Shuai and B. Wang, "Design of Pattern Reconfigurable Antennas Based on a Two-Element Dipole Array Model," IEEE Transactions on Antennas and Propagation, vol. 61, pp. 4867, 2013.

[34] A.H. Ramadan, J. Costantine, M. Al-Husseini, K.Y. Kabalan, Y. Tawk and C.G. Christodoulou, "TUNABLE FILTER-ANTENNAS FOR COGNITIVE RADIO APPLICATIONS," Progress in Electromagnetics Research B, vol. 57, pp. 253, 2014. 
[35] A.C.K. Mak, C.R. Rowell, R.D. Murch and C. Mak, "Reconfigurable Multiband Antenna Designs for Wireless Communication Devices," IEEE Transactions on Antennas and Propagation, vol. 55, pp. 1919, 2007.

[36] S. Pendharker, R.K. Shevgaonkar and A.N. Chandorkar, "Optically Controlled Frequency-Reconfigurable Microstrip Antenna With Low Photoconductivity," IEEE Antennas and Wireless Propagation Letters, vol. 13, pp. 99, 2014.

[37] S. Yao, X. Liu and S.V. Georgakopoulos, "A mode reconfigurable Nojima origami antenna," pp. 2237-2238, 2015.

[38] X. Liu, S. Yao, B.S. Cook, M.M. Tentzeris and S.V. Georgakopoulos, "An Origami Reconfigurable Axial-Mode Bifilar Helical Antenna," IEEE Transactions on Antennas and Propagation, vol. 63, pp. 5897, 2015.

[39] Shun Yao, S.V. Georgakopoulos, B. Cook and M. Tentzeris, "A novel reconfigurable origami accordion antenna," pp. 1-4, 2014.

[40] Xueli Liu, Shun Yao, S.V. Georgakopoulos, B.S. Cook and M.M. Tentzeris, "Reconfigurable helical antenna based on an origami structure for wireless communication system," pp. 1-4, 2014.

[41] P. Muri, O. Challa and J. McNair, "Enhancing small satellite communication through effective antenna system design," pp. 347-352, 2010.

[42] S.G. Hay, T.S. Bird and Z.N. Chen, "Handbook of Antenna Technologies," 2015. 
[43] J. Costantine, Y. Tawk and C.G. Christodoulou, "Reconfigurable deployable antennas for space communications," in Antenna Technology:" Small Antennas, Novel EM Structures and Materials, and Applications"(iWAT), 2014 International Workshop on, pp. 151-154, 2014.

[44] S.M. Tripathi, A. Kumar, R.K. Varshney, Y.B.P. Kumar, E. Marin and J.-. Meunier, "Strain and Temperature Sensing Characteristics of Single-Mode-Multimode-Single-Mode Structures," Jlt, vol. 27, pp. 2348-2356, Jan. 2009.

[45] R. Bhattacharyya, C. Floerkemeier, S. Sarma and D. Deavours, "RFID tag antenna based temperature sensing in the frequency domain," pp. 70-77, 2011.

[46] M.S. Khan, M.S. Islam and H. Deng, "Design of a Reconfigurable RFID Sensing Tag as a Generic Sensing Platform Toward the Future Internet of Things," IEEE Internet of Things Journal, vol. 1, pp. 300, 2014.

[47] H.V. Nguyen, R. Benzerga, C. Borderon, C. Delaveaud, A. Sharaiha, R. Renoud, C. Le Paven, S. Pavy, K. Nadaud and H.W. Gundel, "Miniaturized and reconfigurable notch antenna based on a BST ferroelectric thin film," Mater.Res.Bull., vol. 67, pp. 255-260, 2015.

[48] S. Pavy, C. Borderon, S. Baron, R. Renoud and H.W. Gundel, "Study of wet chemical etching of $\mathrm{BaSrTiO} 3$ ferroelectric thin films for intelligent antenna application," J.Sol Gel Sci.Technol., vol. 74, pp. 507-512, 2015. 
[49] L. Liu and R.J. Langley, "Liquid crystal tunable microstrip patch antenna," Electron.Lett., vol. 44, pp. 1179-1180, 2008.

[50] P.S. Neelakanta, Handbook of electromagnetic materials: monolithic and composite versions and their applications, CRC press, 1995, .

[51] J. So, H. Koo, M.D. Dickey and O.D. Velev, "Ionic Current Rectification in SoftMatter Diodes with Liquid-Metal Electrodes," Advanced Functional Materials, vol. 22, pp. 625-631, 2012.

[52] D. Shir, J. Yoon, D. Chanda, J. Ryu and J.A. Rogers, "Performance of ultrathin silicon solar microcells with nanostructures of relief formed by soft imprint lithography for broad band absorption enhancement," Nano Letters, vol. 10, pp. 3041-3046, 2010.

[53] L. Sun, W.M. Huang, Z. Ding, Y. Zhao, C.C. Wang, H. Purnawali and C. Tang, "Stimulus-responsive shape memory materials: a review," Mater Des, vol. 33, pp. 577-640, 2012.

[54] R.S. Kularatne, H. Kim, J.M. Boothby and T.H. Ware, "Liquid crystal elastomer actuators: Synthesis, alignment, and applications," Journal of Polymer Science Part B: Polymer Physics, vol. 55, pp. 395-411, 2017.

[55] Cedric P. Ambulo, Julia J. Burroughs, Jennifer M. Boothby, Hyun Kim, M. Ravi Shankar, and Taylor H. Ware, "Four-dimensional Printing of Liquid Crystal Elastomers," pp. 37332-37339, 2017. 
[56] H. Kim, J.M. Boothby, S. Ramachandran, C.D. Lee and T.H. Ware, "Tough, ShapeChanging Materials: Crystallized Liquid Crystal Elastomers," Macromolecules, vol. 50, pp. 4267-4275, 2017.

[57] S. Ahn, T.H. Ware, K.M. Lee, V.P. Tondiglia and T.J. White, "Photoinduced Topographical Feature Development in Blueprinted Azobenzene-Functionalized Liquid Crystalline Elastomers," Advanced Functional Materials, vol. 26, pp. 5819-5826, Aug 23,. 2016.

[58] J.M. Boothby, H. Kim and T.H. Ware, "Shape changes in chemoresponsive liquid crystal elastomers," Sensors Actuators B: Chem., vol. 240, pp. 511-518, 2017.

[59] T.H. Ware, M.E. McConney, J.J. Wie, V.P. Tondiglia and T.J. White, "Actuating materials. Voxelated liquid crystal elastomers," Science (New York, N.Y.), vol. 347, pp. 982, Feb 27,. 2015.

[60] L.T. de Haan, V. Gimenez-Pinto, A. Konya, T. Nguyen, J. Verjans, C. SánchezSomolinos, J.V. Selinger, R.L. Selinger, D.J. Broer and A.P. Schenning, "Accordion-like Actuators of Multiple 3D Patterned Liquid Crystal Polymer Films," Advanced Functional Materials, vol. 24, pp. 1251-1258, 2014.

[61] N. Torras, K.E. Zinoviev, J. Esteve and A. Sánchez-Ferrer, "Liquid-crystalline elastomer micropillar array for haptic actuation," Journal of Materials Chemistry C, vol. 1, pp. 5183, 2013. 
[62] D.K. Patel, A.H. Sakhaei, M. Layani, B. Zhang, Q. Ge and S. Magdassi, "Highly stretchable and UV curable elastomers for digital light processing based 3D printing," Adv Mater, vol. 29, 2017.

[63] J. Rossiter, P. Walters and B. Stoimenov, "Printing 3D dielectric elastomer actuators for soft robotics," in Electroactive Polymer Actuators and Devices (EAPAD) 2009, pp. $72870 \mathrm{H}, 2009$.

[64] S. Felton, M. Tolley, E. Demaine, D. Rus and R. Wood, "A method for building selffolding machines," Science, vol. 345, pp. 644-646, 2014.

[65] R.J. Morrison, S.J. Hollister, M.F. Niedner, M.G. Mahani, A.H. Park, D.K. Mehta, R.G. Ohye and G.E. Green, "Mitigation of tracheobronchomalacia with 3D-printed personalized medical devices in pediatric patients," Science Translational Medicine, vol. 7, pp. 285ra64, 2015.

[66] G. Villar, A.D. Graham and H. Bayley, "A tissue-like printed material," Science, vol. 340, pp. 48-52, 2013.

[67] M. Zarek, N. Mansour, S. Shapira and D. Cohn, "4D Printing of Shape Memory-Based Personalized Endoluminal Medical Devices," Macromolecular Rapid Communications, vol. $38,2017$.

[68] K.B. Biji, C.N. Ravishankar, C.O. Mohan and T.S. Gopal, "Smart packaging systems for food applications: a review," Journal of Food Science and Technology, vol. 52, pp. 6125-6135, 2015. 
[69] P. Kumar, H.W. Reinitz, J. Simunovic, K.P. Sandeep and P.D. Franzon, "Overview of RFID technology and its applications in the food industry," J.Food Sci., vol. 74, 2009.

[70] C. Varadhan, J.K. Pakkathillam, M. Kanagasabai, R. Sivasamy, R. Natarajan and S.K. Palaniswamy, "Triband antenna structures for RFID systems deploying fractal geometry," IEEE Antennas and Wireless Propagation Letters, vol. 12, pp. 437-440, 2013.

[71] Y. Suh and K. Chang, "A high-efficiency dual-frequency rectenna for 2.45-and 5.8GHz wireless power transmission," IEEE Trans.Microwave Theory Tech., vol. 50, pp. 1784-1789, 2002.

[72] A.T. Mobashsher, M.T. Islam and N. Misran, "A novel high-gain dual-band antenna for RFID reader applications," IEEE Antennas and Wireless Propagation Letters, vol. 9, pp. 653-656, 2010.

[73] J.R. Panda and R.S. Kshetrimayum, "A printed $2.4 \mathrm{GHz} / 5.8 \mathrm{GHz}$ dual-band monopole antenna with a protruding stub in the ground plane for WLAN and RFID applications," Progress in Electromagnetics Research, vol. 117, pp. 425-434, 2011.

[74] C. Occhiuzzi, S. Caizzone and G. Marrocco, "Passive UHF RFID antennas for sensing applications: Principles, methods, and classifcations," IEEE Antennas and Propagation Magazine, vol. 55, pp. 14-34, 2013.

[75] J. Gibson, X. Liu, S.V. Georgakopoulos, T. Ware, J.J. Wie and T.J. White, "Novel reconfigurable antennas using Liquid Crystals Elastomers," pp. 2297-2298, 2015. 
[76] J.S. Gibson, X. Liu, S.V. Georgakopoulos, J.J. Wie, T.H. Ware and T.J. White, "Reconfigurable antennas based on self-morphing liquid crystalline elastomers," IEEE Access, vol. 4, pp. 2340-2348, 2016.

[77] G.N. Mol, K.D. Harris, C.W.M. Bastiaansen and D.J. Broer, "Thermo-Mechanical Responses of Liquid-Crystal Networks with a Splayed Molecular Organization," Advanced Functional Materials, vol. 15, pp. 1155-1159, Jul. 2005.

[78] K.M. Lee, M.L. Smith, H. Koerner, N. Tabiryan, R.A. Vaia, T.J. Bunning and T.J. White, "Photodriven, Flexural-Torsional Oscillation of Glassy Azobenzene Liquid Crystal Polymer Networks," Advanced Functional Materials, vol. 21, pp. 2913-2918, Aug 9,. 2011.

[79] J.J. Wie, K.M. Lee and T.J. White, "Thermally and Optically Fixable Shape Memory in Azobenzene-Functionalized Glassy Liquid Crystalline Polymer Networks," Molecular Crystals and Liquid Crystals, vol. 596, pp. 113-121, Jun 13,. 2014.

[80] K.M. Lee, T.J. Bunning and T.J. White, "Autonomous, Hands-Free Shape Memory in Glassy, Liquid Crystalline Polymer Networks," Adv Mater, vol. 24, pp. 2839-2843, 2012.

[81] J.J. Wie, K.M. Lee, T.H. Ware and T.J. White, "Twists and turns in glassy, liquid crystalline polymer networks," Macromolecules, vol. 48, pp. 1087-1092, 2015.

[82] Y. Sawa, F. Ye, K. Urayama, T. Takigawa, V. Gimenez-Pinto, R.L. Selinger and J.V. Selinger, "Shape selection of twist-nematic-elastomer ribbons," Proceedings of the National Academy of Sciences, vol. 108, pp. 6364-6368, 2011. 
[83] K. Shinyama, T. Oi and S. Fujita, "Dielectric Relaxation Phenomena of Polylactic Acid with $\boldsymbol{\beta}$-Crystalline Chitin," vol. 2018, 2012.

[84] J. Gibson and S.V. Georgakopoulos, "Reconfigurable antenna using shape memory polymers," in Antennas and Propagation (APSURSI), 2016 IEEE International Symposium on, pp. 1673-1674, 2016.

[85] J. Gibson and S.V. Georgakopoulos, "Metallization of LCE helical antenna used for potential RFID," in Antennas and Propagation \& USNC/URSI National Radio Science Meeting, 2017 IEEE International Symposium on, pp. 1169-1170, 2017.

[86] C.A. Balanis, Advanced engineering electromagnetics, John Wiley \& Sons, 1999, .

[87] H.A. Wheeler, "Formulas for the skin effect," Proceedings of the IRE, vol. 30, pp. 412-424, 1942.

[88] Anonymous "Research, Development, and Acquisition: Research Development, Test and Evaluation of Materiel for Extreme Climatic Conditions," 1979.

[89] Anonymous "MIL-STD-883E, Test Method Standard Microcircuit," 1996.

[90] M. Standard, "MIL-STD-810," A Series of Environmental Test Procedures, . 
VITA

\section{JOHN GIBSON}

Born, St. Louis, Missouri

2013

B. S., Computer Engineering

Bethune-Cookman University

Daytona Beach, Florida

2018

$\mathrm{Ph}$. D., Electrical Engineering

Florida International University

Miami, Florida

\section{PUBLICATIONS AND PRESENTATIONS}

1. John S. Gibson, X. Liu, S. V. Georgakopoulos, J. J. Wie, T. H. Ware and T. J. White, "Reconfigurable Antennas Based on Self-Morphing Liquid Crystalline Elastomers," in IEEE Access, vol. 4, no., pp. 2340-2348, 2016.

2. J. Gibson and S. V. Georgakopoulos, "Reconfigurable antenna using shape memory polymers," 2016 IEEE International Symposium on Antennas and Propagation (APSURSI), 2016, pp. 1673-1674.

3. John Gibson; Liu, Xueli; Georgakopoulos, S. V.; Ware, Taylor; Wie, Jeong Jae; White, Timothy J., "Novel reconfigurable antennas using Liquid Crystals Elastomers," Antennas and Propagation \& USNC/URSI National Radio Science Meeting, 2015 IEEE International Symposium on , vol., no., pp.2297-2298, 19-24 July 2015 doi:

4. Yao, Shun; Liu, Xueli; John Gibson; Georgakopoulos, Stavros V., "Deployable origami Yagi loop antenna," in Antennas and Propagation \& USNC/URSI National Radio Science Meeting, 2015 IEEE International Symposium on, vol., no., pp.2215-2216, 19-24 July 2015

5. Shun Yao, Xueli Liu, John Gibson and Stavros V. Georgakopoulos, "A Self-deploy Yagi Loop Antenna Based on Origami Spring Structure," Antennas and Propagation \& USNC/URSI National Radio Science Meeting, 2015 IEEE International Symposium on, vol., no., pp.2215-2216, 19-24 July 2015

6. Quintana, Karina A.; John Gibson; Georgakopoulos, S. V., "Wearable conformal SCMR systems," Antennas and Propagation \& USNC/URSI National Radio 
Science Meeting, 2015 IEEE International Symposium on , vol., no., pp.2355-2356, 19-24 July 2015

7. John Gibson; Kun Bao; Hao Hu; Georgakopoulos, S.V., "Wireless charging for LiIon battery using a printable Conformal SCMR," Antennas and Propagation Society International Symposium (APSURSI), 2014 IEEE, pp.1349,1350, 6-11 July 2014

8. Hao Hu; Kun Bao; John Gibson; Georgakopoulos, S.V., "Printable and Conformal Strongly Coupled Magnetic Resonant systems for wireless powering," Wireless and Microwave Technology Conference (WAMICON), 2014 IEEE 15th Annual, pp.1,4, 6-6 June 2014

9. Beiwen Li; John Gibson; Jill Middendorf; Yajun Wang; Song Zhang; Comparison between LCOS projector and DLP projector in generating digital sinusoidal fringe patterns. Proc. SPIE 8839, Dimensional Optical Metrology and Inspection for Practical Applications II, 883908 (September 6, 2013); 